\title{
THE OBESITY EPIDEMIC: TOWARDS A REGULATORY FRAMEWORK TO COMBAT \\ OBESITY IN NEW ZEALAND
}

\author{
By \\ Sarah Barker \\ A dissertation \\ submitted to the Victoria University of Wellington \\ in partial fulfilment of the requirements for the degree of \\ Master of Laws
}

Victoria University of Wellington

2011 


\section{ABSTRACT}

There is currently a global obesity epidemic and New Zealand, like many other countries, has high levels of obesity both in the adult and child population. This presents a threat to society due to the risk to individual and population health, and the impact on public services.

A major contributor to obesity levels is the nature of the current eating environment; one in which various factors make it natural and easy to lead an unhealthy lifestyle. By targeting these, the law could help to combat the obesity epidemic. Historically, attempts to address obesity through legal means have encountered opposition on paternalistic grounds. Given the threat that obesity poses, both to the individual and society as a whole, a certain level of paternalism is justified to control it, particularly when it comes to the protection of children. Currently, legal measures to control obesity can be implemented in New Zealand without resorting to hard paternalism. The law should be used to increase regulation of the food industry, rather than using it to control food intake directly. This is a softer paternalistic approach and includes changes to labelling requirements and the regulation of the marketing to mandate for improved information to be disseminated about food products. It also includes the implementation of a universal nutrient profiling system to overcome any problems associated with deciding which food products should be subject to increased regulation. Change to the eating environment in New Zealand could also be facilitated via the implementation of a fat-tax to address the price inequalities between healthy and unhealthy food products.

Currently the food industry in New Zealand is minimally regulated by statute, with an emphasis on food safety and hygiene. This is no longer appropriate given rising levels of obesity. Furthermore, it is no longer appropriate that food product marketing be regulated by the industry, given its contribution to obesity levels, and the obvious conflict of interest. 
Notwithstanding that obesity control in New Zealand can presently be tackled using such an approach, a higher level of paternalism is necessary for measures aimed at children. Therefore, in the current food environment, paternalistic health laws, designed to protect children, are justified on the basis of the risk to children, and the need to protect them.

Additionally, the need for a more paternalistic approach to obesity control generally must be kept under continual review, particularly in light of studies linking food with addiction. Although food litigation has been initiated against food companies by the obese in other jurisdictions, and has had an impact on the eating environment, this is not a realistic prospect in New Zealand, even as a last resort, in the absence of appropriate regulation.

WORD COUNT: 38,194 
CONTENTS

ABSTRACT

2

I INTRODUCTION

12

II WHAT IS THE OBESITY EPIDEMIC?

14

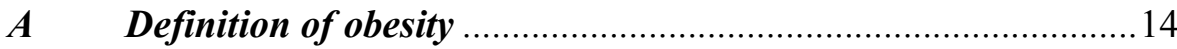

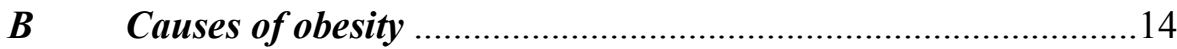

C Extent of the epidemic; obesity statistics .................................. 15

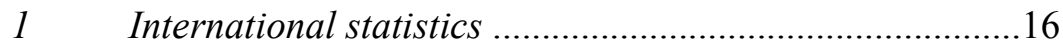

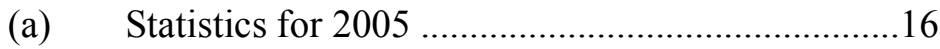

(b) Projected statistics for 2015 .................................16

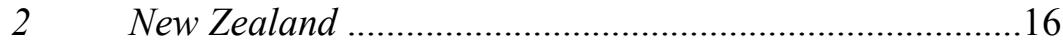

(a) Statistics for $2002-2005$..................................16

(b) Statistics for 2006/07 ….....................................16

(c) Projected statistics for 2015 ................................17

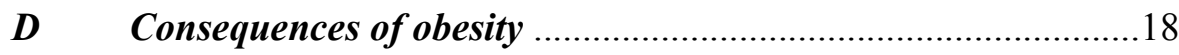

$1 \quad$ Health conditions associated with obesity ........................18

2 Monetary costs of obesity ...............................................20

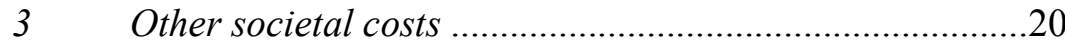

III PATERNALISM AND THE ROLE OF THE LAW IN

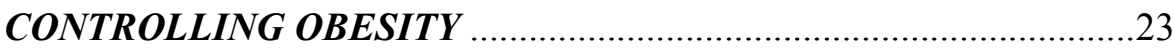

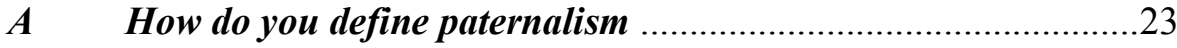


B Paternalism and obesity control

C The justification for the use of paternalistic, measures to control obesity

D Obesity measures, paternalism, and the health of the individual and population .28

$1 \quad$ Is obesity a public health law issue? .29

(a) The analogy between the use of tobacco and the consumption of unhealthy foods

(b) Is the tobacco analogy an appropriate one to make?

E Obesity measures, paternalism and the lack of autonomy in current eating decisions 35

$1 \quad$ Autonomy and the eating environment .35

2 Autonomy in eating decisions and the nature of some food products

(a) The Food Industry and the hijack of anti-paternalistic arguments

IV CONTROLLING OBESITY AND THE CREATION OF A HEALTHY ENVIRONMENT

A The need to address the causes of obesity and the creation of a healthy environment

B Encouraging healthy choices; New Zealand law and the promotion of a healthy environment .42 
V THE PROMOTION OF A HEALTHY ENVIRONMENT

THROUGH THE REGULATION OF THE FOOD

INDUSTRY - LABELLING OF FOOD PRODUCTS

A Food product labelling in New Zealand

$1 \quad$ The Food Act 1981

B Food product labelling regulation in other

jurisdictions

1 The regulation of food product labelling

in the United States

2 The regulation of food product labelling

in Canada

$3 \quad$ The regulation of food product labelling

in the United Kingdom

C The future of food product labelling in New Zealand

$1 \quad$ A more prescriptive labelling system for

New Zealand

(a) The scope of food product labelling

(i) Nutrient profiling for New

Zealand .54

(b) Not everyone makes healthy

decisions

(c) The specific content and presentation

of food labels

(d) International compliance and

standardisation

(e) Increased compliance costs for

businesses 
(f) Industry opposition, lobbying

and public opinion .............................................61

2 Health Warnings ...........................................................62

(a) Food products and health warnings ....................62

(i) Soft drinks and health warnings ...............63

(ii) Health warnings and non

food products ............................................64

(b) Why not use health warnings on

food products

(i) Past attempts to impose health

warnings on products other than

tobacco in New Zealand ............................65

(ii) Would health warnings

discourage individuals;

warning fatigue? .66

(iii) Should a new labelling

regime mandate for health

warnings on certain food

products?

VI THE PROMOTION OF A HEALTHY ENVIRONMENT

THROUGH REGULATION OF THE FOOD

INDUSTRY - CONTROLLING THE MARKETING

OF CERTAIN FOOD PRODUCTS

A Why have restrictions on the marketing of certain

food products in New Zealand?

B The influence of food product marketing

and obesity

C Current regulation of food product

marketing in New Zealand 


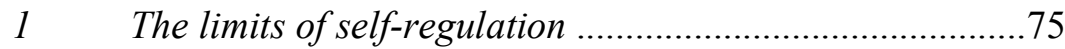

$2 \quad$ Marketing and individual autonomy ...............................78

D Regulation of the marketing of food products

overseas

$1 \quad$ Sweden and the total ban of advertising

to children

2 Canada and the total ban of advertising

to children

$3 \quad$ Marketing regulation in the United

Kingdom

E The implementation of statutory regulation of

food product marketing in New Zealand

$1 \quad$ Extent of marketing restrictions

required in New Zealand; controlling

advertising to children

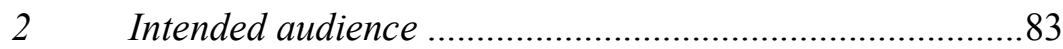

3 Dealing with other forms of marketing ............................84

$4 \quad$ What products would be subject to

restrictions?

5 The Smoke Free Environments Act;

a model for the regulation of food

product marketing to children?.

$6 \quad$ Marketing restrictions and the New Zealand Bill

of Rights Act 1990

(a) Challenges to the Consumer

Protection Act in Quebec;

a limitation of freedom of

expression? 
(b) Marketing restrictions freedom of expression and the New Zealand

Bill of Rights Act

VII FAT-TAX AND OBESITY CONTROL .92

A What is a fat-tax? .99

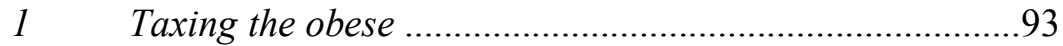

2 Fat-tax in the form of price manipulation .........................94

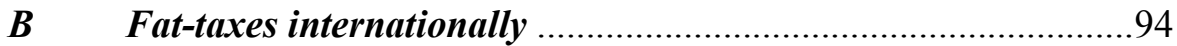

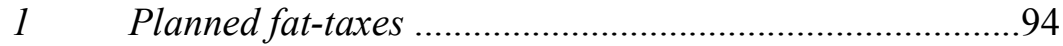

$2 \quad$ Fat-taxes in the United States ........................................95

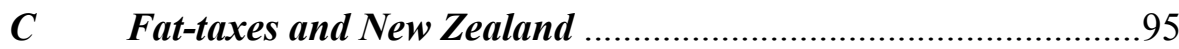

$1 \quad$ Do fat-taxes change eating behaviour? ...........................95

2 Arguments against a fat-tax; possible negative

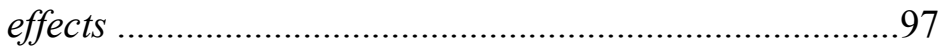

(a) A fat-tax is likely to be regressive …....................97

(b) A fat-tax is too paternalistic .................................98

(c) A fat-tax would be too difficult to

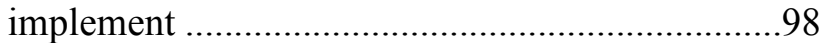

$3 \quad$ How could a fat-tax be implemented in

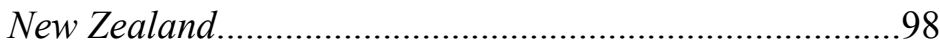

(a) Deciding which foods would be subject to a fat-tax or subsidy?

(i) Taxing according to nutrient

Profile

(ii) Taxing specific products 100 
(b) Which businesses would be required to levy a fat-tax

on their products

(c) A fat-tax and compliance costs

(d) A fat-tax may result in unintended

consequences or negative outcomes

(e) Industry and public opposition

$4 \quad$ Using Goods and Services Tax on certain

food products to implement a fat-tax

\section{NEW ZEALAND PUBLIC HEALTH LAW AND THE}

CONTROL OF OBESITY

A Current New Zealand public health legislation

and non-communicable diseases

$1 \quad$ The Health Act 1956 and Tuberculosis Act 1948 106

2 The Public Health Bill 2007 and the attempt to make obesity a public health issue

3 Future of the Public Health Bill

\section{LITIGATION AND OBESITY IN NEW}

ZEALAND

A Fast food litigation in the United States 115

B Does tobacco litigation provide a model for

fast food litigation?

1 Food as an addictive product

2 Chain of causation 
3 Range of food products, manufacturers

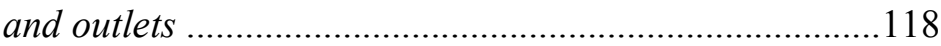

C Food litigation a possibility in New Zealand?

1 A tortious claim and the Accident Compensation

Act 2001

2 Elements required for a successful tortious

food claim?

(a) Do food manufacturers owe a duty of care?

(i) Are some food products more dangerous than consumers might reasonably expect 124

(b) Have the manufacturers of food products, believed to contribute to obesity, breached a duty of care? 125

(c) Food products and causation ...............................126

$3 \quad$ The Fair Trading Act 1986 ............................................127

X CONCLUSION

XI BIBLIOGRAPHY 
There is no need to worry about mere size. We do not necessarily respect a fat man more than a thin man. Sir Isaac Newton was very much smaller than a hippopotamus, but we do not on that account value him less

Bertrand Russell

I INTRODUCTION

The world is currently in the grip of an obesity epidemic with an estimated 300 million people currently obese. ${ }^{1}$ If, by 2015 , nothing is done to address obesity in New Zealand, the World Health Organisation (WHO) estimates that 35.2 per cent of males, and 48.1 per cent of females will be obese. ${ }^{2}$ The Government Report on Obesity and Type 2 diabetes listed the following key points: ${ }^{3}$

- $\quad$ Obesity and type 2 diabetes are crucial issues for New Zealand; they adversely affect the health of many and the social and economic welfare of all New Zealanders.

- These "epidemics" have the potential to overwhelm the health system if left unchecked.

- These epidemics impact disproportionately on Māori and Pacific people. The trends in children and young people are particularly worrying.

Obesity has ramifications at both personal and societal levels, and is both disabling and life threatening. It places a great burden on those who care for the obese, and a burden for society as a whole, not least, in the percentage of healthcare expense that is used to treat obesity related illness; estimated at " 2 to 7 percent of the annual health budget."

\footnotetext{
${ }^{1}$ International Association for the study of obesity www.iotf.org (accessed 4 June 2010).

${ }^{2}$ World Health Organisation [WHO] www.who.int (accessed 12 August 2008). Based on an age range of 15-100 and a Body Mass Index [BMI] of greater than/equal to 30 .

${ }^{3}$ Health Select Committee Inquiry into Obesity and Type 2 Diabetes in New Zealand (Parliament, Wellington, 2007) 3.

${ }^{4}$ Ministry of Health [MOH] www.moh.govt.nz (accessed 12 August 2008).
} 
Clearly government intervention is necessary to reverse the current obesity trend. Internationally governments are taking action. Some steps have already been taken to address obesity in New Zealand, but further action is required. This paper examines what role the law can, and should play in reducing obesity.

The New Zealand food industry has minimal mandatory regulation, and its marketing is regulated by the industry. This requires change, through stricter labelling requirements and a new statutory marketing regulation regime, to provide better quality information. It includes the implementation of a universal nutrient profiling system and the implementation of a fat-tax. This will both encourage and enable consumers to make the appropriate choices based on health. By regulating the food industry and implementing a fat-tax the law could, by providing the appropriate regulatory structure, change the current eating environment from one that fosters high obesity levels to one in which it is easier for individuals to live a healthy lifestyle. This would reduce obesity levels in New Zealand.

Obesity control measures are frequently opposed on paternalistic grounds, but a paternalistic approach to obesity control is justified. By regulating the food industry rather than dictating what individuals should, or should not, eat the law could facilitate an approach to obesity control that uses a soft rather than hard paternalistic approach. This is an approach that is more likely to receive support from the public (and government), but is one that should be kept under review as there may be a need to utilise a harder paternalistic approach in the future. The use of hard paternalistic measures is however currently justified for measures directed at children, who are particularly vulnerable, and therefore in need of extra protection. This is the case even in situations in which the level of paternalism might be considered too extreme for the adult population. 


\section{WHAT IS THE OBESITY EPIDEMIC?}

\section{A The definition of obesity}

WHO defines overweight and obesity as "abnormal or excessive fat accumulation that may impair health." It is measured by using the Body Mass Index (BMI). BMI is calculated by dividing an individual's weight in kilograms by the square of their height in metres. Individuals are classified depending on their BMI, as follows:

BMI range 18.5-24.9 $\mathrm{kg} \mathrm{m}^{2}$ is considered normal.

BMI range $25.0-29.9 \mathrm{~kg} \mathrm{~m}^{2}$ is considered overweight.

BMI range 30 or greater $\mathrm{kg} \mathrm{m}^{2}$ is considered obese.

For Māori and Pacific people a BMI of 32 or more $\mathrm{kg} \mathrm{m}^{2}$ is considered obese. $^{6}$

\section{B Causes of obesity}

In order to control obesity it is important to understand its causes, thus enabling the appropriate steps to be taken to address them. ${ }^{7}$ The Public Health Advisory Committee (PHAC) concluded (a view also held by WHO) that "weight gain is caused by excess energy intake (energy-dense foods) and, increasingly lowered energy output (exercise)." 8

\footnotetext{
${ }^{5}$ WHO, above $\mathrm{n} 2$.

${ }^{6}$ For more information see ibid; $\mathrm{MOH}$ Food and Nutrition Guidelines for Healthy Adults: A Background Paper (MOH, Wellington, 2003) 50.

${ }^{7}$ For a further discussion of the need to understand causes see Christopher Reynolds "Law and Public Health: Addressing Obesity" (2004) 29.4 AltLJ 162.

${ }^{8}$ National Health Committee Public Health Advisory Committee [PHAC] Advice on Obesity Inquiry (National Health Committee, Wellington, 2006) 1; and see for example, WHO Fact Sheet number 311 Obesity and Overweight www.who.int/mediacentre/factsheets (accessed 11 January 2011).
} 
According to the Obesity Action Coalition (OAC) we are living in an obesogenic environment that is: ${ }^{9}$

one where it is easier and 'normal' to be inactive and eat too much food. For example technology provides labour saving devices, mechanised transport and a food system which supplies a large range of highly processed energy-dense foods.

Clearly, poor diet, an increasing intake of junk-food, and lack of physical activity are taking its toll on the world population. Action to curb obesity should therefore aim to reduce the intake of unhealthy foods and increase exercise by promoting: ${ }^{10}$

an environment that discourages unhealthy choices and encourages healthy choices. It should be an environment that supports and encourages daily exercise and healthy eating as an ordinary, expected part of life.

Any legal measures to control obesity in New Zealand must therefore target the obesogenic influences and thus foster the appropriate healthy environment.

\section{The extent of the epidemic; obesity statistics}

A brief summary of obesity statistics provides an indication of the extent of the problem in New Zealand (and internationally). The rate of obesity in New Zealand is comparatively high. According to a recent report issued by the Organisation for Economic Co-operation and Development (OECD), New Zealand had the third highest obesity rate of all OECD countries, at $26.5 \%$ in $2007{ }^{11}$ Clearly, obesity is a problem of particular concern to New Zealand.

\footnotetext{
${ }^{9}$ Obesity Action Coalition [OAC] Would you like Lies with that: Food, Kids and TV Advertising (OAC, New Zealand, 2007) 7 coins the term obesogenic; OAC www.obesityaction.org.nz (accessed 22 January 2009) (note that following a cut in funding National by the Government the OAC ceased to exist on 1 March 2010).

${ }^{10}$ PHAC, above n 8,1 .

${ }^{11}$ Organisation for Economic Cooperation and Development [OECD] OECD Health Data 2010 How does New Zealand Compare (OECD, Paris, 2010) 2; paper referred to in Rebecca Todd "Govt Criticised for Lack of Action on Obesity" (12 July 2010) stuff.co.nz www.stuff.co.nz/national/health (accessed 12 July 2010).
} 
$1 \quad$ International statistics

(a) Statistics for 2005

WHO estimates that in $2005,41.8$ per cent of females and 36.5 per cent males were obese in the United States; in the United Kingdom 24.2 per cent of females and 25.2 per cent of males; and in Australia 24.9 per cent of females and 23.8 per cent of males. ${ }^{12}$

(b) Projected statistics for 2015

WHO estimates that, by $2015,54.3$ per cent of females and 51.7 per cent of males will be obese in the United States, 28.3 per cent of females and 25.8 per cent of males in the United Kingdom, and 33.5 per cent of females and 33.3 per cent of males in Australia. ${ }^{13}$

\section{$2 \quad$ New Zealand}

(a) Statistics for $2002-2005$

The results of the New Zealand Ministry of Health (MOH) 2002/03 Health Survey ${ }^{14}$ indicated that one in five adults was obese (percentage males 19.2; percentage females 21). WHO estimates put the figures at 23 and 31.5 respectively. ${ }^{15}$

(b) Statistics for $2006 / 07$

The results of 2006/07 MOH New Zealand Health Survey indicated that one in four adults was obese. ${ }^{16}$

\footnotetext{
${ }^{12}$ WHO, above $\mathrm{n} 2$ (accessed 10 November 2008).

13 Ibid.

${ }^{14} \mathrm{MOH}$ A Portrait of Health: Key results of the 2002/03 New Zealand Health Survey (MOH, Wellington, 2004) 69 [2002/03 New Zealand Health Survey].

${ }^{15}$ WHO, above n 2.

${ }^{16}$ 2002/03 New Zealand Health Survey, above n 14.
} 
(c) Projected statistics for 2015

WHO estimates that, by 2015, 35.2 per cent of males and 48.1 per cent of females in New Zealand will be obese. ${ }^{17}$

The international figures therefore show a significant increase in obesity levels, with the possibility of the number of obese individuals reaching frightening levels if the epidemic is not addressed. This trend is reflected in the New Zealand statistics.

These statistics relate to the adult population, but are mirrored in children, with obesity at alarming levels and rising. For example, it is estimated that in the United Kingdom: ${ }^{18}$

each year in England 220,000 more children become overweight or obese ... [and] ... that by 2012 a million English children will be obese and by 2025 around a quarter of all boys will be classified as dangerously overweight.

The situation is the same in New Zealand where, according to the results of the 2006/07 MOH Health Survey, the number of children who were overweight was one in five, and those who were obese, one in twelve. ${ }^{19}$ The majority of such children are destined to become obese adults "with the result that the length and quality of their lives will be reduced."20 Alarmingly, it has even been stated that "poor diet and lack of exercise among today's youngsters [will] lead them to having a lower life expectancy than their parents for the first time in more than a century.,"21

\footnotetext{
${ }^{17} \mathrm{WHO}$, above $\mathrm{n} 2$.

${ }^{18}$ Beth Hale, and Sophie Borland "Overweight Youngsters will be Taken into Care, Parents are Warned" (16 August 2008) Daily Mail London 7.

19 2002/03 New Zealand Health Survey, above n 14, xiv.

${ }^{20}$ Dr Francesco Brance "10 Things you Need to Know about Obesity" (WHO, 10 Things you Need to Know about Obesity, European Ministerial Conference on Counteracting Obesity, November 2006 Istanbul) 2.

21 Sarah-Kate Templeton "Focus: The Thin Line between Poor Diet and Child Abuse" (25 February 2007) Sunday Times London.
} 
The fact that projected levels of obesity in New Zealand are greater than those in the United Kingdom and Australia is an indication of the severity of the problem. New Zealand could become a world leader in obesity if the epidemic is not brought under control.

\section{Consequences of obesity}

$1 \quad$ Health conditions associated with obesity

Obesity causes and exacerbates many serious health conditions
including: $^{.22}$

- Hypertension (high blood pressure)

- Osteoarthritis (a degeneration of cartilage and its underlying bone within a joint)

- Dyslipidemia (for example, high total cholesterol or high levels of triglycerides)

- $\quad$ Type 2 diabetes

- Coronary heart disease

- $\quad$ Stroke

- Gallbladder disease

- Sleep apnoea and respiratory problems

- Some cancers (endometrial, breast, and colon)

According to the United Kingdom Department of Health approximately " $58 \%$ cases of type- 2 diabetes, and $21 \%$ of heart disease ... are attributable to excess body fat." 23 In the United States it is estimated that "in 2002, about 41,000 new cases of cancer ...were estimated to be due to obesity ... [which is] 3.2 percent of all new cancers." 24 The World Cancer research fund has reported that

\footnotetext{
${ }^{22}$ United States Department of Health and Human Services www.cdc.gov (accessed 12 January 2009).

${ }^{23}$ United Kingdom Department of Health, www.dh.gov.uk (accessed August 2008).

${ }^{24}$ The United States National Cancer Institute www.cancer.gov (accessed 27 May 2010).
} 
"modifying diet and exercise ... [could prevent] around 43 per cent of colon cancer cases and 42 per cent of breast cancer cases in the United Kingdom. ${ }^{, 25}$

The MOH has estimated "that higher than optimal BMI accounted for about 3200 deaths in 1997."26 Since 1997 levels of obesity have risen, and therefore the number of obesity related deaths will have risen. The United Kingdom Department of Health estimates that "obesity is responsible for 9,000 premature deaths each year in England, reducing life expectancy by, on average, 9 years." 27 In 2003 in the United States, the Surgeon General stated that "one out of every eight deaths in America [was] caused by an illness directly related to overweight and obesity., 28

It is also interesting to note that WHO defines "overweight as a BMI equal to or more than 25 and obesity as a BMI equal to or more than $30,{ }^{, 29}$ and states that "there is evidence that risk of chronic disease in populations increases progressively from a BMI of 21." ${ }^{30}$ The health conditions associated with obesity are therefore not merely the domain of the obese, but a risk to all those with weight problems. Any initiatives to control the obesity epidemic would therefore also benefit many members of the population.

The health effects of obesity have a knock-on effect, not only in terms of healthcare expense, but in other major effects on the population as a whole.

\footnotetext{
${ }^{25}$ Otago University "Many Cancers could be Prevented Across the Globe: Landmark Report" (27 February 2009) Press Release; World Cancer Research Fund [WCRF], and American Institute for Cancer Research [AICR] Policy and Action for Cancer Prevention Food, Nutrition, and Physical Activity: a Global Perspective (WCRF, and AICR, Washington DC, 2009); World Cancer Research Fund www.wcrf.org (accessed 3 June 2010).

${ }^{26} \mathrm{MOH}$ Looking Upstream: Causes of Death Cross-classified by Risk and Condition (MOH, Wellington, 1997) 11.

${ }^{27}$ United Kingdom Department of Health, above $\mathrm{n} 23$.

28 Richard H Carmona, United States Surgeon General "The Obesity Crisis in America" (Testimony before the Subcommittee on Education Reform and Committee on Education and the Workforce, United States House of Representatives, Washington, 16 July 2003).

${ }^{29} \mathrm{WHO}$, above $\mathrm{n} 2$.

${ }^{30}$ Ibid.
} 
Caring for the obese places enormous strain on healthcare systems; for example, in New Zealand in 1991: $:^{31}$

\author{
the direct costs of obesity to New Zealand's health care system were \\ conservatively estimated at $\$ 135$ million per year, or 2.5 percent of \\ health expenditure for that year. On this basis the figure for $2000 / 01$ \\ would have been at least $\$ 247.1$ million.
}

A more recent estimate puts this figure at $\$ 500$ million. $^{32}$

The expense involved in treating the obese has considerable ramifications for healthcare, where budgets are limited, reducing the resources available for the treatment of other illness. Therefore, addressing obesity in New Zealand (and worldwide) has become a health priority.

\title{
$3 \quad$ Other societal costs
}

In addition to the health costs of obesity, WHO has stated that there is a further cost to society caused by "loss of lives, productivity and related income that is at least two times higher [than the related health care expenditure]. ${ }^{, 33}$

For example, within the health sector: ${ }^{34}$

Treating obese patients has ... practical implications, including
additional risks to patients and health professionals, the need for
special equipment and training, and prolonged rehabilitation. People
who are obese also displace other people in need of treatment.

This situation is clearly evident in New Zealand where, in early in 2008, the Dominion Post reported that hospitals were "strugg[ling] to cope with obese Kiwis." 35

\footnotetext{
${ }^{31}$ Health Select Committee, above n 3, 10.

${ }^{32}$ Rebecca Todd "Govt Criticised for Lack of Action on Obesity" (12 July 2010) stuff.co.nz www.stuff.co.nz/national/health (accessed 12 July 2010).

${ }^{33}$ Brance, above n 20, 2.

${ }^{34}$ Health Select Committee, above n 3, 10.
} 
In the United Kingdom the spokesman of the Local Government Association $^{36}$ stated recently that: $:^{37}$

Obesity is increasingly costing the council taxpayer dear ... Council equipment and infrastructure is having to be modified to deal with a population that is getting larger and larger ... It's a massive issue for public health but it also risks placing unprecedented pressure on council services.

Although extreme examples, other costs associated with obesity include increased costs for burials. For example, in Scotland it is reported that cranes are required to bury the corpses of those who were morbidly obese, ${ }^{38}$ and, according to The Times, "councils across the country are spending tens of thousands of pounds widening crematorium furnaces to deal with the spiralling number of fatter corpses" 39 This example is listed as one of the ramifications of the obesity epidemic in the United Kingdom, which include: ${ }^{40}$

- New ambulances have been introduced across Wales with special equipment for fat patients, including a winch and an extra-wide strengthened stretcher

- $\quad$ Fire services are threatening to charge police or hospitals a fee if they are called in to move grossly overweight people out of dangerous buildings

- Many schools are having to adapt their furniture to cope with heavier, wider children. Each larger table and chair costs around $£ 30$

- It is estimated that nearly 2,000 people are too overweight to work

35 Broun Britton "Hospitals Struggle to Cope with Obese Kiwis" (15 February 2008) The Dominion Post Wellington.

${ }^{36}$ The Local Government Association is an organisation acting on behalf of local government in the United Kingdom www.lga.gov.uk (accessed 12 January 2009).

${ }^{37}$ Hale, and Borland, above n 18.

${ }^{38}$ Mike Larkin "Crane Gang Called in to Help Bury Bulky Scots; Undertakers Feeling the Strain of Scotland's Obesity Crisis" (22 October 2007) The Express Scotland.

39 Jill Sherman "Fat Children should be taken into Care" (August 16 2008) The Times London.

${ }^{40}$ Ibid. 
Also worrying from an environmental perspective, is a study by the University of Illinois that has indicated that "Americans are burning nearly 1 billion more gallons [of fuel] each year than ... in 1960 [due to] expanding waistlines ... [which] translates to about US\$2.2 billion spent on gas each year." Therefore, if the obesity epidemic is left unchecked it will become a serious environmental hazard.

If obesity rates in New Zealand follow the global trend, and no action is taken, such experiences overseas have worrying implications for the future of publicly funded services. The issue of obesity has therefore become one with enormous economic and social consequences for New Zealand.

The law has an important and essential role to play in reducing obesity. Nonetheless, before its role in dealing with the obesity epidemic is explored, it is important to consider whether or not use of the law is justified. Legal interventions are often paternalistic in nature, or at least perceived to be so, and therefore viewed as a threat to personal autonomy. The question of whether the law should interfere with individuals' eating choices will now be examined.

\footnotetext{
${ }^{41}$ University of Illinois "Weight Gain of U.S. Drivers has Increased Nation's Fuel Consumption" (24 November 2006) News Release; Lindsey Tanner “Americans' Obesity adds to Gasoline Consumption, study says" (October 2006) USA Today United States.
} 


\section{PATERNALISM AND THE ROLE OF THE LAW IN CONTROLLING OBESITY}

When adopting measures to prevent obesity it may be necessary to sacrifice some level of individual autonomy in eating choices; for example, by controlling what food can be sold, or by banning certain foods or ingredients. Using the law in such a way to change individuals' food choices can therefore often lead to a tension between paternalism and individual autonomy where there has to be a "trade-off ... between regard for the welfare of another [or that individual] and respect for their right to make their own decisions."42 As a result, many measures to control obesity are frequently challenged on paternalistic grounds. Thus, the idea of measures to control obesity can present an ideological, political and public relations minefield. This paper will therefore examine some of the issues surrounding the use of paternalism to control obesity.

\section{A How do you define paternalism?}

There is a great deal of literature on the subject of paternalism, and it is not possible to include a complete analysis of paternalism and its various forms. Broadly speaking, paternalism can be defined as: ${ }^{43}$

\footnotetext{
in ways that will harm them which:

(i) is motivated and/or justified by a beneficial concern for their welfare, and

(ii) uses means other than reasoned persuasion.
}

the attempt to induce [individuals] ... to act in ways that will benefit them or not act

Paternalism can involve measures that that are coercive; forcing individuals to act in a certain way. This is often referred to as hard paternalism. For example, compulsory seatbelt and bike helmet laws, the prohibition on smoking in public places, and the banning of certain foods, fall into this category.

\footnotetext{
42 Stanford Encyclopaedia of Philosophy www.plato.stanford.edu (accessed 2 April 2010); see also Michelle M Mello, David M Studdert and Troyen A Brennan "Obesity the New Frontier of Public Health Law: Health Policy Report” (2006) 35.24 New England Journal of Medicine 2601.

${ }^{43}$ Danny Scoccia “In Defense of Hard Paternalism” (2008) 27 Law and Philosophy 351, 380.
} 
Paternalistic measures can also be those that are likely to encourage certain behaviour in individuals, such as the use of health warnings on cigarette packets, subsidising healthy foods, imposing levies on unhealthy foods, or mandating the better labelling of food products. These measures are often referred to as soft paternalism. $^{44}$

Paternalism is opposed by many members of the public, the food industry, and some politicians, because it restricts personal autonomy; that is, "the opportunity to regulate one's own life for one self according to one's own judgement, even when one's judgment is bad." ${ }^{45}$ Philosophers such as John Stuart Mill believe that the only justification for compromising an individual's autonomy is the prevention of harm to others and not the prevention of harm to that individual. ${ }^{46}$ Autonomy is important in a democratic society, because it represents "liberty ... [or] the right not to be interfered with by the state or others. ${ }^{.47}$ Nonetheless in New Zealand (and internationally) there are examples of the use of legal paternalism the intention of which has not been solely the prevention of harm to others (for example, the restrictions on smoking in public places or the compulsory use of seatbelts when in a car).

Therefore, although a level of autonomy is essential for a democratic society, there are times when individual autonomy should be restricted or controlled by the law for the sake of individual and public welfare. Obvious examples are criminal laws that forbid certain behaviours harmful to others (for example murder, or assault). Paternalistic interventions to control eating behaviours however, are to be differentiated from laws to prevent criminal acts. This is because, despite the fact that both are imposed for the benefit of society, the latter has very different, often moral, objectives in mind, including the punishment of offenders, and the maintenance of order. It would, for example, be an extremely draconian measure for the law to attempt to exercise complete

\footnotetext{
${ }^{44}$ Mario Rizzo and Douglas Glen Whitman "Perspectives on the New Regulatory Era: Little Brother is Watching You: New Paternalism on the Slippery Slopes" (2009) 51 Ariz L Rev 685, 694; for a good discussion of hard and soft paternalism see Danny Scoccia, ibid, 354.

${ }^{45}$ MNS Sellers "An Introduction to the Value of Autonomy in Law" (2007) 1 IUSGEN 1.

${ }^{46}$ John Stuart Mill On Liberty (Longman, Roberts \& Green, New York, 1869).

${ }^{47}$ Ibid.
} 
control over what individuals eat, and it is hard to imagine an environment where buying lollies from the local dairy could amount to an offence. ${ }^{48}$

Paternalistic measures can also be justified to protect both the public from an individual's behaviour that is not criminal (for example, legal restrictions on smoking in public places), and to protect an individual from the consequences of his or her own behaviour (for example, seat belt legislation, and tobacco marketing restrictions). Legislative measures to control obesity interfering with individual liberty, will quite rightly, come under a great deal of public, political and industry scrutiny. Such measures must therefore be justifiable, not just because of the need for society to maintain individual freedom, but in order to ensure the appropriate policy decisions are made to allow such measures to be implemented. This paper will argue that legal measures to control obesity are justifiable even when they are considered paternalistic. ${ }^{49}$

\section{B Paternalism and obesity control}

Anti-obesity advocates believe that levels of obesity have now reached such proportions that the law should be used in every way it can to control obesity, even if that means the sacrifice of some autonomy. This is a view that is not always popular, with the result that obesity control measures are frequently opposed on the grounds that they are overly paternalistic. Dealing with the paternalistic objections to obesity measures is critical to the success of them. The nature of such objections will depend upon the measures proposed, and at whom the measures are aimed. Objections to measures that utilise hard paternalism (for example, the banning, or restriction of the sale of certain food products) will be greater than those for softer paternalistic measures (for example, mandating the information required on certain food products). This is because the former are in direct conflict with personal autonomy, whereas the latter promote personal autonomy by requiring information that will allow an informed choice to be made.

\footnotetext{
${ }^{48}$ Raymond Perry "Hold the Fries" (2003) 153.7108 NLJ 1858.

${ }^{49}$ Ibid.
} 
Additionally, society's view of obesity is often coloured by the perception that there is an element of blame towards the individuals concerned. This also fuels public opposition towards intervention (paternalistic or not). ${ }^{50}$ Such views are illustrated by the reaction of the ACT New Zealand Health spokesman to the suggestion that fast food advertising should be banned: ${ }^{51}$

\footnotetext{
We each exercise personal responsibility over what we eat and parental responsibility over what our children eat. Treating us all as imbeciles is the stuff of nightmares, not of a civilised society... will Ministry officials check our supermarket trolleys as we do the groceries?
}

A consultation by the United Kingdom Government has also indicated that members of the public do not want to be told how to eat and that regarding health, "the overriding message was: go away!"52 It also reported that there were: ${ }^{53}$

\footnotetext{
many choices ... such as what to eat or drink, whether to smoke, whether to have sex and what contraception to use [that] were very personal issues [and] people do not want government, or anyone else, to make these decisions for them
}

The results of consultations such as these indicate that in order to succeed, approaches to obesity control must address individuals' rights to make their own decisions and take an approach that encourages the appropriate choices to be made, rather than forcing those choices on the individual. These are approaches that are more likely to find favour with both politicians and the public because they are less paternalistic. Nevertheless, although the public may currently choose personal autonomy over both individual health, and the general health of

\footnotetext{
${ }^{50}$ Lucy Wang "Weight Discrimination: One size fits all Remedy" (2008) 117.8 Yale L J 117, 120; Alice Miles "The Chance of Cutting Obesity? A Big Fat Zero" (17 January 2009) Timesonline www.timesonline.co.uk (accessed 25 January 2009).

${ }^{51}$ New Zealand Associate Health Spokesman Dr Muriel Newman "Banning Fast Food Advertising is Preposterous" (3 December 2002) Press Release.

${ }^{52}$ Miles, above n 50.

${ }^{53}$ Ibid.
} 
the population, it may not remain feeling this way when access to public services is affected by the rising numbers of the obese in the population. ${ }^{54}$

The issue may also be further complicated by the views of some health experts who claim that the "emphasis on childhood obesity is having a backlash",55 and that the "anti-obesity message is driving girls to anorexia," 56 with "children ... becoming obsessed with calorie-counting." ${ }^{, 57}$ This represents an extreme reaction to promoting the health message, but it may well be indicative of unforeseen hazards in a society in which the dangers of over eating are constantly reinforced. This potential hazard can be addressed by ensuring that the emphasis of obesity control measures is in reinforcing a healthy lifestyle, rather than attacking or demonising those individuals and food products that are associated with an unhealthy lifestyle.

In New Zealand there is already a history in of legal paternalistic measures to protect the general health and wellbeing of the population when "individual choice and autonomy are perceived to harm the community as a whole"58 (for example, the legal restrictions on when and where smoking is permitted); and individuals from themselves (for example, seatbelt legislation and the legal prohibition on certain drugs, and smoking restrictions). ${ }^{59}$ In such cases it was considered necessary, for the sake of the safety of society (and to protect individuals from the dangers of their own behaviour), to compromise autonomy and enact legislation to control certain behaviours. ${ }^{60}$

\footnotetext{
${ }^{54}$ Karen Michels "A Maternalistic Approach to Prevention”, (2005) 34.1 International Journal of Epidemiology 3.

${ }^{55}$ Fran Yeoman, and Rosemary Bennett "Anti-obesity Message is 'Driving Girls to Anorexia'” (3 February 2007) The Times London 9.

${ }^{56}$ Ibid.

${ }^{57}$ Ibid.

58 Human Genome Research Project Choosing Genes for Future Children: Regulating Preimplantation Genetic Diagnosis (Human Genome Research Project, Dunedin, 2006) Main findings www.otago.ac.nz/genome/resources/index (accessed 12 May 2008) 2.

${ }_{59}$ See: Smoke-free Environments Act 1990 for tobacco legislation; Land Transport (Road User) Rule Regulations 2004 for seatbelt legislation; and Misuse of drugs Act 1975 for drugs legislation.

${ }^{60}$ Human Genome Research Project, above n 58, 2.
} 
C The justification for the use of paternalistic measures to control obesity

The promotion and maintenance of autonomy is a persuasive argument against the imposition of paternalistic measures to control obesity. ${ }^{61}$ Therefore, to justify any restriction there must be equally convincing arguments in favour. Paternalistic measures to control obesity are justified because, inter alia:

- it is necessary to protect the health of individuals (that is protecting them from the consequences of their detrimental eating behaviours) and reduce the general levels of obesity related illness in the population as a whole;

- obesity poses a threat to society due to the effects on healthcare and public spending, and productivity in general; and

- the current eating environment arguably compromises personal autonomy, and therefore paternalistic measures are a counter measure.

\section{Obesity measures, paternalism, and the health of the individual and population}

Some paternalistic measures are already enshrined in legislation in New Zealand for the sake of the health of both individuals and the population. For example, seat belt legislation (clearly protecting individuals who would not be inclined to wear a seat belt, and the public from the ramifications of accident costs and use of healthcare resources) ${ }^{62}$ the Public Health Act (containing extensive provisions restricting personal autonomy in specific circumstances); ${ }^{63}$ and legislation controlling the marketing, sale and use of tobacco products (measures that protect both those who smoke and third parties affected by such behaviour). ${ }^{64}$ The threat that obesity poses both to individual, and population health, places

\footnotetext{
${ }^{61}$ K D Brownell and K E Warner "The Perils of Ignoring History: Big Tobacco Played Dirty and Millions Died. How similar is Big Food?” (2009) 87.1 Milbank Quarterly 259, 265.

${ }^{62}$ Land Transport (Road User) Rule Regulations 2004.

${ }^{63}$ Health Act 1956.

${ }^{64}$ Smoke Free Environments Act 1990.
} 
obesity measures in a similar category. Thus, adopting a similar hard paternalistic approach to obesity (for example, by banning certain food ingredients, or controlling where products can be sold); or a soft (minimally) paternalistic approach (for example, clearer and more informative labelling, or a form of fat tax), can be justified because it is in the interests of the health of both the individual and the population.

High levels of obesity, and associated health problems in the population, clearly have a significant effect on public health. The law can be a "powerful instrument of public health."65 Given the threat that obesity levels pose to the health of the population, the use of public health law (that is law dealing with the health of the population as whole, rather than specific individuals) is appropriate. In this context, it should also be noted that, to date: ${ }^{66}$

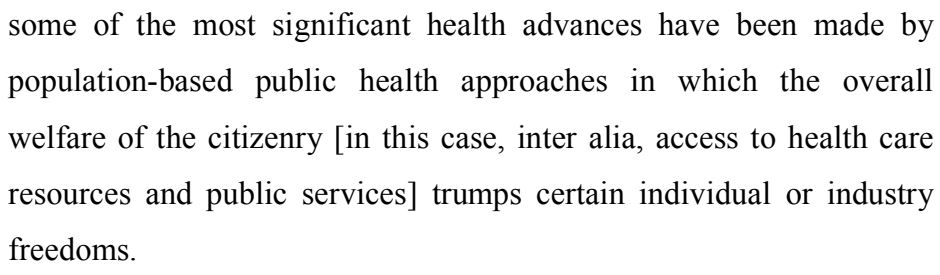

Many such health advances have taken a paternalistic approach, but have been in relation to communicable diseases. Obesity is not a communicable disease, but can still be considered a public health issue. Its status as such will now be examined.

\section{$1 \quad$ Is obesity a public health law issue?}

Obesity has become a significant health issue causing high levels of disease and death in the population. It has even been described as the "public health challenge of our time." 67 Nonetheless, obesity is not always viewed as a public health problem, and this has proved a contentious issue. Public health goals include "the prevention of disease to reduce human suffering," 68 and to deal

\footnotetext{
${ }^{65}$ Mello, above n 42.

${ }^{66}$ Ibid.

${ }^{67}$ Mary T Bassett and Sarah Perl "Obesity: The Public Health Challenge of Our Time" (2004) 94.9 Am J Public Health 1477.

${ }^{68}$ Michels, above n 54, 3.
} 
with "things that threaten the health and wellbeing"69 of individuals in the population. Initiatives that reduce obesity would certainly achieve these goals.

Historically, public health issues have been those relating to communicable diseases and "public nuisances like widespread pollution,"70 but more recently, the concept of public health has also included some noncommunicable diseases (for example, the illnesses caused by smoking). This wider concept of what constitutes a public health issue clearly includes obesity. This is however a view that is not embraced by all, because obesity is still viewed by many as a problem to be dealt with on an individual rather than public level. ${ }^{71}$

The more modern, extended view of what constitutes a public health issue therefore includes some non-communicable diseases caused by "normal behaviours such as the consumption of tobacco and alcohol"72 or an excess of foods. Such behaviours have an element of personal choice, and critics believe public health issues should not "reach beyond the traditional domain of infectious disease" 73 into such areas. Since obesity is commonly perceived as a matter of personal choice it has traditionally not been considered a public health problem, and therefore not one that should be addressed through public health legislation. Clearly however, the wider definition of public health law issue does include obesity.

Therefore, despite the significant societal health risks and mortality associated with obesity, the public may not consider it poses the same public health threat as, for example, severe acute respiratory syndrome (SARS) or avian flu, because of the nature of the causes of obesity and the element of perceived personal responsibility involved. ${ }^{74}$ Similar arguments were however raised when the regulation of tobacco consumption was first considered and its regulation is

\footnotetext{
${ }_{70}^{69}$ Reynolds, above n 7, 162.

${ }^{70}$ Richard A Epstein "In Defense of the 'Old' Public Health: The Legal Framework for the Regulation of Public Health" (2004) 69 Brook L Rev 1421, 1425.

${ }^{71}$ For a further discussion see: Reynolds, above $\mathrm{n} 7,162$; and ibid.

${ }^{72}$ Reynolds, above n 7, 162.

${ }^{73}$ Lawrence O Gostin and M Gregg Bloche "The Politics of Public Health: a response to Epstein" (2003) 46.3 Perspectives in Biology and Medicine S160, S172.

${ }^{74}$ Reynolds, above n 7, 162.
} 
now considered a justified restriction of individual behaviour. Indeed, an analogy is frequently drawn between tobacco and obesity as justification for obesity measures that restrict individual behaviour. This analogy therefore warrants closer examination. $^{75}$

(a) The analogy between the use of tobacco and the consumption of unhealthy foods

The analogy between tobacco and food consumption (leading to obesity) is often cited as a justification for obesity control measures. That said, there are clearly differences between the two products.

Tobacco was proved to contain an addictive substance; nicotine, and therefore the concept of informed choice and personal responsibility was superfluous. Additionally tobacco companies lied about the addictive properties of tobacco, failed to warn consumers, and altered levels of nicotine to promote addiction. $^{76}$

The argument that food consumption leading to obesity is a matter of personal responsibility may, at first glance, be convincing, but increasingly, studies indicate that some food products may be addictive. A recent study by the University of Oregon showed a decrease in the sensitivity of the pleasure areas in the brain with regular intake of high-fat and high-sugar foods, leading to increased consumption. ${ }^{77}$ This study led some journalists to describe junk food as being as addictive as cocaine or heroin. ${ }^{78}$ Additionally, other studies show that

\footnotetext{
${ }^{75}$ For more detailed discussion of perception of obesity as public health issue see Reynolds, above n 7, 162; and Brownell and Warner, above n 61.

${ }^{76}$ See discussion in Dustin A Frazier "The Link between Fast Food and the Obesity Epidemic" (2007) 17.2 Health Matrix 273; and for a good account of the analogy see Brownell and Warner, above n 61.

${ }^{77}$ Eric Stice, Sonja Yokum, Kenneth Blum and Cara Bohon "Weight Gain is Associated with Reduced Striatal Response to Palatable Food" (2010) 30.39 Journal of Neuroscience 13105.

${ }^{78}$ Lois Rogers "Junk food as Addictive as Cocaine" (5 September 2010) The Sunday Times London, 9; and Steve Connor "Junk Food could be Addictive 'like Heroin'; Rats become 'Hooked' on Sausage and Cheesecake in the same way as Drug Abusers" (29 October 2010) The Independent London.
} 
high fat and sugar diets in rats may cause changes to brain chemistry that are similar to addiction, ${ }^{79}$ and a New Zealand study in 2008 concluded that: ${ }^{80}$

\begin{abstract}
Empirical scientific and clinical studies support an addictive component of eating behaviour, with similar neurotransmitters and neural pathways which may be triggered by consumption of high GI food, as with other addictive drugs.
\end{abstract}

In addition to studies pointing to a link between certain foods and addiction, for foods to which caffeine (an addictive substance) has been added, this link is not disputed. Although the number of food items that have caffeine added (which would not include coffee or tea, in which it is naturally occurring) are relatively few given the vast number of food items available, the use of caffeine in some of these products may be a significant factor in the obesity epidemic; for example, the link between caffeinated soft drinks and obesity.

Studies have shown that individuals can become addicted to "caffeinated soft drinks ... feeling compelled to continue consuming soft drinks despite desires and recommendations that they quit." University School of Medicine in the United States has even stated that "caffeine is a mildly addictive drug." 82 This link between caffeinated soft drinks and addiction may explain the contribution that the consumption of soft drinks makes to the obesity epidemic. ${ }^{83}$

\footnotetext{
${ }^{79}$ See Rachael Newcombe "Is Junk Food Addictive" (19 July 2003) BUPA Investigative News www.bupa.co.uk (accessed 16 January 2009); Louise Hall "Revealed: Why some Foods are Addictive" (13 January 2009) Sydney Morning Herald www.smh.com.au (accessed 16 January 2009); Adam Drewnowski, Dean D Kruhm, Mark A Demitrack, Karen Nairn and Blake A Gosnell "Naxolone, an Opiate Blocker, Reduces the Consumption of Sweet High-fat Foods in Obese and Lean Female Binge Eaters" (1995) 61 Am J Clin Nutr 1206,1206.

${ }^{80}$ Simon Thornley, Hayden McRobbie, Helen Eyles, Natalie Walker and Greg Simmons "The obesity Epidemic: Is Glycemic Index the Key to unlocking a Hidden Addiction?" (2008) 71.5 Medical Hypotheses 709, 713.

${ }^{81}$ Roland R Griffiths, Ellen M Vernotica "Is Caffeine a Flavouring Agent in Cola Soft Drinks" (2000) 9 Arch of Fam Med 727; Brownell and Warner, above n 61, 281.

${ }^{82}$ Center for Science in the Public Interest "Label Caffeine Content of Foods, Scientists tell FDA. Health Activists Say Caffeine Causes More than a 'Buzz': Miscarriages, Withdrawal Symptoms, Poor Nutrition" (31 July 1997) Press Release.

${ }^{83}$ For a discussion on the link between obesity and soft drink consumption see: Michael $\mathrm{F}$ Jacobson Liquid Candy: How Soft Drinks are Harming Americans Health (2 ed, Centre for Science in the Public Interest, Washington DC, 2005).
} 
Clearly products containing caffeine can be addictive, and have other health risks associated with them. Many consumers may not be aware of the levels of caffeine in what they consume, and that the products containing it may be addictive. It is worth noting that the Centre for Science in the Public Interest in the United States has lobbied for foods to be labelled with the amount of caffeine they contain. ${ }^{84}$ Therefore, for food products such as caffeinated sweetened soft drinks, paternalistic measures (for example banning their sale in schools or restricting the marketing of them) are more justified because any autonomy associated with choosing caffeinated products is compromised by the possibility of addiction. It is also worth noting, from a health perspective, that caffeine consumption can also lead to: ${ }^{85}$

increased risk of infertility, miscarriage, and impaired [foetal] growth
$\ldots$.. [it also] affects bone health, exacerbating the low calcium intake of
women and teenagers and increasing the risk of osteoporosis.

Tobacco and food are very different products, but the possibility that some food products (both those with added caffeine and those without) may be addictive makes them comparable. This is an important comparison to be able to make when attempting to justify the need for legally paternalistic measures on the basis of experiences with tobacco.

The analogy between using tobacco products and consuming food products is perhaps weakest in the context of the direct health risks to third parties. Second-hand smoke means that an individual's smoking affects third parties, whereas the over-consumption of foods by an individual, leading to obesity, does not. Because of this "the collective costs of obesity are easily overlooked because obese people's burden on society is much less obvious than ... smokers." 86

\footnotetext{
${ }^{84}$ For a fuller discussion see Centre for Science in the Public Interest www.cspinet.org (accessed 31 March 2010).

${ }^{85}$ Ibid.

${ }^{86}$ Burnett David "Fast Food Lawsuits and the Cheeseburger Bill: Critiquing Congress's Response to the Obesity Epidemic" (2006) 14.3 Va J Soc Pol'y \& L 357, x.
} 
Nonetheless, there are serious fiscal ramifications that impinge on the health of third parties, due, inter alia, to a significant percentage of limited health care resources being spent on the obese. Additionally, from a health perspective, there is similarity between the risk to the health of the general population (and, of course, the individual) caused by the consumption of tobacco and food products.

The serious health problems caused by over-consumption of food products also differ to those caused by tobacco in another significant way; namely the specific cause of those health problems. There is a proven link between consumption of tobacco and the resulting detrimental health effects (both on individual and community health). Obesity (and the resultant health problems) however, has a variety of causes and it is extremely hard to prove that a particular food product, such as a certain brand of fast food, or chocolate bar, was the sole cause of an individual's obesity. Another significant difference is the vast and diverse range of food products, manufacturers and retailers.

Tobacco is a discrete product produced by an easily identifiable number of companies, whereas this is not the case with food products. There are many food products, manufacturers and retailers ranging from the large corporate to the corner dairy, the local cafe, and even a school canteen or charity sausage sizzle. The sheer variety of manufacturers and retailers is not analogous with the tobacco industry, but it does not make an analogy between the two any less valid. It does nonetheless mean that there are different challenges to the regulation and control of the consumption of food products. ${ }^{87}$ These will be addressed later in the paper.

Another significant difference between tobacco and food products is the nature of the products themselves. Food products are not harmful per se, and "all foods have certain nutritional and caloric value necessary to sustain life unlike tobacco, which has no essential physiological value." 88 Furthermore, any food product eaten in excess has the potential to cause or contribute significantly to obesity. Additionally, not all food products are unhealthy. This can be a major

\footnotetext{
${ }^{87}$ Ibid; and Brownell and Warner, above n 61, 281.

${ }^{88}$ Burnett, above n 86, 381.
} 
stumbling block for those who rely upon the tobacco analogy to justify measures to control obesity.

The fact that many food products are healthy, and that consuming them is necessary to survive, does present a major difference between tobacco and food products. There are however, many food products that are not healthy, and provide little nutritional value (for example, caffeinated sugared soft drinks, or fast food). For such products the analogy is more appropriate.

(b) Is the tobacco analogy an appropriate one to make?

Therefore, despite some significant differences in the nature of the products themselves, the similarities between tobacco and food products are such that it is appropriate to draw on the experiences of the way in which tobacco was viewed, and dealt with, in justifying legally paternalistic measures to control obesity for the sake of both individual and general society health.

In addition to the need to protect the individual and population health, the use of a paternalistic approach is further justified by the fact that, whilst obesity measures are perceived as a restriction of autonomy, this is not in fact, the case. Arguably, given the influences of the current obesogenic environment, individuals are not truly exercising autonomy.

\section{E Obesity measures, paternalism and the lack of autonomy in current eating decisions \\ $1 \quad$ Autonomy and the eating environment}

An individual's eating habits are traditionally perceived as a matter of personal choice (and therefore a process that should not be interfered with by the state), but this is arguably not the case. The environment has changed as a result of aggressive marketing, larger portion sizes, energy dense food products, and the price and availability of unhealthier foods. Therefore, unhealthy choices are now easier to make than healthy ones. Such choices are made more attractive and 
harder to resist because of marketing strategies and an environment in which "food choices are not equivalent." 89 Unhealthy foods are cheaper, more accessible, and more aggressively promoted than healthy foods. The influence this change in the environment has had on the autonomy of eating decisions is also evident because, "whilst levels of obesity have risen dramatically "there is no evidence ... [of] decreased personal responsibility." 90 One good example of the changing environment is the change in portion size in one fast food restaurant: ${ }^{91}$

\footnotetext{
"When ... [it] opened its doors in the middle of the twentieth century, the restaurant offered one size for an order of French fries; today, the chain offers three sizes, with the original size as the smallest option. In the early days, [a typical meal was] ... a total of 590 calories. By 2002 [it was] ... 1550 calories."
}

Since consumers are influenced by such "factors beyond their control," $" 92$ it is not appropriate "to place the onus on individuals [to make] healthier choices." 93 Therefore, when eating decisions are influenced in such way, it is spurious to rely on anti-paternalistic arguments when opposing measures to control obesity. On the contrary, the use of paternalistic measures, which provide information to allow consumers to make an informed decision, can provide "a clean slate for consumers to truly make their own choices rather than being manipulated by ... [environmental influences]."94

Thus, the fact that individuals are now exercising less autonomy in decisions to purchase and consume food products makes the concept of personal

\footnotetext{
${ }^{89}$ Marlene B. Schwartz The Role of the Food Industry in Childhood Obesity (Rudd Center for Food Policy and Obesity Yale University International Society of Behavioural Nutrition and Physical Activity, Boston, 2006) 27 www.yaleruddcenter.org/resources (accessed 21 November 2010).

${ }^{90}$ Ibid 78; for a good discussion of eating environment see: Susan Levine, Lori Aratani "Sweet Surrender; Under Siege: Companies Begin Replacing Familiar Junk-Food Pitches and Products" (22 May 2008) The Washington Post United States D01.

${ }^{91}$ Tamara Schulman "Menu Labelling: Knowledge for a Healthier America" 47 Harv J on Legis (2010) 587, 593.

${ }^{92}$ Burnett, above n 86, 372.

${ }^{93}$ Mark Henderson "Welcome to the Town that will make you Lose Weight" (18 February 2008) The Times London 3.

94 Oliver Mytton, Alastair Gray, Mike Rayner and Harry Rutter "Could Targeted Food Taxes Improve Health?” (2007) 61 J Epidemiol and Community Health” 689, 692.
} 
eating choices superfluous. ${ }^{95}$ This provides a convincing argument for the use of legal paternalistic measures as a way to address environmental influences (such as the aggressive marketing of unhealthy products, availability and relative cost of unhealthy products, and the possible addictive nature of some food products) contributing to this lack of autonomy.

Arguments centred on lack of autonomy are all the more convincing when applied to children, who cannot be expected to be responsible when it becomes to the decisions they make about food, due to their immaturity. Children are particularly vulnerable to the effects of the current food environment, and food marketing has frequently targeted children. ${ }^{96}$ As one news commentator states ${ }^{97}$

Children on the whole, do not really understand the concept of selfregulation ... it is in their natures to be unrestrained. They have no experience to tell them otherwise. ... Give a child $£ 1$ to spend in the corner shop, and he or she is unlikely to come home with a banana and a pint of semi-skimmed milk. They will cram as much rubbish into their pockets as their budget allows.

Children are not able to "understand the persuasive intent of marketing," therefore, it is unethical "to expose children ... to something that we know is harmful and that they are not capable of understanding." 99

Children cannot, and should not be relied upon to make healthy decisions, even if provided with the appropriate information that could assist them to do so. They are therefore deserving of a higher level of protection from the environmental influences. Furthermore, since childhood is the time that many of the "physical attributes and the social and psychological structures for life and

\footnotetext{
${ }^{95}$ Sunstein, Thaler "Libertarian Paternalism is not an Oxymoron" (2003) 70.4 U Chi L Rev 1159, 1170 .

${ }^{96}$ Scientific Committee of the Agencies for Nutrition Action Does Watching TV contribute to Increased Body Weight and Obesity in Children? (Scientific Committee of the Agencies for Nutrition Action, Wellington, 2006) 21.

97 Sarah Vine "A Tax on Chocolate? Utterly Idiotic... but a Surcharge on Sugar would Taste Sweet" (13 March 2009) The Times London, 10.

${ }^{98}$ Caroline Shaw “(Non) Regulation of Marketing of Unhealthy Food to Children in New Zealand (2009) 122 NZMJ 76, 77.

${ }^{99}$ Ibid.
} 
learning" $" 100$ are acquired, ensuring a healthy environment is essential to encouraging children to learn the correct lifestyle habits. ${ }^{101}$ The very real possibility that "children today run the risk of becoming the first generation ... with a shorter life expectancy than their parents for more than a century"102 is sufficient justification for paternalistic measures to control obesity, even in situations in which the level of paternalism might be considered too extreme for the adult population. In the current food environment, paternalistic health laws, designed to protect children, are justified on the basis of the risk to children, and the need to protect them.

\section{Autonomy in eating decisions and the nature of some food products}

Another significant factor contributing to the lack of autonomy in eating decisions is the nature of some foods that are currently on offer. Some foods have been greatly processed and have therefore been transformed into something that is unhealthier than would normally be anticipated for a product of that nature. In such instances, "consumers are not actually getting what they think they are buying." "103 For example, the fries offered in fast food restaurants might reasonably be expected to be fried potatoes, but the list of ingredients shows that this is not always the case. ${ }^{104}$ It is possible that at least some consumers would not choose a particular food product if they knew the extent to which it had been processed. Therefore, if the appropriate information was provided to consumers via better labelling and control of food marketing, they might make different decisions. This approach is a soft form of paternalism and therefore not one that can be so successfully opposed by anti-paternalists. This is an argument that was

\footnotetext{
${ }^{100}$ British Medical Association Board of Science Preventing Childhood Obesity (British Medical Association, England, 2005) 1.

101 Ibid.

${ }^{102}$ B Ashley "The Role of Litigation in Combating Obesity Among Poor Urban Minority Youth: A critical analysis of Pelman v McDonald's Corp" (2009) 15 Cardozo Journal of Law \& Gender" 275.

${ }^{103}$ British Medical Association Board of Science, above n 100, 28.

${ }^{104}$ See Pelman v McDonald's Corp. (2003) 237 F.Supp.2d, 535 (SDNY) [Pelman]: Sweet J lists the ingredients of fries as follows: partially hydrogenated soybean oil, natural flavour (beef source), dextrose, sodium acid pyrophosphate (to preserve natural colour). Cooked in partially hydrogenated vegetable oils, (may contain partially hydrogenated soybean oil and/or partially hydrogenated corn oil and/or partially hydrogenated canola oil and/or cottonseed oil and/or corn oil). TBHQ and citric acid added to preserve freshness. Dimethylpolysiloxane added as an antifoaming agent.
} 
raised in litigation against a major fast food chain in the United States Pelman $v$. McDonald's Corp. ${ }^{105}$

Despite the reality that the autonomy of eating decisions has been compromised, the food industry continues to advance, and promote the concept of autonomy (and personal responsibility) as an argument against stricter regulation. ${ }^{106}$

(a) The Food Industry and the hijack of anti-paternalistic arguments

Anti-paternalism arguments are significant hurdles for many measures to control obesity, and because of this they have been hijacked ${ }^{107}$ by the food industry to justify voluntary regulation and avoid stricter control. The food industry influences policy decisions by lobbying politicians, and can also manipulate public perception. It has much to gain by making the public suspicious of any paternalistic measures, and has to some extent, already done so. Headline grabbing terms such as fat police or nanny state reinforce such suspicions. ${ }^{108}$ In this way the public are led to believe that "the environment is a result of their choices rather than a reflection of corporate desires,"109 and the "the food industry controls and manipulates the way in which the obesity problem is understood, and how it should be dealt with." consider the industry's enthusiasm for anti-paternalism in the context of its "wish to sell as much of its products as possible." paternalism is not likely to boost sales.

\footnotetext{
${ }^{105}$ Pelman; see also most recent judgment for summary of all actions in Pelman v. McDonald's Corp. (27 October 2010) (SDNY) (slip copy, 2010 WL 4261390).

${ }^{106}$ Brownell and Warner, above n 61, 266.

${ }^{107}$ Robert Quigley and Carolyn Watts "Challenging Beliefs about the Marketing of Food" (2005) 118.1218 NZMJ 4. The article uses the word hijack in this context.

${ }^{108}$ Ibid; also see James Chapman "Obesity Poses as Big a Threat to our Nation as Terrorism, Government adviser warns" (15 August 2008) MailOnLine www.dailymail.co.uk/news/article (accessed 19 August 2008); Tracy Elliott "No need for the Fat Police" (2007) 157 NLJ 427; Nicole E Hunter "Revisiting the Regulation Debate: The Effect of Food Marketing on Childhood Obesity" (2009) 7.2 Pierce L Rev 205, 229; and Jess Alderman and others "Application of Law to Childhood Obesity Epidemic" (2007) 35 J L Med \& Ethics 90, 102.

${ }^{109}$ Hunter ibid, 230.

${ }^{110}$ Ashley, above n 102, 280.

111 Reynolds, above n 7, 164; also for a good discussion of the industry's vested interest in promoting the personal responsibility arguments see ibid; and Schwartz, above n 89.
} 
Thus, use of legal paternalistic measures to control obesity is justified, both in the interests of individual and public health, and due to the current lack of autonomy in eating decisions. Notwithstanding such arguments, a soft paternalistic approach to obesity control is easier to justify, and at this time, a hard paternalistic approach is not essential. This should however, be something that is kept under regular review.

It is therefore possible to make changes to the current obesogenic environment by the use of measures that are not coercive, but act to encourage and assist individuals to make healthier choices. For example in providing more information and better regulating the information (including marketing information) that is disseminated about food products. In this way the law would target obesogenic influences in the environment. The current National Government has indicated that it does not intend to adopt a paternalistic approach to obesity control, therefore this approach is more likely to enjoy success. Nonetheless, the justification for paternalism in obesity control remains an important issue, because even soft paternalistic measures have, in the past, been opposed on paternalistic grounds. This less paternalistic approach to obesity control in New Zealand, and how the law can facilitate this, will now be examined. 


\section{A The need to address the causes of obesity and the creation of a healthy environment}

In order to provide an effective solution to obesity, any measures (be they via legal means or otherwise) must address the causes of obesity. ${ }^{112}$ As already discussed, obesity is a problem with many causes involving both the environment and genetics, ${ }^{113}$ with: ${ }^{114}$

\footnotetext{
multiple risk factors ... which interact to create an environment where unhealthy food is more visible, more readily available, [cheaper] and far more heavily promoted than healthy food. As a result less healthy choices have become the easy choices.
}

Therefore, a reasonable conclusion is that legal intervention must target these obesogenic influences; for example, by providing better information on, and about food products, controlling marketing, and the imposition of a form of fat tax or subsidy on unhealthy products to address price inequalities. This is in line with the strategies recommended by WHO, which include those that focus on "universal prevention, involving population-wide measures that directly address the social, economic, and environmental determinants of the problem." ${ }^{115}$ New Zealand law can play a part in the obesity control by providing the appropriate regulatory framework for this.

\footnotetext{
112 PHAC, above n 8, 1 .

113 PHAC, ibid; see also: Yvonne Martin "Who Shoulders the Blame for Obesity?" (3 March 2007) The Press Stuff www.stuff.co.nz (accessed 14 August 2008); David S Ludwig, Karen E Peterson and Steven L Gortmaker "Relation between Consumption of Sugar Sweetened Drinks and Childhood Obesity: A Prospective, Observational Analysis" (2001) 357.9255 Lancet 505, 507.

${ }^{114}$ New Zealand House of Representatives Inquiry into Obesity and Type 2 Diabetes in New Zealand Report of the Health Committee (New Zealand House of Representatives, Wellington, 2007), 3 .

115 Ibid, 15.
} 


\section{B Encouraging healthy choices: New Zealand law and the promotion of a healthy environment}

As outlined above, the most appropriate approach to controlling obesity in New Zealand is the adoption of initiatives that encourage the consumption of healthy foods, and heighten awareness of dietary issues (for example, the risks of the over-consumption of fast foods), thus addressing the problems of the current eating environment. ${ }^{116}$ In examining any role that the law can play in the promotion of this type of environment, it is vital to consider which initiatives might encourage a healthy lifestyle. It will then be possible to determine in what way such initiatives could be supported or facilitated by the law.

There are many initiatives that could assist the promotion of a healthy environment, including:

- Regulation of the food and marketing industries (including marketing restrictions (especially to children), improving the labelling/information given on foods or providing health warnings on foods considered particularly unhealthy).

- Promotion of the consumption of healthy foods in schools and early learning centres.

- Imposing a tax or fat-tax on unhealthy foods to discourage overconsumption and/or provide revenue for subsidising healthier foods or other obesity initiatives. ${ }^{117}$

The current food environment in New Zealand presents many opportunities for intervention to control obesity, and by addressing obesogenic influences, the law can facilitate changes that will promote a healthier way of life. By regulating the food industry, to improve the information that is disseminated on and about food products, and the imposition of a fat-tax, the law will make a

\footnotetext{
${ }^{116}$ See discussion in PHAC, above $\mathrm{n} 8$.

117 See discussion in Ibid; and Michael Cardin, Thomas A. Farley, Amanda Purcell and Janet Collins "Preventing Obesity and Chronic Disease: Education vs. Regulation vs. Litigation" (2007) 35.4 J of Law Med \& Ethics 120, 122.
} 
dramatic change to the eating environment. The details of such an approach will now be examined. 

FOOD PRODUCTS

Fundamentally, regulation and the risk of being penalised, ensure that the food industry engages in responsible behaviour in relation to its products so that the public is not misinformed, or unduly manipulated. This is particularly relevant when there is an element of risk; for example, in over-consumption, or if food products are addictive. ${ }^{118}$

The regulation of the food and beverage industry, whether via selfregulation, or a mandatory set of rules administered by an appropriate government agency, is therefore an opportunity to introduce measures aimed at controlling obesity. Rather than the law seeking to control food intake directly, regulating the food industry could have a positive effect on obesity by controlling the information that is available to those buying and consuming food products. Therefore, the current law in relation to labelling and marketing of food products will be reviewed. Increased food industry regulation to improve the information required on food products (possibly including a health warning), and the control of marketing (and manipulative) information will then be explored.

\section{A Food product labelling in New Zealand}

The food industry in New Zealand is regulated by the New Zealand Food Standards Authority (NZFSA), with various statutory powers under the Food Act. ${ }^{119}$ The industry is also subject to consumer law applicable to all products sold in New Zealand. Consumer legislation includes some requirements and restrictions on what should, and can, be included on the labels of food produced and sold in New Zealand. The emphasis however, is on the prevention of

\footnotetext{
${ }^{118}$ See: Ashley, above n 102, 280.

${ }^{119}$ New Zealand Food Safety Authority [NZFSA] www.nzfsa.co.nz (accessed 16 January 2009); Food Act 1981.
} 
misrepresentation, rather than the regulation of information about the relative nutritional merits of a food product in the context of promoting health. ${ }^{120}$

A review of food labelling and policy is currently being carried out by the Council of Australian Governments, and the New Zealand Food Regulation Ministerial Council (NZFRM). The review, announced in October 2009 has already undertaken consultation, and was due to report to NZFRM in December 2010. In submissions on the review consultation paper, the New Zealand Government indicated a strong preference for voluntary labelling for health and safety information, and indicated that "mandatory labelling regulation should focus on food safety."121 This is reflected in New Zealand's current labelling regime.

The Food Act was enacted nearly thirty years ago and in May 2010 a new Food Bill was introduced to Parliament. ${ }^{122}$ This Bill merely updates the current Food Act and does not contain any additional measures for the control of obesity, and it is therefore disappointing that it has not included any specific health labelling provisions. Until this Bill has been enacted, the Food Act 1981 remains in force.

\section{$1 \quad$ The Food Act 1981}

The labelling requirements of the Food Act prohibit misleading information and packaging, ${ }^{123}$ with criminal sanctions for breach. ${ }^{124}$ The Act contains no labelling requirements relating to the nutritional merits of particular

\footnotetext{
${ }^{120}$ See discussion in: Sue Pollard "Front of Pack Labelling" (Food and Beverage Law Conference 2008, New Zealand, 13 November 2008) 1.

${ }^{121}$ New Zealand Government New Zealand Submission on Food Labelling and Policy Review (New Zealand Government, Wellington, 2010); also see Review of Food Labelling Law and Policy www.foodlabelling.gov.au (accessed 22 November 2010); and Council of Australian Governments "Release of issues Consultation Paper on Review of Food Labelling" (5 March 2010) Press Release. The review website indicates that public release of the report will be decided once the Food Standards Ministerial Council receives the final report due in early 2010 (accessed 26 January 2011).

${ }^{122}$ Food Bill 2010, no 160-2.

${ }^{123}$ Food Act 1981, s 10(1).

${ }^{124}$ Ibid, s 10(2)
} 
food products, their place in the diet, ${ }^{125}$ or a warning or health message stating the dangers of excessive consumption or possible addiction. It does provide the Government with powers to issue food standards "in respect of food manufactured or prepared for sale or sold in New Zealand, or imported into New Zealand." 126 These standards include the New Zealand (Australia New Zealand Food Standards Code) Food Standards 2002, New Zealand Food (Supplemented Food) Standard 2010, and Food (Imported Milk and Milk Products) Standard 2009. ${ }^{127}$

The Australia New Zealand Food Standards Code (ANZFSC) is incorporated into New Zealand law under the Food Act and administered by Food Standards Australia New Zealand. ${ }^{128}$ It sets out various requirements including, when and which health claims can be made about a particular food. It contains detailed labelling requirements, including listing the ingredients in a specified manner. The labelling requirements of this standard do not include information about the nutritional merits of a particular food in the diet or a warning relating to the dangers of excessive consumption.

ANZFSC Rule 1.2.3 does require certain "mandatory warning and advisory statements and declarations to be made in relation to certain foods or foods containing certain substances." ${ }^{29}$ These statements do not relate to the dangers of overconsumption and obesity. Additionally Rule 2.6.4 requires certain advisory statements be made on "caffeinated beverages that are manufactured for the purpose of enhancing mental performance." 130 Caffeine is also dealt with in a similar manner under the New Zealand Food (Supplemented Food) Standard,

\footnotetext{
${ }^{125}$ Pollard, above n 120, 14.

${ }^{126}$ Food Act 1981, s 11(c),

127 Other food standards are: New Zealand (Maximum Residue Limits of Agricultural Compounds) Food Standard 2010; Food (Tutin in Honey) Standard 2008; Food (Tutin in Honey) Imported Food Standard 2008; Food (Uncooked Comminuted Fermented Meat) Standard 2008; Food (Prescribed Foods) Standard 2007; New Zealand (Mandatory Fortification of Bread with Folic Acid) Food Standard 2007; New Zealand (Bee Product Warning Statements - Dietary Supplements) Food Standards 2002.

${ }_{128}$ Food Act, 181 s 11B-11ZE; see New Zealand Food Safety Authority [NZFSA] Health, Nutrition and Related Claims: Enabling Provisions in New Zealand Law: NZFSA Public Discussion Document No 04/07 (NZFSA, Wellington, 2007) 7.

${ }^{129}$ Ibid, Standard 1.2., Mandatory warning and advisory statements and declarations.

130 Australia New Zealand Food Standards Code, Standard 2.6.4, Formulated Caffeinated Beverages.
} 
which came into force on 31 March 2010.

The emphasis of the Food Act is on the safety of food in terms of hygiene and "food-borne"131 illness, rather than any risks in the context of nutrition or obesity. Therefore it does not provide any real assistance in controlling obesity, other than the possibility of creating food standards that could; for example, prescribe certain obesity related nutritional labelling requirements. Currently no such standards have been issued.

In addition to the Food Standards, the Fair Trading Act contains some labelling requirements prohibiting any "conduct that is liable to mislead the public as to the nature, manufacturing process, characteristics, suitability for a purpose, or quantity of goods."132 This requirement prevents misleading nutritional health claims on labels, but does not impose any requirement for nutritional guidance or contextual information.

Therefore, current New Zealand labelling requirements have clearly not been imposed with the obesity epidemic in mind, and do not provide for the inclusion of information that can really assist consumers to make decisions based on health issues. Given current obesity levels, it is surprising that the labelling of foods and beverages has not been utilised as a better tool to provide this information. This should be remedied. A major advantage of implementing better labelling to control obesity is that it preserves and promotes personal autonomy by providing the information to allow a truly informed decision to be made. Therefore moves to change the labelling regime should not be opposed on paternalistic grounds.

Before considering the details of any possible change in current New Zealand labelling law to improve the information provided, examples of the regulation of labelling in some other jurisdictions will be examined briefly. Labelling regimes overseas, many imposed with the control of the obesity

\footnotetext{
${ }^{131}$ Wilkinson, Kate, Minister of Food Safety "New Food Bill introduced to Parliament" (26 May 2010) Press Release.

${ }^{132}$ Fair Trading Act 1986, s 10.
} 
epidemic in mind, may provide useful information for policy makers considering change in New Zealand.

\section{B Food product labelling regulation in other jurisdictions}

\section{$1 \quad$ The regulation of food product labelling in the United States}

Labelling of foods in the United States is controlled by the Federal Food Drug and Cosmetic Act, requiring "food labelling ... for most prepared foods, such as breads, cereals, canned and frozen foods, snacks, desserts, drinks, etc. Nutrition label[1]ing for raw produce (fruits and vegetables) and fish is voluntary" $" 133$ The requirements are extensive relating, inter alia, to portion size, calorific content, fat, saturated (and trans) fat content, sodium, potassium, carbohydrate, and cholesterol. ${ }^{134}$ The Federal Labeling Education and Nutrition Act of 2009 (also termed the Lean Act), reintroduced to Congress in March $2009,{ }^{135}$ would also mandate the posting of calories "on a sign on the same wall as a menu board or as a supplement to or insert in a menu [in] restaurants and grocery stores that serve prepared food." ${ }^{136}$

Additionally, the United States recently passed legislation (the Patient Protection and Affordable Care Act) that, inter alia, contains provision for mandating the inclusion of calorie information on menus in chain restaurants. ${ }^{137}$ Some States already require nutritional information to be provided on restaurant menus. Such menu labelling requirements include the provision of "the total number of calories, grams of trans fat, grams of saturated fat, grams of

\footnotetext{
${ }^{133}$ United States Department of Health and Human Services www.hhs.gov (accessed 7 June 2010).

${ }^{134}$ United States Code of Federal Regulations Title 21 Food Labeling parts 100 to 169 and parts 170 to 199.

${ }^{135}$ Full title: A Bill to Amend the Federal Food, Drug, and Cosmetic Act with Respect to Nutrition Labeling of Food offered for sale in Food Service Establishments (United States); Paul Frumkin "Breaking News: Congress to reconsider LEAN Act" (3 November 2009) Restaurant News www.nrm.com (accessed 4 December 2009).

136 Jason Szep "Massachusetts sets Tough Fast-food Rules" (13 May 2009) Reuters United Kingdom www.uk.reuters.com (accessed 4 December 2009); Charles E Cantu "Fattening Food: Should Purveyors of Fast Food be Required to Warn? A call for a New Tort" (2006) 2 Journal of International Food Law and Policy 39, 40.

${ }^{137}$ Tamara Schulman "Menu Labelling: Knowledge for a Healthier America" (2010) 47 Harv J on Legis 587; the legislation became law on 23 March 2010.
} 
carbohydrates, and milligrams of sodium"138 for each menu item. Compulsory nutritional labelling on restaurant menus encountered opposition with some groups calling the move "a government sponsored guilt plan."

\section{The regulation of food product labelling in Canada}

Food labelling in Canada is regulated under the Food and Drugs Act ${ }^{140}$ via the Food and Drug Regulations. These Regulations mandate nutrition labelling on packaged foods. The mandatory information includes:

- a nutrition facts table giving information about 13 basic ingredients, and the number of calories in a certain portion of that food;

- an ingredients list that lists the weight of the ingredients in the food, listing them in order of size with the greatest weight at the beginning; and

- health claims can be made; for example, if the product is high in calcium or a certain vitamins, or low fat or reduced calories. There are also controls to ensure that these claims are not misleading.

The intention behind these requirements was to provide the information required by consumers to make healthier eating choices. The nutritional labelling of prepackaged foods became mandatory in December $2007 .{ }^{141}$

\section{The regulation of food product labelling in the United Kingdom}

Food labelling in the United Kingdom is regulated under the Food Safety Act and Food Labelling Regulations. ${ }^{142}$ There are various requirements that ensure that "falsely describing, advertising or presenting food is an offence,",143

\footnotetext{
${ }^{138}$ Lauren F Gitzi "State Menu-labelling Legislation: a Dormant Giant Waiting to be Awoken by Commerce Clause Challenges (2008) 58 Cath U L Rev 501, 503.

${ }^{139}$ Centre for Consumer Freedom "Study on Menu labelling Effectiveness NYC's Battle of the Bulge Falls Flat" (8 October 2009) Press Release www.consumerfreedom.com (accessed 4 Nov 09).

${ }^{140}$ Food and Drugs Act RS C 1985 c F-27.

${ }^{141}$ See Health Canada www.hc-sc.gc.ca (accessed 19 October 2010).

${ }^{142}$ Food Safety Act 1990 (UK); United Kingdom legislation www.opsi.gov.uk (accessed 12 November 2009); Food Labelling Regulations 1996 (UK).

${ }^{143}$ United Kingdom Food Standards Agency Understanding Labelling Rules at United Kingdom Food Standards Agency www.food.gov.uk (accessed 11 June 2010).
} 
and prevent "dishonest labelling and mis-description." 144 The Food Standards Agency is responsible for enforcement. ${ }^{145}$

The regulations contain general requirements including provision of the name of the food, its ingredients, storage instructions, details of the manufacturer, and its place of origin. ${ }^{146}$ There is no requirement that the ingredients be displayed in the context of their place in a healthy diet, ${ }^{147}$ or the potential for obesity as a result of over-consumption. The current emphasis of the requirements appears to be the prevention of both misrepresentation and misleading consumers.

Recent attempts in Europe to impose a system of labelling using colour coding in the form of traffic lights indicating fat, salt and sugar levels failed (although some food manufacturers had already adopted the system voluntarily). ${ }^{148}$ Following this, the abolition of the Food Standards Agency, which campaigned for the scheme, was announced by the United Kingdom Health Secretary. The media accused him of "caving into big business."149 This may give an indication of the level of opposition to stricter regulation that might be encountered from the food industry.

Clearly, some attempts are being made overseas to move towards labelling regimes that can assist in controlling levels of obesity, by providing consumers with increased, better quality, and more relevant information on food labels. It is also time for New Zealand to make better use of labelling as an obesity control tool, and this will be examined further.

\footnotetext{
144 Ibid.

145 Ibid.

${ }^{146}$ Food Labelling Regulations 1996 (UK), s 5.

147 See: Pollard, above $\mathrm{n} 120$.

148 For details of the scheme see: Eatwell UK www.eatwell.gov.uk/foodlabels/trafficlights (accessed 18 November 2010).

${ }^{149}$ See media coverage, for example Randeep Ramesh "Food Standards Agency to be Abolished by Health Secretary: Victory for Food Manufacturers as Health Groups accuse Andrew Lansley of Caving in to Big Business" (12 July 2010) Gardian.co.uk www.gardian.co.uk (accessed 18 November 2010).
} 
As already discussed, current labelling requirements in New Zealand are designed to prevent the consumer from being misled, and not to assist the consumer in making health based decisions. Nonetheless, obesity levels in New Zealand remain high. This could indicate that the general public is either confused; unaware of the dangers of consuming too much of a certain product; ignorant of what constitutes a healthy balanced diet; is simply unable to resist; or that it simply does not care. For example, "few ... would guess that three scoops of ice cream with whipped cream and chocolate sauce is actually healthier [being fewer calories] than a slice of [carrot] cake." ${ }^{, 150}$ In New Zealand, for individuals who wish to make a conscious effort to chose healthier options it "become[s] more arduous when faced with the task of choosing a meal based on dietary restrictions," 151 because current labelling in New Zealand is of very little nutritional use to the average consumer.

There is some evidence that increased nutritional information does affect consumer choices. For example, a study by Burton et al showed that: ${ }^{152}$

levels of calories, fat, and saturated fat in less-healthful restaurant items were significantly underestimated by consumers ... fat and saturated fat levels were twice consumers' estimates and calories approached 2 times more than what consumers expected.

It also showed that: ${ }^{153}$

\begin{abstract}
For items for which levels of calories, fat, and saturated fat substantially exceeded consumers' expectations, the provision of nutrition information had a significant influence on product attitude, purchase intention, and choice.
\end{abstract}

\footnotetext{
${ }^{150}$ Gitzi, above n 138, 501.

${ }^{151}$ Ibid.

${ }^{152}$ Scot Burton, Elizabeth H Creyer, Jeremy Kees and Kyle Huggins "Attacking the Obesity Epidemic: The Potential Health Benefits of Providing Nutrition Information in Restaurants" (2006) 96 Am J Public Health 1669.

153 Ibid.
} 
The study therefore concluded that "most consumers are unaware" 154 of just how unhealthy some menu items are, and that the "provision of nutrition information ... could potentially have a positive impact on public health by reducing the consumption of less healthful foods." ${ }^{155}$ This study related to restaurant food and items listed in a menu, but an analogy can be drawn between a menu and the labelling of products, whether purchased in a restaurant setting or supermarket. ${ }^{156}$ Studies such as this indicate that providing easy to understand nutritional information in New Zealand could impact on obesity levels by providing consumers with the appropriate information to make health based decisions. Furthermore, should such mandatory labelling requirements be introduced, food manufacturers may be forced to change the composition of their products in the quest to gain a good health rating for display on their product labels.

The use of product labelling as a tool to address obesity does of course, assume that at least some consumers, when provided with the appropriate nutritional information, would make a conscious choice to purchase the healthy options. This may not be the case for some individuals, but for those who wish to take steps towards a healthier lifestyle, better labelling would assist, and would most likely, provide nutritional information that was previously unknown to them. This is a compelling argument for imposing an appropriate mandated labelling system in New Zealand.

\section{$1 \quad$ A more prescriptive labelling regime for New Zealand}

Changes to the current labelling regime could be implemented via amendment to the Food Act 1981 or by issuing a new food standard under it. ${ }^{157}$ Amended requirements could, for example, provide consumers with information about the place of that particular food in a person's diet, "the energy expenditure necessary to burn off the food," ${ }^{158}$ and the appropriate portion size. ${ }^{159}$

\footnotetext{
154 Ibid.

155 Ibid.

${ }^{156}$ Ibid.

${ }^{157}$ Food Act 1981, s 11.

${ }_{158}$ Reynolds, above n 7, 163.

${ }^{159}$ For discussion see ibid.
} 
As already discussed, more prescriptive labelling to include nutritional information has arguments in its favour, but such labelling presents challenges that would need to be addressed in its implementation, including:

- The scope of labelling; what products would it apply to?

- A proportion of the population would still opt for unhealthier foods;

- Implementation; that is, the actual content (including the volume of information) and presentation of labels (it is important that the information is presented in such a way that consumers will realistically read it);

- The possible negative effects of over labelling;

- International compliance and standardisation of labelling;

- Increased compliance costs for businesses; and

- Industry opposition.

Given the need for a more prescriptive labelling regime in New Zealand, it is essential that an appropriate regime is designed to overcome these challenges. This will now be explored.

(a) The scope of food labelling

In order to implement mandatory, nutritionally informative labelling in New Zealand, a system of classification would have to be devised to provide a universal method of determining what defines an unhealthy product. This type of system of classification, or "the science of categorizing foods according to their nutritional composition," 160 is known as "nutrient profiling."161 Profiling usually centres round four basic features:

- "Choice of nutrients ... [for example amount of fat, sugar, or salt]

- Choice of base ...[for example per serve or per 100g]

- Choice of Model... type [for example a scoring system]

\footnotetext{
${ }^{160}$ European Food Safety Authority [EFSA] The setting of Nutrient Profiles for Foods Bearing Nutrition and Health Claims pursuant to Article 4 of the Regulation (EC) No 1924/2006: The EFSA Journal (2008) 644, 1-44 Scientific Opinion of the Panel on Dietetic Products, Nutrition and Allergies (EFSA, Parma, 2008) 1.

${ }^{161}$ United Kingdom Food Standards Agency (UK), above n 143.
} 
- Choice of numbers... [the levels of a particular nutrient that warrant a particular score]."162

A universal nutrient profiling system in New Zealand would provide the necessary information for obesity control measures. This would allow food products to be more easily and reliably identified as unhealthy or healthy, by being above or below, for example, certain levels of fat, sugar, caffeine or salt. The product could then be appropriately labelled, making its nutritional worth instantly ascertainable. This would avoid consumers having to wade through a long list of meaningless figures that they probably will not understand.

A universal nutrient profiling system in New Zealand would be invaluable, not only in the implementation of more informative easier to understand labelling, but in other obesity measures. It therefore warrants more detailed examination.

\section{(i) Nutrient profiling for New Zealand}

As outlined above, in order to implement obesity control measures in New Zealand it would clearly be necessary to be able to define those products that are considered unhealthy and warrant special treatment (be it, for example, certain labelling requirements, restrictions on marketing, or the imposition of a fat$\operatorname{tax})^{163}$

There are some food categories set out in the MOH Food and Nutrition Guidelines, ${ }^{164}$ (for example, the definition of treat food as "foods that are high in fat, salt or sugar and are best left for occasional treats"165), and the classification

162 Mike Rayner, Peter Scarborough and Lynn Stockley British Heart Foundation Health Promotion Research Group Nutrient profiles: Options for Definitions for use in Relation to Food Promotion and Children's Diets Final report (Department of Public Health, Oxford, 2004) 9.

${ }^{163}$ United Kingdom Food Standards Agency, above n 143; also see discussion in Cardin, above n 117.

164 See: Food and Nutrition Guidelines www.moh.govt.nz/foodandnutrition (accessed 13 July 2010). These are also referred to in the Advertising Standards Authority [ASA] Children's Code for Advertising Food (ASA, Wellington, 2010).

${ }_{165}$ Ministry of Health Food and Nutrition Guidelines for Healthy Children Aged 2-12 Years (Ministry of Health, Wellington 1997) 32. 
system relating to foods for schools and early learning centres in New Zealand (classifying foods as every day, sometimes, and occasionally, based on energy levels, ${ }^{166}$ levels of "saturated fat and/or added sugar and/or sodium, and which provide minimal nutritional value" ${ }^{\$ 167}$ ). There is currently no universally used standard profiling system in New Zealand. The result of this is that different manufacturers can adopt different standards to quantify their products nutritionally, resulting in confusion about what nutritional information means. ${ }^{168}$ This could also be used by food manufacturers to avoid proper disclosure. Therefore, any nutrient profiling system would be of little use unless it is universally used. To achieve this it will be necessary to legislate for it. This can be achieved by amendment to the Food Act 1981, or by creating a new Food Standard. It would be necessary to restrict mandatory nutritional profiling to products sold by fast food restaurants exceeding a specified turnover, and prepackaged foods. This is because it would impose unacceptable compliance costs to smaller businesses to mandate profiling for all food products sold in New Zealand. Charity events and school events such as sausage sizzles, would also be exempt from profiling for the same reason.

The United Kingdom Department of Health, and the Food Safety Authority, have been developing a nutrient profiling system. They have recommended a model that is currently used in the regulation of advertising. The model has a "simple scoring system where points are allocated on the basis of nutritional content in $100 \mathrm{~g}$ of a food or drink."169 A score of 4 points or more means that the "food is classified as less healthy" $" 170$ and a score of 1 point or more means that "a drink is classified as less healthy." "171 New Zealand could use a similar model, or at the very least, learn from the experiences of its use in the United Kingdom. ${ }^{172}$

\footnotetext{
${ }^{166}$ See: Ministry of Health The Food and Beverage Classification System Nutrient Framework for Schools (Ministry of Health, Wellington) 1, 2.

${ }^{167}$ Ibid.

${ }^{168}$ See discussion at United Kingdom Food Standards Agency, above n 143.

${ }^{169}$ United Kingdom Food Standards Agency (UK) www.food.gov.uk (accessed 5 November 2009).

${ }^{170}$ Ibid.

171 Ibid.

${ }^{172}$ For a detailed discussion see ibid.
} 
New Zealand legislation should therefore include provisions requiring the scoring of food products, per 100 grams in relation to content, for example for:

- levels of salt

- levels of sugar

- levels of fat

The ultimate score would represent the nutrient profile of that particular food product. Statutory provisions would also have to mandate for how the score would be displayed on the product in a way that is easy for consumers to recognise. The display of such information would be required for all prepackaged foods, and for products sold at fast food restaurants exceeding a specified turnover. A high score would be indicative of a food product that was unhealthier than one with a lower score. The former category of food products would therefore be a candidate for certain labelling requirements, and other obesity initiatives.

The definition of what constitutes a healthy food product is not the only issue that would arise in implementing a mandatory labelling system. Further policy decisions would have to be made about the scope of labelling rules. For example, whether labelling would be mandatory for all products including fast food, ready-made meals, restaurant and cafe foods, and foods sold for fundraising, such as a school sausage sizzle or kindergarten bake sale, or merely pre-packaged foods.

In New Zealand there are many small restaurants and cafes for which prescriptive mandatory menu and food labelling would present great difficulty, both logistically, and due to the additional compliance costs. This makes mandatory labelling an unrealistic prospect for all but the larger restaurants in New Zealand. This, in turn, presents a further problem in defining what constitutes a larger restaurant. This can be overcome by requiring mandatory labelling only for fast food restaurants that exceed a certain turnover, with the labelling being in the form of information to be provided on the menu rather than on each product per se. This is not a measure that would be greeted favourably by the food industry who might feel unfairly singled out by such a requirement. 
Nonetheless some fast food restaurants already display nutritional information for their products. Thus mandating for certain information to be provided could merely require reformulating this information. It would also be unrealistic for organisations running one-off fundraisers to determine the appropriate information for labelling, and such events would have to be specifically excluded. Similar exclusions have been included in legislation in Canada.

Notwithstanding that such proposed legislative provisions exclude a range of food products, the provisions would include all pre-packaged foods sold (for example, chippies, biscuits, cakes and lollies), items in fast food restaurants, and soft drinks (that are high in sugar, and often caffeine). The labelling regime would therefore target the foods that are notoriously linked with high levels of obesity.

If the appropriate nutritional labelling information is mandated, individuals may still, if given the choice, not opt for the healthier product.

(b) Not everyone makes healthy decisions

There is no guarantee that individuals will exercise informed choice sensibly (that is to chose the healthier option), even when presented with all the necessary information to allow choices, based on health, to be made. It is likely that a proportion of the New Zealand population will still chose the less healthy products because they like them. ${ }^{173}$ This may "threaten the validity of [labelling] legislation" $" 174$ and the increased compliance costs it would bring. Nonetheless, the potential benefits to that portion of the population that would make better decisions as a result of better labelling, provides a more convincing argument for a new labelling regime. Therefore this is not a potential problem that should hinder implementation.

\footnotetext{
${ }^{173}$ Hunter, above n 108, 229.

${ }^{174}$ Gitzi above n 138, 530.
} 
(c) The specific content and presentation of food labels

Having defined the scope of labelling requirements, further problems may be encountered in deciding what information should be included in labels, and how it is presented. Issues include whether the information should be in the form of a "front-of-pack [or] back-of-pack" $" 175$ label, and deciding on a format that is easily understood by the consumer. This should also take into account the volume of information presented to avoid information overload that might make consumers merely switch off, or be used to deliberately confuse. The use of an instantly recognisable and prominent indication of the nutrient profile would also avoid the need for a large volume of information

One example of a front of pack label used around the world is the Heart Foundation Symbol, for which the Heart Foundation charges. This symbol provides an "immediate, and, easy to understand, indication of the health rating of a particular product." $" 176$ Nonetheless, some health experts have criticised the Heart Foundation symbol for being misleading, and one that many food manufacturers cannot afford to use. ${ }^{177}$

Criticism has also been levelled at a programme called Smart Choices in the United States that uses a similar easy to recognise logo. It has been claimed that "some products with [scheme's logo] ... are almost 50\% sugar" "nutritionists [claim] its ratings ... give foods undeserved nutritional standing."179 This highlights the potential pitfalls of an independent voluntary system not regulated by statute. ${ }^{180}$

\footnotetext{
${ }^{175}$ Pollard, above n 120, 1.

176 Ibid.

${ }^{177}$ Claire Weaver "McFatty Meal - Doctors Urge Consumers not to Trust the Heart Foundation's Tick of Approval” (11 February 2007) Sunday Telegraph Australia 79. See also useful discussion in Pollard, above n 120.

${ }^{178}$ Andrew Zajac "FDA Clamps Down on Food Labelling" (21 October 2009) Los Angeles Times Los Angeles 2.

179 Ibid.

${ }^{180}$ For more detail see Smart Choices Program www.smartchoicesprogram.com (accessed 28 October 2009).
} 
In its submissions on the review of Food Labelling and Policy the New Zealand Government indicated that it "does not support mandating front-of-pack labelling" 181 There is however, merit in the inclusion of an easily recognisable health symbol that provides the consumer with an instant indication of the place of a particular food product in the diet. This avoids consumers having to wade through volumes of figures. Additionally, the use of such a symbol has the advantage of catering to different levels of literacy. ${ }^{182}$ The use of a health symbol of this type on the front-of-pack should be provided for in the legislative provisions. Such provisions would permit manufacturers, retailers and fast food restaurants to use the symbol when a nutrient profile score that warrants it.

Therefore, it is important that a labelling system in New Zealand is mandatory, standardised and easily recognisable. This will provide both clarity for consumers, and avoid them being misled by voluntary systems that may not be bona fide, or are designed purely to serve the interests of the food industry rather than the consumer.

International compliance and standardisation

Problems could be encountered internationally if too prescriptive a labelling system were to be mandated in New Zealand requiring information not required overseas. Such differing jurisdictional labelling requirements could have ramifications in terms of the ultimate cost to the consumer. For example, one Canadian newspaper reported that a manufacturer of jelly beans was required to "to maintain two separate inventories [and] ... pay for two separate sets of packaging"" due to a "problem [with] ... regulations governing nutritional labelling" 184 in different countries. Situations such as this could lead to excessive compliance costs that would be passed onto the consumer. ${ }^{185}$

\footnotetext{
${ }^{181}$ New Zealand Government New Zealand Submission on Food Labelling and Policy Review (New Zealand Government, Wellington, 2010).

${ }^{182}$ See discussion in: Review of Food Labelling Law and Policy A Summary of the Submissions to the initial Public Consultation (Review of Food Labelling Law and Policy, Australia, 2010) 6.

${ }^{183}$ Elizabeth Thompson "That which we Sell as a Jelly Bean by the Same Label would Taste as Sweet..." (22 August 2007) The Gazette Montreal A12.

${ }^{184}$ Ibid.

${ }^{185}$ For useful commentary see Thompson, above n 183
} 
A statutory labelling regime in New Zealand requiring the prominent display of a nutrient profile, and (if appropriate) a health symbol, can however, cut down on the amount of information to be provided. Therefore compliance costs need not be such an issue.

(e) Increased compliance costs for businesses

Devising an appropriate labelling system without imposing significant compliance costs to avoid "the cost of testing and labelling ... $\operatorname{driv}[\mathrm{ing}] \ldots$ products of the shelves, ${ }^{\prime 186}$ could prove a significant obstacle. If certain food retailers and manufacturers were asked to provide further nutritional content information, this might involve incurring laboratory costs to carry out the appropriate analysis. ${ }^{187}$ One commentator has estimated that, in the United States, the analysis costs for "one menu item could cost a restaurant US\$500 ... and a 100-menu item could cost as much as US\$22,000." "188 There would also be a cost in "creating new internal systems and procedures [within the company] to ensure compliance with ... [any new] regulations."189 Therefore unless care is taken to draft labelling requirements with the appropriate exclusions, a mandated system could run the risk of making food products more expensive by passing compliance costs on to the consumer. If labelling is intended to inform consumers that a particular product is good for them, it would be a self-defeating exercise if the result was that increased compliance costs meant the consumer could not afford to buy it.

For many products however, the additional information that would be required by the new legislative provisions is already available to manufacturers and would merely require reformulating into a more accessible and understandable format; namely the inclusion of the nutrient profile, and where appropriate, the health logo. Additionally the industry could be given a period of time before the labelling became compulsory that would mean the appropriate

${ }^{186}$ Bernard Chan "Food Labelling Boils down to Public Health" (9 May 2008) South China Morning Post China 12.

${ }^{187}$ Gitzi, above n 138, 526.

${ }^{188}$ Ibid.

${ }^{189}$ Ibid. 
changes could be made over time, and that labelling on existing products in stock would not require change. Therefore, compliance costs may not be as high as some manufacturers would have the public believe.

Businesses in New Zealand would face similar compliance costs, albeit on a smaller scale, and given the large numbers of small businesses this is a strong argument against more prescriptive labelling that includes restaurant or cafe foods. Therefore, at this time a prescriptive labelling system should exclude non chain restaurants and cafes. This would still include the fast food restaurants that are more notoriously associated with high obesity levels.

(f) Industry opposition, lobbying and public opinion

The food industry is generally opposed to any policy change that increases regulation and costs of production. It is powerful and influential. Its "interests [are] not necessarily served by strategies to reduce obesity."190 Such opposition and any lobbying that might accompany it would be a significant obstacle for any government intending to impose a stricter labelling regime. It is likely that any more prescriptive regime would be opposed by the food industry and it would therefore be necessary for a policy decision to be made to proceed in the face of opposition by the industry. The food industry is however, already subject to some a labelling requirements and the legislative provisions suggested represent a reformulation of the information currently required.

A more prescriptive labelling regime in New Zealand is required, and there are many arguments in its favour. Therefore, it is essential that a labelling regime is designed to overcome the challenges and difficulties as set out above. Fundamentally, the public deserves to be fully informed about the products it is consuming. This includes easy to read and understand nutritional information that will assist in making sensible eating decisions. ${ }^{191}$

\footnotetext{
${ }^{190}$ Reynolds, above n 7, 1.

191 Alcohol Health Watch Briefing Paper: Health and Safety Advisory Statements (Warning Labels) in New Zealand (Alcohol Health Watch, Auckland, 2003).
} 
More comprehensive and understandable nutritional information is not the only labelling change with the potential to assist consumers in making health based decisions about what they eat. An individual's eating decisions may be influenced by the use of health warnings about the risks of over-consumption.

\section{$2 \quad$ Health warnings}

Given the health dangers associated with obesity, and the threat that this poses to the public, it could be appropriate to mandate health warnings on certain food products. The use of health warnings could act as a deterrent to individuals to over-consume.

\section{(a) Food products and health warnings}

The current health warning requirements of the Smoke-free Environments Act 1990 provide precedents in New Zealand for the use health warnings on a product considered detrimental to health. Section 32 of this Act imposes the requirement that tobacco packages, inter alia, display a "message relating to the effects of its use on health." 192 The Act also contains tobacco marketing restrictions. ${ }^{193}$

As already discussed, it is appropriate to draw an analogy between the use of tobacco and consumption of food products leading to obesity. The differences between the consumption of tobacco and food products are particularly relevant in the context of health warnings; not least because tobacco presents a discrete range of products that are easy to identify. This is not the case with food products. Furthermore, humans must eat to survive, and any food product eaten in excess has the potential to lead to obesity. It would be unrealistic and self-defeating to place a health warning on all food products. ${ }^{194}$

Therefore, a major obstacle for any food health warning legislation would be in determining what foods should display them. This is a problem that would

\footnotetext{
${ }^{192}$ Smoke-free Environments Act 1990, s 32(1)(a).

${ }^{193}$ See ibid part 2.

${ }^{194}$ See discussion in Brownell and Warner, above n 61, 263.
} 
be overcome with a universal nutrient profiling system, with those food products with a specified profile requiring a warning. This is a further illustration of the need for a nutrient profiling system in New Zealand.

A strong candidate for the use of a health warning in New Zealand is soft drinks. These are of little nutritional value, high in sugar and frequently have added caffeine. It is also worth noting that there already exists a voluntary agreement between the New Zealand Government and Coca-Cola Amatil NZ (CANZ), (the Voluntary Schools Beverage Statement, signed in 2006) in which CANZ agreed to stop selling certain soft drinks in schools in New Zealand. In December 2009 CANZ indicated that it "no longer suppl[ied] any schools with full sugar or carbonated energy drinks." ${ }^{\prime 95}$ This could amount to a form of implicit acknowledgment of the role that such products play in childhood obesity (and obesity generally), and, as such, it may be easier to persuade the food industry that a warning on soft drinks is necessary.

(i) Soft drinks and health warnings

The arguments for including a health warning on certain categories of soft drinks are compelling. Many studies link obesity with soft drink consumption, ${ }^{196}$ and according to one commentator, "sugared beverages ... now account for around $10 \%$ of calories consumed by children and adolescents." 197 One study has concluded that "the odds ratio of becoming obese among children increased 1.6 times for each additional can or glass of sugar-sweetened drink that they consumed every day."198 Other studies have shown that increased soft drink consumption is associated with reduced consumption of "fruits and vegetables

195 See media coverage Pete Hodgeson "Full Sugar Fizzy Drinks out of Schools by 2009" (11 December 2006) www.beehive.co.nz (accessed 15 January 2009); Coca Cola Amatil "World's first agreement on soft drinks in schools" (11 December 2006) Press Release; Coca Cola Amatil (NZ) Limited and Frucor Beverages Group Limited "Companies Remove Full Sugar Drinks from Schools" (10 December 2009) Infonews.co.nz www.infonews.co.nz/news (accessed 9 July 2010).

${ }^{196}$ Details in Jacobson, above n 83.

197 Centre for Science in the Public Interest Taxing Sugared Beverages would help Trim State Budget Deficits, Consumers' Bulging Waistlines, and Health Care Costs (Center for Science in the Public Interest, United States, 2009) 2.

${ }^{198}$ David S Ludwig, Karen E Peterson and Steven L Gortmaker "Relation between Consumption of Sugar Sweetened Drinks and Childhood Obesity: A Prospective, Observational Analysis" (2001) 357.9255 Lancet 505, 507. 
and calcium rich foods ... osteoporosis (due to lower calcium intakes), tooth decay and erosion, and possibly kidney stones."199 Furthermore, due to the addition of caffeine in many soft drinks, they can be addictive. Because of this, the consumption of soft drinks possibly presents the strongest analogy with the use of tobacco. It is a food product that, in certain circumstances, is already required to carry a form of health warning in New Zealand. Under the New Zealand Food (Supplemented Food) Standard, and the Australia New Zealand Food Standard Rule 2.6.4., some soft drinks are already required to carry an advisory statement that the drink contains caffeine, the levels of it, and that it is not "recommended for children, pregnant or lactating women, or individuals sensitive to caffeine."200 These warning statements do not relate to the risks of addiction or overconsumption.

Given evidence of increasing soft drink consumption, the detrimental health ramifications, and the addictive nature of caffeine, the labelling of certain soft drinks should be extended to include an appropriate health warning or statement giving the health effects of over consumption, and both the addictive nature of caffeine, and its possible health consequences.

(ii) Health warnings and non food products

Since food is not the only factor contributing to obesity there is an argument that health warnings should not only be restricted to food products, but should also include other products encouraging a sedentary lifestyle, such as televisions and game consoles. The reality is, however, that it would be hard to quantify the negative health effects for such products and there is no reason why these things should be distinguished from playing a board game, chess, or reading a book. Therefore, it would be unrealistic to impose a system in which every product that encourages sedentary behaviour required a health warning. Nonetheless, it might be appropriate to encourage industry to voluntarily use

\footnotetext{
199 Jacobson, above n 83, 13-19.

200 New Zealand Food (Supplemented Food) Standard; and the Australia New Zealand Food Standard Rule 2.6.4.
} 
health warnings on products more notoriously associated with a sedentary lifestyle, such as video, and computer gaming consoles, and televisions.

(b) Why not use health warnings on food products?

(i) Past attempts to impose health warnings on products other than tobacco in New Zealand

It is worth briefly examining the failed attempts, to date, to impose health warnings on alcohol in New Zealand. This provides an indication of the level of resistance that might be encountered should an attempt be made to mandate health warnings on certain food products.

Evidence of the addictive nature and detrimental effects of alcohol is well documented. As a "mind altering depressant drug" ${ }^{201}$ it is clearly a product to be consumed with caution "with no level of consumption ... considered safe for all people at all times."202 Additionally, its consumption below a certain age is controlled. Surprisingly however, publicly supported attempts to legislate for mandatory health warnings on alcohol in New Zealand have failed. ${ }^{203}$

In an international context, the United States legislated for mandatory health warnings on alcohol in 1989; Canada's parliament has voted for mandatory wording on alcohol, but similar health warning legislation in the United Kingdom was rejected by the House of Lords in 1991 without public debate. ${ }^{204}$

Given the failed attempts to include a mandatory warning on a product with such easily quantifiable dangers, it is perhaps too optimistic to hope that the labelling of food products (save perhaps for caffeinated beverages as outlined above) would not suffer the same fate. Additionally, notwithstanding any public

\footnotetext{
${ }^{201}$ Alcohol Health Watch, above n 191.

${ }^{202}$ Ibid, 2.

${ }^{203}$ For a good commentary of the issue of health warnings on alcohol see Alcohol Health Watch, above $\mathrm{n} 191$.

204 Ibid.
} 
or political opposition to health warnings, there may be other unforeseen effects that may undermine their use.

(ii) Would health warnings discourage individuals; warning fatigue? ${ }^{205}$

According to a study in the United Kingdom, ${ }^{206}$ health warnings may not have the intended effect, or may be of no use at all with the "shock tactics [used in] health promotions backfiring [because of] hidden psychological effects."207 Therefore, the implementation and use of health warnings should be approached with care. The possibility of such effects is an important factor in any policy decisions regarding health warnings, to avoid the risk that they become so common-place that the general public becomes immune to them. The study “identified three types of adverse reaction to the high 'doses' of health-scares and warnings." 208 These adverse effects were: ${ }^{209}$

- Warning fatigue ... [where] people became desensitised ... and eventually [paid] no attention at all ...

- Riskfactorphobia [where some people] ... develop hyper-sensitivity to scares and warnings becoming increasingly fearful and anxious about the hazards and 'risk factors' in their diet, lifestyle and environment.

- Forbidden-fruit effect: ... increased desire for the 'forbidden' substance or activity. In many cases, the constant stream of warnings, scares and bans has [led] to deliberate defiance.

The forbidden-fruit effect is particularly pertinent for teenagers, and could elevate foods products with health warnings to the category of defy and must have, thus making such products more, not less, attractive. The effects reported in this study should therefore be taken into account, not only when considering health warnings, but for labelling generally, so that the general public does not simply

\footnotetext{
205 The term warning fatigue is coined in the following study: Social Issues Research Centre, Oxford "Shock-tactics in Health-promotion Campaigns have Backfired: New Analysis from the Social Issues Research Centre in Oxford indicates that Health Warnings may have Hidden Psychological Side Effects" (12 May 1999) Press Release.

${ }^{206}$ Ibid.

207 Ibid.

208 Ibid.

${ }^{209}$ Ibid.
} 
switch off when presented with excess labelling. ${ }^{210}$ It is therefore be important to ensure that labelling legislation requires information that is useful and easily accessible, but not excessive (the display of a nutrient profile coupled with the addition, or lack of it, of an accepted health logo is a good example of such information).

(iii) Should a new labelling regime mandate for health warnings on certain food products?

There are compelling reasons for a mandatory labelling regime in New Zealand to include more easily understandable and accessible nutritional information. The reasons for the inclusion of a health warning in revised labelling legislation are less compelling. Therefore, the use of health warnings generally on food products is not something that should be implemented currently in New Zealand. The use of health warnings on caffeinated soft drinks is however, a more justifiable measure and one in which can and should be achieved by amendment to the current food standard requirements to extend the warning to include the risks of addiction and over-consumption.

Thus, food labelling in New Zealand currently provides minimal assistance to individuals who wish to make decisions based on health (including weight gain). More nutritionally informative and accessible labelling is therefore required. Such labelling should include the use of an instantly recognisable symbol for those foods with the requisite health profile. The general use of health warnings on foods more notoriously associated with obesity is not appropriate at this time. It will also be necessary to implement a universal nutrient profiling system allowing food products to be categorised according to nutritional worth. This approach to obesity control has the advantage of promoting personal autonomy and therefore changes to the labelling regime should not be opposed on paternalistic grounds.

${ }^{210}$ Ibid. 
Mandating the labelling of the food products is not the only way of regulating the food industry that could assist in the control of obesity. The marketing of food products is also a prime target for better regulation in New Zealand. The link between the way that food products are marketed and the current obesity epidemic will now be explored, followed by an examination of the current regulation of marketing of food products in New Zealand, and the need for stricter control. 
VI THE PROMOTION OF A HEALTHY ENVIRONMENT THROUGH REGULATION OF THE FOOD INDUSTRY - CONTROLLING THE MARKETING OF CERTAIN FOOD PRODUCTS

A Why have restrictions on the marketing of certain food products in New Zealand?

Manufacturers are not free to market their products however they choose, and are subject to the same contract and consumer laws applicable to any product. Nonetheless it is possible for manufacturers to stay within the letter of the law, while adopting practices that are considered irresponsible or unethical, in order to maximise sales. This is particularly pertinent when it comes to the marketing of food products that are not considered healthy, as it risks the public being encouraged to consume such products without understanding the possible dangers involved. Soft drink manufacturers, for example, have been known to market their products in ways that "are among the most aggressive ... in the world us[ing] a myriad of techniques, including ones that some consider unethical." ${ }^{\text {"211 }}$ Attitudes to marketing have however, changed. Food companies have been forced, through regulation and the threat of litigation, to adopt a more responsible approach to the marketing of their products; thereby being forced to provide better quality information about their products. ${ }^{212}$

Therefore, additional restrictions specifically applicable to food marketing have been introduced. In some countries, for example Sweden and Canada, these are supported by legislation and in others, including New Zealand they are not, and the additional restrictions take the form of self-regulation by the industry. Such measures have been taken, inter alia, to attempt to ensure that consumers are not unethically manipulated, or misled into buying foods that are not healthy. Marketing practises that might once have been considered acceptable now fall foul of such restrictions; for example, in the past, soft drink promotional material

\footnotetext{
${ }^{211}$ Jacobson, above n 83, 19.

${ }^{212}$ Frazier, above n 76, 291.
} 
in the United States has made claims that would certainly now be considered unacceptable. $^{213}$

\begin{abstract}
As refreshing sources of needed liquids and energy, soft drinks represent a positive addition to a well-balanced diet....These same three sugars also occur naturally, for example, in fruits....In your body it makes no difference whether the sugar is from a soft drink or a peach.
\end{abstract}

The change in approach is reflected in how the issue of hydration is currently stated on the American Beverage Association website: ${ }^{214}$

\begin{abstract}
We all need to ensure our bodies are properly hydrated to stay in good health ... The beverage industry provides multiple beverage options to meet our bodies' hydration needs, such as bottled water, 100 percent juice, sports drinks and ready-to-drink teas, among others.
\end{abstract}

The more recent posting does not make the same fallacious statements comparing soft drinks nutritionally with fruit and has had to change its message (and its products) to avoid making such statements.

\title{
B The influence of food product marketing and obesity
}

There are several studies linking the marketing of food products with obesity. WHO has even stated that "the heavy marketing of energy dense foods and fast food outlets is a probable cause of obesity." ${ }^{215}$ Furthermore, when it comes to the influence of marketing on the consumption of food products, much evidence has shown that children in particular are vulnerable to marketing techniques. For example, a New Zealand study conducted in 2006 by the Scientific Committee of the Agencies for Nutrition Action ${ }^{216}$ is believed by some commentators to provide sufficient evidence to justify measures by the Government to control the advertising of certain foods and beverages to

\footnotetext{
213 Jacobson, above n 83, 8; it also contains a good general discussion of marketing practices.

${ }^{214}$ American Beverage Association www.ameribev.org (accessed 4 November 2009).

${ }^{215}$ WHO Diet, Nutrition and the Prevention of Chronic Diseases: WHO Technical Report Series 916 (WHO, Geneva, 2003); for a good discussion of the link see also: Scientific Committee of the Agencies for Nutrition Action, above n 96.

${ }^{216}$ Scientific Committee of the Agencies for Nutrition Action, above $n 96$.
} 
children. ${ }^{217}$ The study claimed that, inter alia, there was a "likelihood that the increase in obesity was due to children being bombarded by advertising of high fat, high sugar foods and drinks,", 218 and that "a ban on the advertising of high fat, high sugar foods and drinks during children's television programmes [was] a key strategy to reducing childhood obesity.",219

There can be no doubt that the advertising of foods is big business. In New Zealand in 2005 fast food outlets spent over \$67 million on advertising, ${ }^{220}$ and in the United States "between 1986 and 1997 the top four soft drink companies spent US\$6.8 billion on advertising."221 Such figures are an indication of the aggressive nature of the advertising of some food products. It is also self evident that food companies would not continue to spend money on such extensive marketing if it was not going to affect consumer behaviour. ${ }^{222}$

Thus, given the link between marketing of food products and obesity levels, and that the public continues to over consume products detrimental to health, it is clearly time to review the regulation of food marketing in New Zealand. Studies showing a link between certain food products and addiction (not disputed for caffeinated food products; albeit a small proportion) reinforce the need for the marketing of such products to be restricted to some extent. The extent to which current regulation of marketing in New Zealand is geared to controlling the marketing of unhealthy food products will now be examined.

\section{Current regulation of food product marketing in New Zealand}

There is currently no legislation with the sole purpose of controlling the nature of the marketing of foods and non-alcoholic beverages in New Zealand.

\footnotetext{
${ }^{217}$ See: Public Health Association of New Zealand "Call for Ban on Fast Food Advertising” (6 July 2006) Press Release.

218 Ibid.

219 Ibid.

${ }^{220}$ OAC, above n 9, 7.

${ }^{221}$ Jacobson, above n 83, 19.

222 Sonia Livingstone UK Department of Media and Communications A Commentary on the Research Evidence regarding the Effects of Food Promotion on Children" (2004, London, Department of Media and Communications) 29.
} 
The Fair Trading Act 1986 does however contain provisions that prohibit misleading and deceptive conduct and representations in relation to the sale of goods (section 13 specifically prohibits the making of false or misleading representations in relation to the supply of goods). The marketing of food products is also subject to other consumer legislation; for example, the implied guarantees in respect of the supply of goods in the Consumer Guarantees Act $1993^{223}$ (inter alia: that goods be of acceptable quality; ${ }^{224}$ are fit for the purpose for which they are sold; ${ }^{225}$ and they comply with their description ${ }^{226}$ ). In addition, there is other legislation that can restrict advertising including, the Defamation Act 1992, the Sale of Liquor Act 1989, the Securities Act 1978, and the Smoke Free Environments Act 1990. ${ }^{227}$ The most significant of these is the Smoke Free Environments Act, which actually bans the advertising of a particular type of product; namely tobacco. ${ }^{228}$ These limited statutory provisions prevent misleading and deceptive descriptions, but have not been enacted to regulate marketing in the context of the obesity epidemic.

In addition to the limited statutory provisions outlined above, the food industry in New Zealand is regulated by non-statutory restrictions that are managed by the industry. This regulatory system is administered by the Advertising Standards Authority (ASA), with Codes of Practice "providing the rules by which all advertisements in all media should comply." 229 The system is reliant on members of the public making complaints about a breach of the Codes to the Advertising Standards Complaints Board, with a right of appeal to the Advertising Standards Complaints Appeal Board. When a complaint is upheld, a request is made to

\footnotetext{
${ }^{223}$ Consumer Guarantees Act 1993, part 1.

${ }^{224}$ Ibid, s 6-7.

${ }^{225}$ Ibid, $\mathrm{s} 8$.

${ }^{226}$ Ibid, s 9.

${ }^{227}$ Advertising Standards Authority [ASA] Bugger, it's okay - the Case for Self-regulation (ASA,Wellington) available at www.ASA.co.nz (accessed 6 July 2010) 8.

${ }^{228}$ Smoke Free Environments Act 1990, s 22.

${ }^{229}$ ASA www.asa.co.nz (accessed 16 January 2006); The Code for Advertising to Children and Code for Advertising of Food were recently reviewed (final recommendations for the review issued in March 2010 in ASA Final Report on the Review of the Code for Advertising to Children and the Code for Advertising of Food (ASA, Wellington, 2010).
} 
withdraw that particular advert, and, according to the ASA, such requests are always complied with. ${ }^{230}$

There are two Advertising Codes of Practice relevant to the advertising of foods and beverages; namely the Code for Advertising of Food, and Children's Code for Advertising Food. ${ }^{231}$

The stated purpose of the Code for Advertising of Food is to "ensure that advertising of food will be conducted in a manner that is socially responsible and does not mislead or deceive the consumer." ${ }^{232}$ Principle one of the Code states specifically that "advertisements should be prepared with and observe a high standard of social responsibility. ${ }^{233}$

The Children's Code for Advertising Food has specific guidelines applicable to food product advertising to children that, inter alia, state: ${ }^{234}$

(a) Advertisements should not undermine the role of parents in educating children to have a balanced diet and be healthy individuals.

(b) Children should not be urged in advertisements to ask their parents, guardians or caregivers to buy particular products for them.

(c) Advertisements for treat food, snacks or fast food should not encourage children to consume them in excess.

(d) Advertisements for treat food, snacks or fast food should not encourage children to consume them in substitution for a main meal on a regular basis, nor should they undermine the Food and Nutrition Guidelines for Healthy Children.

\footnotetext{
${ }^{230}$ ASA, ibid.

${ }^{231}$ ASA Children's Code for Advertising Food (ASA, Wellington 2010); and; ASA Code for Advertising of Food (ASA, Wellington 2010). There is also an additional code for advertising to children: ASA Code for Advertising to Children (ASA, Wellington, 2010).

${ }^{232}$ ASA Code for Advertising of Food, ibid.

${ }^{233}$ Ibid, Principle 1.

${ }^{234}$ For full text see ASA Children's Code for Advertising Food, above n 231.
} 
Principle 2 of the Code states: ${ }^{235}$

Advertisements should not by implication, omission, ambiguity or exaggerated claim mislead or deceive or be likely to mislead or deceive children, abuse the trust of or exploit their lack of knowledge or without reason play on fear.

One recent example of the codes being used successfully was the 2008 ASA decision regarding the advertising of Bluebird Chips. The complaint was made by $\mathrm{MOH}$ and upheld by the ASA. ${ }^{236}$ The advertising campaign encouraged the collection of 50 cards with well known sportsmen on them. The ASA agreed that the campaign was in breach of the code as it encouraged over-consumption of the chips and associated them with celebrities.

There are also Industry Standards; for example, those prepared by the New Zealand Television Broadcasters Council. ${ }^{237}$ This is also a self-regulatory body, and currently has, inter alia, a policy of restricted advertising to children including:

- no advertising during pre-school television programmes;

- limited advertising during school-age children's programmes;

- separation of programmes and advertisements;

- limits on repeating advertisements; and

- $\quad$ limits on sponsorship ${ }^{238}$

In addition, any food advertisement must be approved before broadcast is permitted. $^{239}$ Industry initiatives to stop advertising during certain hours are a step in the right direction, but studies have shown that children watch large amounts of television outside these times. ${ }^{240}$ Therefore, such controls will be, to a large extent, redundant unless they target food advertising that is aimed at

\footnotetext{
${ }^{235}$ Ibid, principle 2.

${ }^{236}$ ASA Decision 10 June 2008, Complaint 08/241.

${ }^{237}$ New Zealand Broadcasters Council www.nzbtc.co.nz (accessed 16 January 2009) [NZBC]; New Zealand Broadcasters Council Advertising on Television: Getting it right for Children (New Zealand Broadcasters Council, Auckland, 2008) (available at www.nztbc.co.nz (accessed 5 June 2010)).

${ }^{238}$ Ibid, 2.

${ }^{239}$ Ibid, 4-8.

${ }^{240}$ See for example: Scientific Committee of the Agencies for Nutrition Action, above n 96.
} 
children (as has been done in Sweden), or take into account real viewing times. Children's real viewing patterns are already reflected in rules and legislation overseas, by anticipating that children watch television outside traditional times. $^{241}$

Thus the restrictions on food product advertising in New Zealand are not mandatory. There have been many studies linking obesity with the marketing of foods to children particularly. ${ }^{242}$ These are reflected in international action, which shows a trend towards stricter controls. ${ }^{243}$ In this context it is worth noting that one study even went so far as to say that "New Zealand is one of the few developed countries in the world that does not protect the wellbeing of children from excessive food marketing." 244 Therefore, food product marketing to children in New Zealand requires stricter and statutory regulation rather than relying on self-regulation by the industry.

\section{$1 \quad$ The limits of self-regulation}

Current marketing regulation in New Zealand is achieved solely through industry self-regulation and voluntary industry compliance, via ASA codes and individual industry standards. The rules are not mandated by statute or regulated by an independent body therefore the system is open to abuse. It is worth noting that one study published in 2005 showed internationally New Zealand is one of the few countries with no statutory guidelines relating to advertising to children, ${ }^{245}$ and with a solely self-regulatory approach to the marketing of foods and beverages. ${ }^{246}$ Furthermore, bodies that self-regulate have an obvious conflict of interest when it comes to the level of regulation they propose. Anti-obesity

\footnotetext{
${ }^{241}$ See Part V D 4 Regulation of the marketing of food products overseas.

${ }^{242}$ See for example: Scientific Committee of the Agencies for Nutrition Action, above n 96; and WHO United Marketing of Food and Non-Alcoholic Beverages to Children report of a WHO Forum and Technical Meeting (WHO, Oslo, 2006) 17

${ }^{243}$ See Part V D 4 Regulation of the marketing of food products overseas.

${ }^{244}$ Scientific Committee of the Agencies for Nutrition Action, above n 96, 23.

245 Martin Caraher, Jane Landon and Kath Dalmeny "Television Advertising and Children: Lessons from Policy Development” (2005) Public Health Nutrition 9(5) 596, 599.

${ }^{246}$ Shaw, above n 98, 80 .
} 
advocates who do not support the current self-regulatory system consider that it is: ${ }^{247}$

\begin{abstract}
fundamentally flawed [because a] codes and complaints based selfregulatory system is not designed to be a public health policy tool; it is designed to identify advertising 'outliers' who breach acceptable standards, rather than reduce large volumes of effective advertising.
\end{abstract}

For example, despite the fact that the codes were used successfully in the case of the Bluebird Chips campaign outlined above, the system was reliant on a member of the public (in this instance the $\mathrm{MOH}$ ) to make the complaint and take action, rather than providing mandatory rules to prevent industry behaviour of this nature in the first place.

Some steps have been taken to limit food advertising in New Zealand, but there are many advocates for the further restrictions. ${ }^{248}$ In this context it is interesting to note that in New Zealand in 2005, "advertising on chocolate, confectionary and carbonated drinks $(\$ 57,289,000)$ was over nine times the amount spent on advertising vegetables and fruit $(\$ 6,215,000) .{ }^{249}$ Given that marketing is believed to be a major contributory factor in obesity, especially in relation to children, it is surprising that New Zealand relies wholly on a selfregulatory system. It is time for this to be remedied.

With New Zealand's system of self-regulation there is always a risk that marketers will take advantage of ambiguities in codes and guidelines, and it has been argued that they are so general that they allow for "technical interpretation and nitpicking exclusions." ${ }^{250}$ This has possibly been anticipated by the inclusion of following words in the ASA Children's Code for Advertising Food, and Code for Advertising of Food: ${ }^{251}$

\footnotetext{
${ }^{247}$ Ibid, 80; see also OAC, above $\mathrm{n} 9$.

${ }^{248}$ See: Scientific Committee of the Agencies for Nutrition Action, above $n 96$.

${ }^{249}$ OAC, above n 9, 4.

${ }^{250}$ Reynolds, above n 7, 164.

${ }^{251}$ Children's Code for Advertising Food, above n 231; Code for Advertising of Food, above n 231.
} 
In interpreting the code emphasis will be placed on compliance with both the principles and the spirit and intention of the code. The guidelines are examples, by no means exhaustive of how the principles are to be interpreted and applied. Upon considering a complaint, the ASCB is vested with discretion to ensure a commonsense outcome.

Additionally, the United Nations Convention on the Rights of the Child (UNCROC), an internationally legally binding document protecting the rights of children ratified by New Zealand in $1993,{ }^{252}$ requires measures to protect children "from information and material injurious to his or her well-being." 253 New Zealand's most recent report for the United Nations Committee on the rights of the child, submitted in November $2008,{ }^{254}$ dealt with this issue by setting out, inter alia, details of the ASA Code of Advertising to Children, and the findings of Health Select Committee's report into Obesity and Type 2 Diabetes. The latter included setting "targets for reducing advertising, promotion of unhealthy foods to children and young people and the need to monitor the ... self regulation model for the advertising industry." 255 Arguably these measures do not go far enough to comply with UNCROC. It is interesting to note however that the ASA code of advertising of food for children cites UNCROC as a supporting argument for allowing children access to advertisements as follows: "Article 13 recognises the child's right to freedom of expression. This right shall include the freedom to seek, receive and impart information and ideas of all kinds." 256

A further argument in support of the need for statutory regulation of food product marketing in New Zealand is the effect that it has on individual autonomy.

\footnotetext{
${ }^{252}$ United Nations Convention on the rights of the child UNGA Doc A/RES/44/25 (12 December 1989); UNICEF www.unicef.org (accessed 18 November 2009).

${ }^{253}$ Ibid, Article 17.

254 Ministry of Youth Development Third and fourth periodic report for the United Nations Committee on the Rights of the Child (Ministry of Youth, Wellington, 2008); Ministry of Youth Development www.myd.govt.nz (accessed 18 November 2009).

255 Ibid, 38.

${ }^{256}$ Ibid.
} 
Aggressive marketing removes individuals' autonomy as they are not being provided with all the information that allows an informed choice to be made. The food industry regularly cites anti-paternalistic arguments in its opposition to the prospect of further regulation, but in adopting manipulative marketing techniques it is not promoting the free choice it argues for. ${ }^{257}$ One major study on the link between obesity and television viewing concluded that the "removal of advertisements would provide a clean slate for consumers to truly make their own choices rather than being manipulated by advertising." ${ }^{258}$ This is a convincing argument for the implementation of statutory marketing regulation.

Thus, with the current marketing regulation regime in New Zealand, levels of obesity remain high. Given such continuing levels of obesity, the available evidence of the effect of marketing on purchasing patterns and the effect of aggressive marketing on individual autonomy, stricter statutory regulation of marketing is necessary in New Zealand. It is not appropriate to leave the regulation of marketing in the hands of those who have a vested interest in it continuing. Furthermore, since the "protection of [the public's] ... health and safety is a government duty," 259 statutory regulation "can be argued from a public health perspective.”260 Therefore, it is arguably the New Zealand Government's duty to protect the population by regulating the marketing of food products that contribute to obesity. ${ }^{261}$ Before discussing the specifics of the required changes to marketing regulation required in New Zealand, marketing controls that have been implemented in some overseas jurisdictions will be examined briefly.

\footnotetext{
${ }^{257}$ Quigley, and Watts, above n 107.

${ }^{258}$ Scientific Committee of the Agencies for Nutrition Action, above n 96, 23.

${ }^{259}$ OAC, above n 9, 20.

${ }^{260}$ Ibid.

${ }^{261}$ Ibid.
} 


\section{Regulation of the marketing of food products overseas}

Internationally restrictions on the marketing of foods and beverages differ from country to country. For the most part restrictions centre on advertising to children. In Sweden there is a total ban on all advertising to children, whilst in other countries the regulation of advertising to children is merely restricted, with a mixture of statutory and self regulation by the industry. ${ }^{262}$

\section{$1 \quad$ Sweden and the ban of advertising to children}

Sweden has, since 1991, ${ }^{263}$ banned "all advertising 'aimed' at children under the age of 12 years [and] advertisements before or after children's programmes." 264 Sweden's justification for this action was "the ... fair play and protection of children from undue influence." 265 This change was made "not to reduce obesity or to improve health per se but as a matter of human rights.... [because] children under 12 years of age cannot clearly distinguish advertising messages from programme content.",266

Opponents of the ban in Sweden claim that it has been has had no real effect on childhood obesity but, because there are no obesity figures for Sweden this criticism is flawed. Furthermore, Swedish marketing is not the only factor contributing to obesity because, despite there being a complete ban, this is not in reality the case. This is because Swedish children are exposed to much foreign broadcasting material not subject to the ban. Additionally, the efficacy of the ban has been weakened because of challenges about its scope, in the Courts. Arguments have centred on the true meaning of aimed at children, with advertisers claiming that advertisements are not subject to the ban because they

\footnotetext{
${ }^{262}$ Caraher, Landon, and Dalmeny, above n 245, 298.

263 Neil Browne and Lauren Frances "Advertising to Children and the Commercial Speech Doctrine: Political and Constitutional Limitations" (2009) 58 Drake L Rev 67.

${ }^{264}$ Caraher, Landon and Dalmeny, above n 245, 600.

265 Ibid.

${ }^{266}$ Ibid.
} 
are intended for an adult audience, notwithstanding that they will be viewed by children. $^{267}$

It is difficult to assess the extent to which the ban in Sweden has helped to reduce levels of obesity in children, but the experience does illustrate that marketing restrictions, when imposed, are likely to be challenged by the food industry. It also demonstrates the need for an international approach to marketing restrictions to ensure that children's exposure is really controlled.

\section{$2 \quad$ Canada and the total ban of advertising to children}

The Consumer Protection $\mathrm{Act}^{268}$ in the Canadian province of Quebec came into force in 1980 and, inter alia, forbids "commercial advertising directed at persons under thirteen years of age" commercial advertising." 270 In determining whether an advertisement is directed at persons less than thirteen years of age: ${ }^{271}$

account must be taken of the context of its presentation, and in particular of

(a) the nature and intended purpose of the goods advertised;

(b) the manner of presenting such advertisement;

(c) the time and place it is shown

These are important in dealing with the reality that many children are regularly exposed to marketing that is not specifically aimed at them.

\footnotetext{
${ }^{267}$ Tony Abbot (10 May 2006) "A plan to win the Battle of the Bulge" Sydney Morning Herald Sydney; and Obesity Policy Coalition Effects of Advertising Restriction in Other Jurisdictions (Diabetes Australia, Deakin University and the Cancer Council Victoria, Victoria, 2007)

${ }^{268}$ Consumer Protection Act RS Q c P-40.1.

${ }^{269}$ Ibid, s 248.

270 WHO, above n 242, 16.

${ }^{271}$ Consumer Protection Act, above n 268, ss 248-249; this legislation is discussed further below see Part VI E 4 (b) Marketing restrictions and the New Zealand Bill of Rights Act.
} 
The results of the legislation in Quebec are encouraging from an obesity perspective showing, inter alia, that: ${ }^{272}$

- [There were] fewer high-sugar breakfast cereals in homes.

- No reduction (in fact an increase) in the quality of children's television programmes.

- Inconclusive effects on decrease in total advertising revenue (possibly around US\$10 million), but far lower than predicted by the advertising and television industries.

- Children in Quebec have the lowest prevalence of obesity across all Canadian provinces, and the second lowest prevalence of overweight (significantly lower than the Canadian average).

In 2009 a successful action was brought under this legislation against a food chain for a "campaign that involved distributing [its products] in day care centres."273 The company was fined 44,000 dollars after pleading guilty. At the time this judgment was made Quebec's Consumer Protection Agency indicated that similar charges were pending against other fast food companies. ${ }^{274}$

\section{$3 \quad$ Marketing regulation in the United Kingdom}

In the United Kingdom, television advertising is monitored by the Office of Communications (Ofcom) via powers under the Communications Act. ${ }^{275}$ The Broadcast Committee of Advertising Practice (BCAP) is contracted by Ofcom to take responsibility for the UK Code of Broadcast Advertising (BCAP Code). ${ }^{276}$ Compliance with the code is the responsibility of the Advertising Standards Authority (ASA), a self regulating and independent body. ${ }^{277}$

\footnotetext{
272 OAC, above n 9, 15.

${ }^{273}$ Graeme Hamilton "The Junk Food Wars: Quebec Scores Sweet Victory in Battle against Childhood Obesity" (27 January 2009) National Post (Canada).

274 Ibid.

${ }^{275}$ Communications Act 2003 (UK), s 3.

276 The UK Code of Broadcast Advertising [BCAP Code] first edition came into force on 1 September 2010; see Code of Advertising Practice www.cap.org.uk (accessed 11 November 2010); also see Shaw, above n 98, 80.

${ }^{277}$ United Kingdom Advertising Standards Authority www.asa.org.uk (accessed 17 November 2009).
} 
The BCAP Code has several rules relevant to the advertising of food to children and states, inter alia that "the protection of young viewers and listeners is always a priority". ${ }^{278}$ It defines a child as someone under $16 .{ }^{279}$ Advertisements must "comply with both the spirit and the letter of the Code,"280 a provision that should prevent more unscrupulous marketers from attempting to avoid compliance by, for example, taking advantage of ambiguous wording.

The code is designed to prevent marketers from taking advantage of children's naivety and, inter alia, "advertisements must not condone or encourage practices that are detrimental to children's health."281 Detailed rules also ensure that promotional offers are used responsibly. ${ }^{282}$ The code also provides rules for the scheduling of advertisements to ensure that children are not exposed to unsuitable programmes. These state, inter alia that ${ }^{283}$

\footnotetext{
food or drink products that are assessed as high in fat, salt or sugar (HFSS) in accordance with the nutrient profiling scheme published by the Food Standards Agency [cannot be] advertised in or adjacent to programmes commissioned for, principally directed at or likely to appeal particularly to audiences below the age of 16 .
}

The rules therefore deal with the possibility of children watching programmes that may be broadcast during adult viewing. This is particularly pertinent given that studies have shown that many children watch television outside traditional child viewing times. ${ }^{284}$

Clearly action is being taken overseas to restrict the marketing of food with particular emphasis on marketing to children. This trend, and overseas experiences, provide further support for the implementation of stricter statutory control of food marketing in New Zealand, particularly to children. Given the

\footnotetext{
${ }^{278}$ BCAP Code, above $n$ 276, Introduction j.

${ }^{279}$ Ibid, part 5.

${ }^{280}$ Ibid, part 1.

${ }^{281}$ Ibid, part 5.3.

${ }^{282}$ Ibid, part 2.14 .

283 Ibid, part 32.

${ }^{284}$ See for example Scientific Committee of the Agencies for Nutrition Action, above $\mathrm{n} 96$.
} 
need to introduce some form of statutory food product marketing regulation, the possible logistics of implementation will now be explored.

\section{E The implementation of statutory regulation of food product marketing in New Zealand}

$1 \quad$ Extent of marketing restrictions required in New Zealand; controlling advertising to children

Studies indicate that a complete ban on advertising of all unhealthy foods is likely to have an effect on obesity levels. This is however, an extreme approach, and one that is unlikely to find favour with either the food industry or anti-paternalists. The reality is that support for such a policy change would be extremely difficult to gain, and such a limitation of freedom of expression would also violate the New Zealand Bill of Rights Act (NZBORA). ${ }^{285}$ Nonetheless, as already stated, the arguments for statutory restriction of food advertising to children are extremely strong. The experience in Quebec also demonstrates that there are benefits to be gained in the stricter statutory regulation of marketing to children. Therefore, the nature of such restrictions will now be explored.

\section{$2 \quad$ Intended audience}

It would be relatively easy to devise a system of regulation by merely banning adverts for certain foods during children's viewing times. As already outlined studies have shown that children watch television outside such times. ${ }^{286}$ Therefore, such ban would be largely superfluous. It is therefore essential that statutory marketing regulation in New Zealand includes restrictions that cover programmes which, whilst not necessarily shown during traditional viewing times, are still aimed at children (as has been done overseas), or are shown at times when children are likely to be watching. For example, New Zealand could

\footnotetext{
${ }^{285}$ New Zealand Bill of Rights Act 1990. For a fuller discussion of advertising in the context of the New Zealand Bill of Rights Act see V E 5 Marketing restrictions and the New Zealand Bill of Rights Act.

${ }^{286}$ See for example Scientific Committee of the Agencies for Nutrition Action, above $\mathrm{n} 95$.
} 
adopt legislation similar to that in the Quebec Consumer Protection Act "... no person may make use of commercial [certain food products] advertising directed at persons under thirteen years of age. ${ }^{\text {287 }}$ To address what constitutes such advertising New Zealand could once again, draw on the Canadian legislation: ${ }^{288}$

To determine whether or not an advertisement is directed at persons under thirteen years of age, account must be taken of the context of its presentation, and in particular of

(a) the manner of presenting such advertisement;

(b) the time and place it is shown.

The use of provisions of this nature would ensure that the food industry did not attempt to breach marketing restrictions by merely advertising outside children's viewing times.

\section{$3 \quad$ Dealing with different types of marketing}

The legislation would have to provide a definition of what constitutes an advertisement because both children and adults are constantly exposed to marketing via other media; for example, the internet, product placement in movies, and sponsorship. One study in New Zealand found that "the sponsorship of popular sports for young people is dominated by unhealthy sponsorship" 289 and concluded that there was a need for "governments to consider regulations that limit unhealthy sponsorship and/or adopt alternative funding mechanisms for supporting popular sports." 290 In the United Kingdom, alarmingly, it was revealed that companies were producing curriculum packs for school as a way of marketing products to children. These packs often contained "misleading or incorrect information" 291 and some packs were even "teaching children that they should include fatty or sugary food as part of their breakfast ... and that soft

\footnotetext{
${ }^{287}$ Consumer Protection Act, above n 268, s 248

${ }^{288}$ Ibid, s 249

${ }^{289}$ Anthony Maher, Nick Wilson, Louise Signal and George Thomson "Patterns of Sports Sponsorship by Gambling, Alcohol and Food Companies: an Internet Survey" (2006) 6 BMC Public Health 95.

290 Ibid.

291 "Food Industry are Misleading Children and Advertising in the Classroom" (5 January 2009) Sustainweb www.sustainweb.org/news (accessed 22 July 2010).
} 
drinks are made with 'gooditives', an invented term to put a positive spin on artificial additives." 292

Television advertising is clearly not the only way that food products are marketed and, what may on the surface appear to be a community spirited gesture on the part of food companies can be viewed in a more sinister way; that is, just another way of marketing unhealthier foods to a captive, impressionable audience. It is therefore clear that the food industry can, and will, find new ways around marketing regulation regimes unless they include provisions that regulate a wide range of advertising media and marketing techniques. This could be achieved by defining advertisement to include the range of advertising media; for example, like the definition used in the Code of Advertising to Children defines advertisement as including "all advertisements in all forms of media directed at children whether contained in children's media or otherwise."

Arguably, whilst this does include advertisements in media other than television, it does not deal with sponsorship and other forms marketing such as those in schools, outlined above. Therefore legislation would have to include specific provisions restricting sports sponsorship and other marketing initiatives by certain food product brands aimed at children.

The constant efforts of the food industry to find new ways of marketing its products to children illustrates the need for a stricter, mandated approach, and one that targets different forms of marketing including the more indirect ones. Regulation will also have to deal with marketing methods that will inevitably evolve as food companies find ways to market their products that do not fall foul of new regulations. Therefore the definition of advertisement and marketing initiative are ones that would have to remain under review.

\footnotetext{
292 Ibid.

${ }^{293}$ ASA Code for Advertising to Children, above n 230.
} 
As with other obesity control initiatives a major problem would be defining what products should be subject to marketing restrictions. This problem would be overcome by using a nutrient profiling system as outlined above. ${ }^{294}$ Thus, only products that were subject to mandatory profiling would be potential candidates for marketing restrictions, and then only if that product had a nutrient profile that placed it in the unhealthy category.

$5 \quad$ The Smoke Free Environments Act 1990; a model for the regulation of food marketing to children?

As already outlined there is already legislation in New Zealand that places restrictions on the marketing of a specific type of product, namely the restrictions on the marketing of tobacco products contained in Smoke Free Environments Act 1990. This Act may provide a possible model for legislation to control (or possibly ban) the advertising of food products to children.

The Smoke Free Environments Act, inter alia, bans the advertising of tobacco products in New Zealand; section 22(1) stating that "no person shall publish, or arrange for any other person to publish, any tobacco product advertisement in New Zealand."295 Other controls include restrictions to the way tobacco products are displayed, and sponsorship. ${ }^{296}$

Statutory restrictions of the marketing of certain food products to children, as outlined above, could be introduced via the Food Act 1981, or via new legislation dedicated to this purpose. It is possible to draw on the experiences of the Smoke Free Environments Act, but the differences in the nature of the products (as discussed above) mean that statutory restriction of marketing of food products does present different challenges. Legislation would require provisions and exemptions to deal with, inter alia, the varied number of food products,

\footnotetext{
${ }^{294}$ See V C 1 (a)(i) Nutrient profiling for New Zealand.

${ }^{295}$ Smoke Free Environments Act 1990, s 22(1).

${ }^{296}$ Ibid, s 23 A and s 24.
} 
manufacturers and retailers, and would have to draw on a nutrient profiling system to overcome the significant hurdle of deciding which food products should be subject to restriction.

As already discussed, given the similarity in the level of health risks associated with the over-consumption of certain foods, the possibility of addiction, and the particular risks for children, the analogy between tobacco and some food products is an appropriate one to make. Therefore, the Smoke Free Environments Act can be viewed as a useful model for stricter statutory controls of the marketing of a particular category of product to children (in this instance certain food products). Nonetheless, any attempt to introduce marketing restrictions could be challenged as an attempt to fetter the right to freedom of expression, under NZBORA. Therefore, when considering legislative marketing restrictions, it is essential to determine at whether such restriction would be an issue under NZBORA.

\section{Marketing restrictions and the New Zealand Bill of Rights Act 1990}

The marketing restrictions in the Quebec Consumer Protection $\mathrm{Act}^{297}$ were challenged by the advertising industry on the basis that they were an unjustified limitation of freedom of expression.

(a) Challenges to the Consumer Protection $\mathrm{Act}^{298}$ in Quebec; a limitation of freedom of expression?

In Irwin Toy Ltd v Quebec (Attorney General). ${ }^{299}$ The Plaintiff sought a declaration that the advertising restrictions in the Consumer Protection Act were ultra vires, inter alia, because they violated the right to freedom of expression provided for in the Canadian Charter of Rights and Freedoms and Quebec Charter of Human Rights and Freedoms.

\footnotetext{
${ }^{297}$ Consumer Protection Act, above n 268.

298 Ibid.

${ }^{299}$ Irwin Toy Ltd v Quebec (Attorney General) [1989] SCR 927 para 17.
} 
The Canadian Charter of Rights and Freedoms includes the following provisions: ${ }^{300}$

1. ... guarantees rights and freedoms set out in it subject only to such reasonable limits prescribed by law as can be demonstrably justified in a free and democratic society.

2. Everyone has the following fundamental freedoms ...

(b) Freedom of thought, belief, opinion and expression, including freedom of the press and other media communication

7. Everyone has the right to life, liberty and security of the person and the right not to be deprived thereof except in accordance with the principles of fundamental justice.

The Quebec Charter of Human Rights and Freedoms provides that: ${ }^{301}$

3. Every person is the possessor of the fundamental freedoms, including freedom of conscience, freedom of religion, freedom of opinion, freedom of expression, freedom of peaceful assembly and freedom of association.

...

9.1 In exercising his fundamental freedoms and rights, a person shall maintain a proper regard for democratic values, public order and the general well-being of the citizens of Quebec.

In this case the Canadian Supreme Court ruled that freedom of expression did apply to commercial activity, and that the Consumer Protection Act was a limit of that freedom of expression. Having thus ruled, the Court had to determine whether such limitation was "demonstrably justified in a free and democratic society,"302 and whether it "maintain[ed] a proper regard for democratic values, public order and the general well-being of the citizens of Quebec."303 In doing so the Court applied the test in $R v$ Oakes namely, ${ }^{304}$ it must be established that:

\footnotetext{
${ }^{300}$ Canadian Charter of Rights and Freedoms (Part 1 of Constitution Act RS C c-11 1982), ss 1, 2(b), and 7.

${ }^{301}$ Quebec Charter of Human Rights and Freedoms RS Q c-12, ss 3 and 9.1

${ }^{302}$ Canadian Charter of Rights and Freedoms, above n 300, ss 1, 2(b), and 7.

${ }^{303}$ Quebec Charter of Human Rights and Freedoms, above n 311, ss 3 and 9.1

${ }^{304} R$ v Oakes [1986] 3 SCR 103 paras 65-83 Dickson CJC.
} 
1. "a limit is reasonable and demonstrably justified in a free and democratic society; [and] ...

2. "[it must be shown] that the means chosen are reasonable and demonstrably justified ... This involves "a form of proportionality test","305

In this case the court decided that the limit was both justified, due to the potential harm to children, and that effects of the limiting measure and the objective were proportional because advertisers were still able to advertise to "parents and other adults. 306

It is likely that any attempt to introduce advertising restriction in New Zealand would be similarly challenged under NZBORA.

(b) Marketing restrictions, freedom of expression, and the New Zealand Bill of Rights Act

NZBORA protects human rights in New Zealand including the "freedom to seek, receive, and impart information and opinions of any kind in any form."307 As in Canada, under NZBORA, this right can only be limited if it is "justified in a free and democratic society." ${ }^{, 308}$ The restriction of the right to market food products as an individual chooses is a limit to freedom of expression, therefore it must be justifiable under NZBORA. Hansen $v R^{309}$ a New Zealand case involving a criminal conviction and the defendant's rights provided by NZBORA, adopted the test set out in $R v$ Oakes $^{310}$ to determine if a breach of NZBORA is a justified limitation of freedom of expression under section 5 of that Act. $R v$ Oakes had used a summary of the test set out in $R v$ Chaulk, namely: $:^{311}$

\footnotetext{
${ }^{305}$ Ibid, paras 65 \& 74, Dickson CJC.

${ }^{306}$ Irwin Toy Ltd v Quebec (Attorney General) [1989] SCR 927 para 90 Dickson CJ, Lamer J and Wilson J.

${ }^{307}$ New Zealand Bill of Rights Act 1990, s 14.

${ }^{308}$ Ibid, s 5.

${ }^{309}$ Hansen $v R$ [2007] 3 NZLR 1, para 64 (SCNZ) Blanchard J.

${ }^{310} R v$ Oakes [1986] SCR 103, 14; Hansen $v R$ [2007] 3 NZLR 1, para 64 (SCNZ) Blanchard J.

${ }^{311} R v$ Chaulk [1992] 3 SCR 1303; Hansen $v R$ [2007] 3 NZLR 1, para 64 (SCNZ) Blanchard J.
} 
(1) The objective of the impugned provision must be of sufficient importance to warrant overriding a constitutionally protected right or freedom; it must relate to concerns which are pressing and substantial in a free and democratic society before it can be characterized as sufficiently important.

(2) Assuming that a sufficiently important objective has been established, the means chosen to achieve the objective must pass a proportionality test; that is to say they must:

(a) be 'rationally connected' to the objective and not be arbitrary, unfair or based on irrational considerations;

(b) impair the right or freedom in question as 'little as possible'; and

(c) be such that their effects on the limitation of rights and freedoms are proportional to the objective.

Thus, whilst imposing a statutory restriction on marketing is a limit to freedom of expression provided in NZBORA, the issue is whether or not this limitation is justifiable under the Act. To justify the limitation, it must therefore pass the test used in Hansen, namely the reasons for such limitation must be of sufficient importance to justify them, and the effects of the limitation must be proportional to the risk involved, affect freedom of expression as little as possible, and must relate directly to the risk involved. A total ban on all food marketing is an extreme measure that "impairs the right to freedom" ${ }^{312}$ considerably more than is necessary to protect children from food product marketing. Therefore this would not pass the proportionality test, and cannot be demonstrably justified in New Zealand at the current time. Given the particular vulnerability of children to the effects of food marketing however, and the health dangers of over consumption of certain food products, legislation that restricts food product marketing to children relates to an issue of sufficient risk to children. Furthermore, such restriction relates directly to the risk involved, limits freedom of expression as little as possible (the right to advertise to other groups is maintained), and is proportional to the risks involved. Therefore, statutory restrictions on advertising to children in New Zealand would not violate NZBORA.

${ }^{312}$ Ibid 
Thus, statutory controls on the marketing of food to children could be introduced in New Zealand via the Food Act, new legislation devoted to this purpose, or through public health legislation (a possibility that will be discussed more fully below ${ }^{313}$ ) using the Smoke Free Environments Act as a model. Any changes to the regulation of marketing will have a more realistic chance of success if made gradually starting with those for which the arguments are more persuasive, and that would incur the least industry opposition; namely statutory control of food advertising to children. With the increasing evidence of the addictive nature of some foods (and in the case of caffeinated food products, their undisputed addictive qualities), the possibility of wider restrictions on the marketing of such products is something that should remain under review. Therefore if a conclusive link between some food products and addiction was established this could mean that the test in Hansen would be satisfied for a wider ban.

Marketing regulation is a significant way to influence eating behaviour, and constitutes one of many initiatives that could help control obesity that are not coercive in nature. Such non-coercive initiatives include the imposition of a fattax to redress the price differential between healthy and unhealthy food products. The possibility of the imposition of a fat-tax in New Zealand will now be explored.

\footnotetext{
${ }^{313}$ See Part VII New Zealand Public Health Law and the control of obesity.
} 


\section{FAT-TAX AND OBESITY CONTROL}

\section{A What is a fat-tax?}

Whilst not a regulatory initiative, the implementation of a so called fat-tax can also have an effect on food choices. It can also provide much needed revenue to help with the implementation costs of obesity initiatives. Frequently, unhealthy foods present the cheaper option, and it is therefore possible that the manipulation of the price of certain foods has the potential to influence eating behaviours. In doing so, consumers are being encouraged to choose a healthier option rather than having that choice forced upon them (for example by removing a food product from the shelves completely). In its Global Strategy on Diet, Physical Activity and Health, WHO stated that "prices influence consumption choices," 314 and that "public policies can influence prices through taxation, subsidies or direct pricing in ways that encourage healthy eating and lifelong physical activity."315 A good example of pricing influencing consumption in New Zealand is the reduced tobacco consumption as a result of tobacco price increases; for example, a recent tobacco price increase was reported by the media as "forc[ing] thousands to quit." $" 316$

The imposition of a levy on unhealthy foods is often referred to as a fat-tax. Its use, either as a levy on certain foods, or the introduction of food subsidies, provides an opportunity to assist in the control of obesity levels in New Zealand by addressing one of the obesogenic influences in the current eating environment; namely the price differential between healthy and unhealthy food products. In doing so it would assist individuals to make good eating choices. This can therefore impact on obesity levels in the population and also be of great benefit to individual health.

\footnotetext{
${ }^{314}$ WHO Global Strategy on Diet, Physical Activity and Health (WHO Geneva, 2004) 8.

315 Ibid.

316 Tracy Watkins "Tobacco Price Increase Prompts Helpline Spike” (14 July 2010) Stuff New Zealand www.stuff.co.nz (accessed 13 November 2010); see also Ministry of Health Tobacco Tax -The New Zealand Experience (MOH, Wellington, 2000) for a discussion of effect of price increase on tobacco consumption in New Zealand.
} 
Manipulating food prices in an attempt to change lifestyles can involve:

- taxing foods on the basis of their nutrient profile;

- taxing foods on the basis of the energy density (the energy density of a food item represents the number of calories it provides in relation to its size. Junk foods have high energy density and are often cheaper than healthier options); ${ }^{317}$

- taxing particular categories or types of food product (for example, soft drinks or chippies);

- Subsidising healthier food products; and

- altering the current Goods and Services Tax (GST) rate on certain foods to make them more or less expensive;

Diabetes New Zealand has indicated that a fat-tax would be justifiable, but there is currently no such tax in New Zealand. ${ }^{318}$ Food products are subject to GST, but this is not imposed with obesity control in mind. Previous suggestions for a fat-tax have been controversial. ${ }^{319}$

This paper will examine the possibilities for fat-tax in New Zealand, based on price manipulation, but a fat-tax can also refer to a levy paid by the obese because of their size. It is beyond the scope of this paper to discuss the latter form of fat-tax, but it is mentioned, and outlined briefly below, for the sake of completeness.

\section{$1 \quad$ Taxing the obese}

Taxing the obese, that is, imposing a financial penalty based on a person's weight is a form of fat-tax. It presents, at first glance, a draconian revenue

${ }^{317}$ R Sturm, A Datar "Body Mass Index in Elementary School Children, Metropolitan Area Food Prices and Food Outlet Density" (2005) 119.12 Public Health 1059, 1060; and R. Sturm and A Datar "Food Prices and Weight Gain During Elementary School: 5-year update (2008) 122 Public Health 1140.

${ }^{318}$ See discussion in Diabetes New Zealand and Fight the Obesity Epidemic, Inc. Cutting the Fat: How a Fat Tax can help Fight Obesity (Diabetes New Zealand and Fight the Obesity Epidemic, Inc, Nelson, 2004).

319 For example see "Government Considers Fat Tax" (25 June 2003) www.tvnz.co.nz/view (accessed 17 December 2008). 
gathering opportunity, but also represents a way of passing the extra costs associated with obesity on to the obese themselves. This form of fat-tax is already a very real possibility as there are moves to impose extra charges on the obese for certain services; for example, charging extra for airline travel, ${ }^{320}$ and charging extra for cremation. ${ }^{321}$ These examples represent an indirect form of a fat-tax based on body size, and may be an indication of what can be expected in the future as extra costs are passed on to the obese.

\section{$2 \quad$ Fat-tax in the form of price manipulation}

The implementation of a fat-tax, in the form of price manipulation is an opportunity to assist in obesity control (from both a society and individual perspective). It is likely to be unpopular as it would invariably result in some higher food prices. Therefore, in order to justify such a move, it is important to demonstrate that it could have a beneficial effect on obesity levels. It is however, worth noting that various forms of fat-tax are already imposed in some jurisdictions and are planned in others. These will be reviewed briefly.

\section{B Fat-taxes internationally}

\section{$1 \quad$ Planned fat-taxes}

Countries planning to impose a form of fat-tax include Romania, which is planning to impose a fat-tax on foods high in fat, sugar and salt; and Taiwan, which is planning a tax on fatty foods. ${ }^{322}$

There have also been unsuccessful attempts to impose a form of fat-tax; for example, plans in France to raise the equivalent of GST from 5.5 to 19.6 per cent on certain foods. ${ }^{323}$

\footnotetext{
${ }^{320}$ Clair Weaver "Call for Airlines to Levy a 'Fat Tax"” (11 November 2007) Sunday Telegraph Australia, 9.

${ }^{321}$ Chris Riches “Anger at Crematorium 'Fat Tax' on Overweight” (27 January 2010) The Express United Kingdom 32.

${ }^{322}$ David Charder "Fast-food Tax to Tip Scales in War on Obesity - and Slim down Huge Deficit in Romania" (16 January 2010) The Times London 5.

323 "France set for Tax on Junk Food" (7 August 2008) Daily Record Scotland 30.
} 
Although the Governor of New York failed to implement a fat-tax in the form of a soft drinks tax, other States have imposed food-taxes successfully in the past. These taxes have included a tax on "soft drinks, candy, chewing gum ... [and] potato chips." 324 Many of these original fat-taxes were repealed (many after pressure from the food industry). Nonetheless, there have since been plans in several states to introduce such taxes, and in 2009, 12 states had proposals for the taxation of soft drinks. ${ }^{325}$ Additionally, "the U.S. Senate briefly considered a soda tax to help fund its health care reform plan."326

Therefore, despite the failure of some attempts to impose fat-taxes overseas, there does appear to be a move towards their use. Internationally in some administrations, a decision has clearly already been made that there is sufficient merit in the use of fat-taxes to justify them. New Zealand should continue to monitor such international developments in order to learn from their experiences.

\section{Fat-taxes and New Zealand}

\section{$1 \quad$ Do fat taxes change eating behaviour?}

There have been several studies to investigate the general effect of food prices on weight gain, and the possible effects of a levy on consumption. Results are not conclusive, but some research has shown that a fat-tax may "influence food choices, change diets, and improve health."327 For example, one study concluded that "for every $10 \%$ increase in price, consumption of soda decreases

\footnotetext{
${ }^{324}$ Michael F Jacobson and Kelly D Brownell "Small Taxes on Soft Drinks and Snack Foods to Promote Health" (2000) 90.6 Am J of Public Health 854, 856.

${ }^{325}$ See ibid; and Kim Geiger, Tom Hamburger "Soft Drink Tax Battle Shifts to States" (21 February 2010) Los Angeles Times online (Los Angeles Times Article Collections) www.articles.latimes.com (accessed 14 June 2010).

${ }^{326}$ Mark Toor "Sales Tax on Soft Drinks Not too Popular: New York Governor Revives Tax Plan, Opposition Piles On” (14 February 2010) www.suite101.com (accessed 23 February 2010).

${ }^{327}$ McColl, Karen "Fat Taxes and the Financial Crisis" (2009) 373 Lancet 797.
} 
by $7.8 \%, " 328$ and another American study, updated most recently in 2008, concluded that "lower real prices for fruit and vegetables ... may slow excess weight gain., ${ }^{, 329}$ A United Kingdom study in 2007 indicated that a tax on certain foods might prevent as many as 3000 deaths from heart attacks and strokes each year, and other studies indicate that the use of a fat-tax would affect obesity levels in the long term. ${ }^{330}$

The studies on the effects of a fat-tax are promising and, in its detailed report on the potential use of a fat-tax in New Zealand, Diabetes New Zealand listed reasons for its use; including using it as a means to change consumer behaviour and to provide revenue for the costs of obesity. ${ }^{331}$ Such revenue could, for example, be used to offset the implementation and compliance costs of increased food industry regulation. Revenue from a fat-tax could also be used to subsidise healthier foods. Additionally the Diabetes New Zealand report stated that: ${ }^{332}$

a tax could deter children or at least reduce their purchases of unhealthy products. This could change the long-term dietary habits and patterns of some members of the population who might be vulnerable to obesity and related health conditions.

Therefore, the use of a fat-tax could be a particularly important tool to combat childhood obesity. These are compelling arguments for imposing a fat-tax in New Zealand, but there are also several arguments against. These will now be addressed.

\footnotetext{
${ }^{328}$ Kellly D Brownell and Thomas R Frieden "Ounces of Prevention - The Public Policy case for Taxes on Sugared Beverages" (2009) 10 New England Journal of Medicine 1056

${ }^{329}$ Sturm, and Datar "Body Mass Index in Elementary School Children", above 316, 1059; see also Sturm and Datar "Food Prices and Weight Gain during Elementary School", above 316, 1140.

${ }^{330}$ See Mytton, Gray, Raynor, and Rutter, above n 94; media coverage: Fat Taxes could save 3,000" (12 July 2007) Daily Mail, London 29.

${ }_{331}$ Diabetes New Zealand and Fight the Obesity Epidemic Inc. above n 317, iii.

${ }^{332}$ Diabetes New Zealand "Cutting the Fat: How a Fat Tax can help Fight Obesity" (24 August 2004) Press Release.
} 
There are several arguments against manipulating the cost of food products as an approach to obesity control. These include:

- it is likely to be regressive; ${ }^{333}$

- it is too paternalistic;

- it would be difficult to implement.

(a) A fat-tax is likely to be regressive

The use of a fat-tax may be regressive because it affects those on the lowest incomes. This could mean that such "households would spend a greater proportion of their income on the tax than higher income households." ${ }^{334}$ This is however, precisely the idea behind a fat-tax, because it means that such foods are not cheap options for those on a low income. Unfortunately, it could also mean that if the tax did not result in a change in food choices, low income households would have even fewer resources available for the purchase of healthier food products.

The potential regressive effects should therefore be offset by using the monies raised from the food levies to provide "subsidies, or tax cuts, to reduce the price of healthier foods." ${ }^{, 335}$ In this way healthier food products would become a more accessible option than unhealthy ones, thus reducing the regressive effects of any levies.

\footnotetext{
${ }^{333}$ For further discussion see Reynolds, above $\mathrm{n} 7$.

${ }^{334}$ Karen McColl "Fat taxes" and the Financial Crisis" (2009) 373 Lancet Volume 797.

${ }^{335} \mathrm{McColl}$, ibid recommends this approach.
} 
(b) A fat-tax is too paternalistic

Opponents of the use of a fat-tax believe that it is too paternalistic an approach, forcing the entire population to be penalised financially for the bad eating habits of some. As stated by Diabetes New Zealand however: ${ }^{336}$

\footnotetext{
taxes respect the basic principle of freedom to choose ...[and] are not examples of a "nanny state" ... . They ... require those engaged in risky behaviour to pay a larger share of the cost of treating the medical conditions that result.
}

Therefore, whilst a fat tax does make unhealthy foods more inaccessible (especially for those on a low income) it does not force individuals to choose healthier products because those individuals would still be free to choose the unhealthy option (albeit at a higher price). Individuals are therefore still at liberty to purchase whatever food products they desire, and therefore this is not an overly paternalistic approach to obesity control.

(c) A fat-tax would be too difficult to implement

Implementing a fat-tax regime that is easy to understand, does not involve excessive compliance costs, and deciding on the criteria for what foods would (or would not) be subject to a fat-tax, poses some hurdles. With careful consideration such hurdles can be overcome. These implementation issues will now be examined.

\section{$3 \quad$ How could a fat-tax be implemented in New Zealand}

A fat-tax regime would have to be implemented with care. Policy decisions would be required about the nature of any regime including: ${ }^{337}$

\footnotetext{
${ }^{336}$ See Diabetes New Zealand and Fight the Obesity Epidemic Inc., above n 317, 16.

${ }^{337}$ Ibid, 33.
} 
- What food types should be exempted from the tax;

- What businesses would be required to calculate and pay the tax;

- What businesses might warrant an exemption; ...

- What would be done with the revenue?

- [the nature of the compliance costs arising from a fattax regime].

(a) Deciding which foods would be subject to a fat-tax or subsidy?

Possibly one of the largest hurdles to successful implementation of a fattax would be deciding which food products would be subject to it. Diabetes New Zealand has suggested that New Zealand should have "one set of criteria for fat content and other criteria for soft drinks, snacks and other foods that are energy dense and nutrition poor." 338 There is a variety of ways in which to decide which foods should be taxed or subsidised, including:

- tax food products according to nutritional merit (or lack of it);

- tax the fat content of foods;

- tax snack foods and soft drinks (specific types of product; for example a tax could be levied on those foods described as treat foods in the $\mathrm{MOH}$ nutrition guidelines);

- tax the energy content or density of food. ${ }^{339}$

(i) Taxing according to nutrient profile

Legislation should require food products to be taxed according to nutritional content; namely according to nutrient profile. This would not pose a problem if a universal nutrient profiling system was implemented in New Zealand, as outlined above. ${ }^{340}$ Thus any proposed legislation should require fat taxes only on those food products the nutrient profiles of which fall into a certain category (that is those food products the profile of which places them in the

\footnotetext{
338 Ibid, iv.

${ }^{339}$ See Pollard, above n 120.

${ }^{340}$ See V C 1 (a)(i) Nutrient profiling for New Zealand.
} 
unhealthy category). Thus fat-taxes would only be levied on those products that require mandatory nutrient profiling in New Zealand under the proposed labelling regime.

Another way of isolating those food products to be taxed would be to tax a particular category of food product. Taxing food products on this basis may also have the benefit of avoiding the need to analyse the nutritional value. This is because it would be easy to decide whether or not a product falls into a particular category; for example, whether or not a product is a caffeinated soft drink or not.

(ii) Taxing specific products

A fat-tax levied on a particular category of food product could be implemented to be mandatory for products that "play little useful role in nutrition;" 341 for example those foods defined as treat foods in the $\mathrm{MOH}$ guidelines for nutrition. New Zealand could possibly follow the United States' lead and consider a tax on soft drinks, given the link between their consumption and obesity rates. One report in the United States has even stated that : "children and adolescents ... intake of ... [soft drinks] surpassed their intake of milk in the $1980 \mathrm{~s}, " 342$ and that "[soft drinks] ... now account for around $10 \%$ of the calories consumed by children and adolescents." ${ }^{, 343}$ A soft drink tax would require policy decisions on which soft drinks would be subject to it; for example, a tax could be levied on soft drinks that contain caffeine and/or added sugar in order to distinguish them from fruit juices.

Thus legislative provisions could require a levy on soft drinks with added caffeine, and/or whose levels of sugar by volume of product exceeded a certain figure. This is information that is easily accessible as levels of caffeine and sugar are already indicated on many soft drinks in New Zealand.

\footnotetext{
${ }^{341}$ Jacobson and Brownell, above $\mathrm{n} 323$.

${ }^{342}$ Center for Science in the Public Interest, above n 197, 2.

${ }^{343}$ Ibid.
} 
(b) Which businesses would be required levy a fat-tax on their products?

Another significant hurdle to successful implementation of a fat-tax would be deciding whether it would be levied on all food products or whether certain businesses would be exempt. By utilising the nutrient profiling system proposed as a part of a new labelling regime this would limit the types of food-product on which a fat-tax is levied (namely only those that fall within the mandatory profilng requirements).

(c) A fat-tax regime and compliance costs

The introduction of a fat-tax regime would invariably involve compliance costs. If however, a fat-tax was imposed by using existing Goods and Services Tax (GST) legislation, compliance costs can be kept to a minimum by avoiding the costs associated with implementing a new regime. ${ }^{344}$ If costs were still viewed as an issue, these could be ameliorated by using fat-tax revenue to subsidise them.

Thus the revenue from a fat-tax in New Zealand could be used to pay for the healthcare costs associated with obesity, and/or could subsidise healthier foods and other obesity control initiatives (such as the compliance costs created by increased regulation). When fat-tax revenue is used on healthcare and measures to fight obesity it has been more popular with the general public. ${ }^{345}$ Additionally, use of the revenue to subsidise healthier foods would help to ameliorate the effects of a fat-tax on those with low incomes and could encourage them to buy healthier foods.

Using fat-tax revenue to pay for the increased health costs associated with obesity also forces individuals to pay for their poor diet decisions and the inevitable health costs associated with them. Diabetes New Zealand views this as

\footnotetext{
${ }^{344}$ Mytton, Gray, Raynor and Rutter, above n 94, 690 for further discussion.

${ }^{345}$ See discussion in Brownell and Frieden, above n 327, 1056.
} 
a form of "insurance premium," 346 and draws an analogy with the Accident Compensation Corporation collecting revenue via petrol tax. ${ }^{347}$

(d) A fat-tax may result in unintended consequences or negative outcomes ${ }^{348}$

Another argument against the use of a fat-tax is the possibility of "unexpected consequences." 349 These may arise because: ${ }^{350}$

\begin{abstract}
changes in the price of one food product can affect the consumption of other products that are either eaten with or instead of that food.... and it can be difficult to predict these effects.
\end{abstract}

Studies have shown, for example, that "reducing saturated fat consumption tended to increase salt consumption, and that fruit consumption tended to fall as a result of taxation on milk and cream.",351

The results of a fat-tax therefore depend on what consumers chose to eat instead of the taxed options; for example, in relation to the consumption of soft drinks, the effects of a tax would depend on "whether consumers substituted water, milk, diet drinks, or equivalent generic brands of sugared drinks." ${ }^{, 352}$ Therefore, it is possible that the use of a fat-tax may result in decreased consumption of some healthy foods, thus defeating the purpose of it.

There is some evidence that such a change would affect purchasing patterns encouraging the purchase of healthier foods. A study carried out in a New Zealand supermarket chain found that, inter alia, "an automatic $12.5 \%$ price reduction on all eligible healthier food products" ${ }^{353}$ resulted in an increase in the purchase of healthier foods of $11 \%$, and concluded that discounting food prices

\footnotetext{
${ }^{346}$ Diabetes New Zealand and Fight the Obesity Epidemic Inc. above n 317, iii.

${ }^{347}$ See full discussion in ibid.

${ }^{348}$ For further discussion see ibid.

${ }^{349}$ McColl, above n 326.

${ }^{350}$ Ibid.

${ }^{351}$ Mytton, Gray, Raynor and Rutter, above n 94, 691.

${ }^{352}$ Brownell and Frieden, above n 328, 1056.

${ }^{353}$ Cliona Ni Mhurchu, Tony Blakely, Yannan Jiang, Helen C Eyles, and Anthony Rogers "Effects of Price Discounts and Tailored Nutrition Education on Supermarket Purchases: a Random Trial (2010) 91 Am J Clin Nutr 736, 737.
} 
had the potential to be a method of improving the amount of healthy foods consumed by the population. ${ }^{354}$ Studies such as this one show that whilst a fat-tax may have unexpected outcomes, overall the effect on purchasing patterns is beneficial. It would however, be necessary to provide for review (including public consultation) of fat-tax legislation within a specified time to assess the success of a fat-tax regime, and allow changes to be made to address any unforeseen consequences.

(e) Industry and public opposition

A fat-tax is also likely to be opposed by the food industry and the public, making it a politically unpopular policy. This problem was encountered in the United States, where plans to impose a soda tax to fund healthcare were abandoned after considerable lobbying by the food industry. Such experiences also demonstrate that the reaction of the food industry can have a real impact on the ultimate success of food taxes (or indeed any obesity control measures). ${ }^{355}$ It is important therefore, to work with the food industry closely when devising a fattax regime (or, in fact, any obesity control regime that affects the industry). Nonetheless the food industry is likely to oppose any obesity initiative that has the potential to affect product sales, and therefore opposition by the food industry is not necessarily a legitimate reason to avoid a fat-tax regime.

\section{$4 \quad$ Using Goods and Services Tax on certain food products to implement a fat-tax}

An alteration of the rate of GST on certain categories of foods could be achieved by making healthier foods exempt or zero rated for GST purposes, whilst designated categories of food product would remain subject to GST (or a higher rate of GST). ${ }^{356}$ The category of food would be decided according to nutrient profile.

\footnotetext{
${ }^{354}$ For a full account of this study see ibid.

355 See media commentary Geiger and Hamburger, above n 324.

${ }^{356}$ Goods and Services Tax Act 1985, s 14.
} 
Using the current GST regime to levy a fat-tax was the thinking behind the Goods and Services Tax (Exemption of Healthy Food) Amendment Bill, introduced to the House on 22 April 2010..$^{357}$ The Bill contained provisions to "(a) exempt healthy food from goods and services tax; and (b) encourage the purchase of healthy food" ${ }^{\text {358 }}$ It defined healthy food as: $:^{359}$

(a) fruit and vegetables (including fresh, frozen, canned, and dried):

(b) breads and cereals (including all bread, grains, rice, and pasta):

(c) milk and milk products (including cheese, yoghurt, and plain milk, but excluding ice cream, cream products, condensed, and flavoured milk):

(d) lean meat, poultry, seafood, eggs, nuts, seeds, and legumes.

These were very broad categories, that were clearly been chosen on the basis of nutritional value. They are vague and open to misinterpretation. This could result in food products that may, strictly speaking, fall into one of the categories, but are not healthy products. Cereal could arguably include breakfast cereals that are high in sugar, and the breads and cereals category could include instant noodles which can have high fat and additive levels. This Bill could have been improved by the inclusion of a mandatory nutrient profiling system that would have allowed foods to be more successfully categorised as healthy or unhealthy. ${ }^{360}$

This Bill was a promising development in the control of obesity in New Zealand. The motion to give the Bill its first reading was not passed and it did not proceed any further in the legislative process. ${ }^{361}$ Nonetheless, it did bring the issue of GST change as a way of promoting healthier eating, to the attention of the public. Since this time the Labour Party has indicated that it will change its health

\footnotetext{
357 The Goods and Services Tax (Exemption of Healthy Food) Amendment Bill, no 140-1 (a private member's bill introduced by Maori MP Rahui Katene).

${ }_{358}$ Ibid, $\mathrm{cl} 4$.

${ }^{359}$ Ibid, cl 5.

${ }^{360}$ See V C 1 (a)(i) Nutrient Profiling for New Zealand.

${ }^{361}$ For a full account of the debate on 8 September 2010 see New Zealand Parliament Hansards (debates) Goods and Services Tax (Exemption of Healthy Food) Amendment Bill - First Reading (New Zealand Parliament, Wellington, 2010) Volume 666, page 13803.
} 
and tax policies to remove GST from fresh fruit and vegetables. This is a promising development for obesity control in New Zealand. ${ }^{362}$

There is some evidence that the use of a form of fat-tax in New Zealand can have a positive effect on obesity levels. ${ }^{363}$ It is an obesity initiative that is not overly paternal. Furthermore, a fat-tax also ensures that those who eat an excess of unhealthy foods are made to pay a contribution towards the consequences. ${ }^{364} \mathrm{~A}$ fat-tax implemented via a change to the GST regime, utilising a nutrient profiling system, and imposed both as a way of both influencing eating behaviours, and raising revenue to deal with obesity related costs, is an excellent opportunity in New Zealand for obesity control. The tax could be based on nutrient profile, or on certain categories of foods; caffeinated beverages or treat foods (such as fast food sold in major chains) being strong candidates. This approach has the benefit of using a current system, thus avoiding investing time and money on a new regime.

Thus, there are several responses to obesity that can be facilitated by the law in New Zealand, either by the implementation of legislation devoted solely to obesity related measures, or amendment of existing legislation such as the Food Act 1981 or GST legislation. ${ }^{365}$ Public health legislation is an obvious place to include obesity related regulation. Therefore the use of public health legislation as a vehicle for introducing obesity control measures in New Zealand will now be examined.

\footnotetext{
362 "Taking GST off Fresh Fruit and Vegetables a Step in the Right Direction" (27 September 2010) University of Otago News www.otago.ac.nz/news (accessed 2 November 2010).

${ }^{363}$ See for example this study: Dana Goldman, Darius Lakdawall and Yuhui, Zheng Food Prices and the Dynamics of Body Weight National Bureau of Economic Research [ NBER] Working Paper No. 15096 (NBER, Cambridge Massachusetts, 2009).

${ }^{364}$ See discussion in Diabetes New Zealand and Fight the Obesity Epidemic Inc., above n, 317, iii.

${ }^{365}$ For example Goods and Services Tax Act 1985.
} 
VIII NEW ZEALAND PUBLIC HEALTH LAW AND THE CONTROL OF OBESITY

As already discussed, public health legislation may be the appropriate place in which to put provisions relating to obesity control.

\section{A Current New Zealand public health legislation and non-communicable diseases}

Public health legislation in New Zealand consists of the Public Health Act 1956, and the Tuberculosis Act 1948. Other legislation also addresses issues of public health; for example, the Smoke Free Environments Act 1990. It is not possible to include a complete analysis of all current public health related legislation, and what follows is a brief overview of it.

$1 \quad$ The Health Act 1956 and Tuberculosis Act 1948.

The Tuberculosis Act contains public health provisions applicable to the treatment and control of tuberculosis and therefore has no relevance to the control of obesity.

The Health Act 1956 contains general public health provisions, inter alia, dealing with sanitation, and water supply. ${ }^{366}$ It also contains extensive powers to deal with infectious and notifiable diseases. ${ }^{367}$ The Act is supported by criminal penalties for non compliance; for example, obstructing a medical officer from using powers granted under the Act, carries a penalty of up to 6 months imprisonment and/or a fine of up to $\$ 4,000$. The powers are extensive and include requiring individuals to undergo medical examination, or testing, and the imposition of quarantine restrictions. ${ }^{368}$

\footnotetext{
${ }^{366}$ Health Act 1956, parts 2 \& 2 A.

${ }^{367}$ Ibid, part 3.

${ }^{368}$ Ibid, ss $70 \& 72$.
} 
There are no specific provisions relating to non-communicable diseases. Section 117(1) does however contain regulation making powers "necessary or expedient for giving full effect to the provisions of [the] Act, and for [inter alia] the improvement, promotion, and protection of public health. ${ }^{369}$ The definition of Public Health can be found in the New Zealand Public Health and Disability Act 2000, and is defined as "the health of all of (a) the people of New Zealand; or (b) a community of section of such people."370

Although the Health Act was enacted with communicable diseases in mind, arguably measures to control obesity (a non-communicable disease), qualify as "expedient [or even perhaps necessary] ... for the improvement, promotion, and protection of public health." ${ }^{, 371}$ If so, these regulation making powers could potentially be used to control advertising, impose labelling requirements, ban categories of food products within schools, or ban certain ingredients, under the guise of measures that are for the improvement, promotion, and protection of public health. It is unlikely that this was the intention behind these regulation making powers at the time they were enacted as levels of obesity in the population were not sufficient to pose a threat to public health at that time.

Current New Zealand public health legislation was clearly not drafted with non-communicable diseases in mind, and it is not surprising, given the threat that obesity now poses to public health, that there has been a recent attempt to legislate for them via the recent Public Health Bill 2007.

\footnotetext{
${ }^{369}$ Ibid, s 117(1)(a).

${ }^{370}$ New Zealand Health and Disability Act 2000, s 6(1).

${ }^{371}$ Health Act 1956, s 117(1)(a).
} 
The Public Health Bill was introduced in November 2007 by the then Labour Government. It was subsequently reported back from the Health Select Committee in 2008 after considering 204 submissions. ${ }^{372}$ It is intended to replace the Health Act 1956, and Tuberculosis act 1948, and its purpose is "to improve, promote, and protect public health in order to help attain optimal and equitable health outcomes for Mãori and all other population groups.”373 It includes many public health provisions including those relating to a national cervical screening programme, health emergencies, and border health. Unlike existing public health legislation the Bill includes provisions for non-communicable diseases. These provisions allow the "identification and effective management of risks to public health ... arising from non-communicable conditions, ${ }^{, 374}$ and include the power, in certain circumstances, to make regulations applicable to industries involved in the sale and marketing of foods and beverages. ${ }^{375}$

The Bill provides for the issuing of codes of practice or sets of guidelines to $\mathrm{a}:{ }^{376}$

sector on a particular activity that the sector undertakes if the Director-

General has reason to believe that the sector can reduce, or assist in reducing, a risk factor associated with, or related to, the activity

Clause 82 requires that consultation take place before any code is issued. The inclusion of a consultation process provides an opportunity for the food industry to have input on the development of codes, and thus it is more likely to comply with them.

\footnotetext{
${ }^{372}$ Public Health Bill 2007, no 77-2.

${ }^{373}$ Ibid, no 77-2 cl 3(1).

${ }^{374}$ Ibid, Part 3.

${ }^{375}$ Ibid, cl 88C; see also discussion in Dr Marie Bismark "Public Health Bill" (Conferenz Annual Medical Law Conference, Wellington, April 2008).

${ }^{376}$ Ibid, cl 81.
} 
The codes and guidelines can contain provisions regarding the following: ${ }^{377}$

(a) the development, completion, and review of health impact assessments:

(b) the development and maintenance of practices that are conducive to promoting health and safety:

(c) the performance, composition, contents, additives, design, and construction of specified goods or substances:

(d) the accessibility of specified goods, substances, or services to members of the public or to sections of the public, in particular, to minors:

(e) the ways in which specified goods, substances, or services are advertised, sponsored, or marketed (whether directly or indirectly):

(f) the information to be given to consumers of specified goods, substances, or services, whether as part of any advertising, sponsorship, or marketing or as part of any packaging or labelling of goods or substances.

Thus, codes/guidelines can have sufficient scope to provide for, inter alia marketing restrictions (clause 83(2)(e)) and a new labelling regime (clause 83(2)(f)).

Additionally, every code or guideline issued under clause 81 must state its objective in terms of reducing a "specified risk factor," against which any progress made in achieving that objective can be assessed." 379 Thus, any code must have a specific objective (for example an increase in the number of healthy food products purchased, or a reduction in the consumption of fast foods or soft drinks by children), and indicate the way in which it will address

\footnotetext{
${ }^{377}$ Ibid, cl 83.

${ }^{378}$ Ibid, cl 83A (a).

${ }^{379}$ Ibid, cl 83A (b).
} 
that objective (for example; by increasing the price of unhealthy food products and subsidising healthy food products). Furthermore, each code must include a way to assess its success. The Bill also provides incentives to the food industry to comply by allowing those food products complying with a particular code to include a statement to that effect in the marketing of that product. ${ }^{380}$ Additionally, the bill provides awards for compliance with the codes. ${ }^{381}$ Such incentives encourage industry compliance.

Were this Bill to be enacted, it would be an ideal way of implementing the measures that have already been outlined in this paper. Therefore, following consultation with the public and the food industry, the power to issue codes (or guidelines) provided for in Clause 81 , should be used to establish certain obesity control initiatives.

Initially, a nutrient profiling system code should be introduced to overcome any problems in deciding what food products fall into the category of unhealthy and are therefore subject to obesity initiatives. This code should:

- Set out the regime for profiling food products and specify what food products are to be profiled (namely pre-packaged food products, and food products sold by fast food restaurant exceeding a specified turnover, and exempting one off fundraisers/school events); ${ }^{382}$

- Set out how nutrient profiles are to be interpreted in the context of what represents a healthy or unhealthy food product;

- Set out exactly how nutrient profile is to be displayed (namely, the position on front-of-pack of a pre-packaged food product, and prominently on the menu of fast food restaurants), and the size and style of display (to avoid information overload);

- Establish a standard health logo, and the requirements a food product must fulfil before being allowed to display it; and

- Provide for a review (to include public consultation) of the code within a specified period of time, to assess its success in addressing obesity (for

\footnotetext{
${ }^{380}$ Ibid, cl 85(1)(a).

${ }^{381}$ Ibid, cl 86.

${ }^{382}$ See V C 1 (a)(i) Nutrient Profiling for New Zealand.
} 
example by analysing changes in purchasing patterns), address any issues that emerge during implementation, and to ascertain whether there has been industry compliance.

A separate labelling code should also be issued to deal with specific food product labelling requirements. This code should:

- Require the display of nutrient profile as set out in the nutrient profile code;

- Require display of all ingredients separately to the nutrient profile and in a different place (ideally the back-of-pack) on the product/menu (by keeping the nutrient profile on the front of pack on its own it will remain easy to spot and the will avoid the risk of information overload for consumers);

- Specifically exempt fundraisers, and one off events such as sausage sizzles in schools; and

- Provide for a review (to include public consultation) of the code within a specified period of time to assess its success addressing obesity, address any issues that emerge in the implementation of it, and to ascertain whether there has been industry compliance.

A separate advertising code should also be issued requiring advertising restrictions for certain food products aimed children. This code should:

- Define what food products are subject to advertising and sponsorship restrictions and other marketing initiatives aimed at children; namely according to nutrient profile;

- Define the word advertisement to include the various advertising media (for example the internet);

- Establish what marketing regimes are covered by the restrictions (for example, sports sponsorship, or other marketing initiatives such as those in schools outlined above);

- Define both the meaning of child for the purposes of advertising restrictions, and the scope of what is meant by aimed at children; 
- Provide for a review (to include public consultation) of the code within a specified period of time to assess its success addressing obesity, address any problems that emerge in the implementation of it, and to ascertain whether there has been industry compliance.

Codes or guidelines issued under the Bill would not be legally enforceable in any civil or criminal proceeding. This provision however, does not "preclude the admissibility in any proceeding that the provider of the goods ... did not comply with ... [a] code ... if that fact is relevant in the proceeding." ${ }^{, 383}$ Clause 88 requires a report on the codes/guidelines within 3 years to determine their success, level of compliance, and whether the law should be changed to make the codes binding. Therefore, Part 5 of the Bill provides, following consultation, regulation making powers if after two years a code or set of guidelines is not successful in "achieving its objective." 384 The regulations can be supported by criminal penalties, ${ }^{385}$ and are provided for the following purposes: ${ }^{386}$

(a) reducing, or assisting in reducing, risk factors:

(b) ... providing for the ways in which specified goods, substances, or services are advertised, sponsored, or marketed (whether directly or indirectly):

(c) ... providing for the information to be given to consumers of specified goods, substances, or services, whether as part of any advertising, sponsorship, or marketing or as part of any packaging or labelling of goods or substances:

(d) prescribing offences in respect of the contravention of noncompliance with any regulations made under this section, and the amounts of fines that may be imposed in respect of any such offences not exceeding $\$ 5,000$.

The permitted purposes of regulations also provide sufficient scope to legislate for nutrient profiling, labelling, and marketing control. Therefore, if the use of codes under the Bill does not, for example, facilitate the necessary industry changes it would be necessary to use the regulation making powers to mandate the

\footnotetext{
${ }^{383}$ Public Health Bill, above n 372, cl 87(2).

384 Ibid, cl 88A.

${ }^{385}$ Ibid, cl 88B.

${ }^{386}$ Ibid, cl 88C.
} 
requirements of the codes. The regulations should contain the same provisions as the codes, but would be able to draw from any experiences or problems that have been encountered in the use of them.

The provisions of the Bill would therefore ultimately provide the Government with powers to mandate regulatory labelling and advertising regimes for the food industry, which could be supported by criminal penalties.

The Bill's two tier approach to imposing regulation provides the opportunity to regulate the food industry with codes and guidelines that are not legally enforceable, before resorting to mandatory regulations. It is only if the industry were not cooperative that a more formal and stricter approach would be considered warranted, and only then after consultation had taken place. The consultation process would give the industry (and the general public) the opportunity to raise objections to any proposed and more formal regulation. This approach reduces the risk that draconian measures would be implemented without reference to the public or the industry; a fear of anti-paternalists.

\section{$3 \quad$ Future of the Public Health Bill}

The Public Health Bill was clearly intended to "establish a generic framework ... for dealing with non-communicable diseases"387 including obesity. In doing so it was complying with the WHO resolution that, inter alia: "member countries should: ... develop established programmes for the prevention and control of non-communicable diseases. ${ }^{388}$ It was well received by obesity action groups, but was not greeted favourably by the food industry in New Zealand. ${ }^{389}$

With the change of government since the Bill's introduction, it faces an uncertain future. As at 15 December 2010 the Bill was placed number 42 in the order paper having progressed no further in the parliamentary process since being

\footnotetext{
${ }^{387}$ Shaw, above n 98, 80 .

${ }^{388}$ PHAC, above n 8, 14.

${ }^{389}$ See Fight the Obesity Epidemic www.foe.org.nz/issues/public-health-bill (accessed 23 November 2010).
} 
reported back from Select Committee. ${ }^{390}$ The National Government has made it clear that it does not favour a paternalistic approach to combating obesity, indicating that it will "kill clauses in Labour's Public Health Bill that would have [inter alia] allowed the Health Ministry to control the composition, availability and advertising of certain foods. ${ }^{, 391}$ This does not bode well for those parts of the Bill designed to assist in the control of obesity. In adopting such an approach it is clear that the influences of the current eating environment on autonomy, and the possible addictive qualities of some foods, have been underestimated. Obesity is a public health issue. If those clauses in the Public Health Bill pertinent to obesity control do not survive through the parliamentary process, it will be a wasted opportunity to use the law to assist in obesity control.

Thus, New Zealand law has an essential role to play in regulating the eating environment. With better regulation of the food industry the law can help create a less obesogenic environment in a way that avoids a high level of paternalism. These measures (save for the possible imposition of a fat-tax) are directed at regulating the food industry more strictly, rather than forcing individuals to eat (or not to eat) certain food products. These measures also target obesogenic influences in the environment. The law is currently not being utilised in this way to combat rising obesity levels. Sadly, it may take some time before such regulatory measures are implemented (if at all) and, until such time as regulatory measures are in place, there may still be an role for tort law to play in influencing the eating environment. Litigation against fast food companies is a reality overseas, and has proved newsworthy. It is therefore worthy of some discussion in the context of the law and obesity control. The final chapter of the paper will examine whether litigation could have a part to play in controlling obesity in New Zealand.

\footnotetext{
${ }^{390}$ New Zealand House of Representatives Order Paper No 166 for Wednesday 15 December 2010 (New Zealand House of Representatives, Wellington, 2010). The Bill had actually moved down from number 40 since August 2010: Order Paper No 130 (provisional) for Tuesday 3 August 2010 (New Zealand House of Representatives, Wellington, 2010) 4.

391 "Tuckshop Free-for All Invites Obesity, say Greens" (7 February 2009) New Zealand Herald Auckland.
} 
Litigation against fast food companies by obese individuals, has hit the headlines and has proved to be a controversial issue, greeted cynically by the general public. Such litigation has been instigated in the United States by the obese claiming that their obesity is the fault of food companies. Despite the failure of such law suits, they have prompted food companies to take more responsibility for the products they sell, and have therefore served the purpose of changing the eating environment. Thus, whilst potentially providing redress for obese individuals, litigation also has the potential to change the obesogenic environment. Therefore its possible role in New Zealand will be examined. ${ }^{392}$

To date there has been no such litigation in New Zealand. Therefore, it is necessary to review the history of such litigation in the United States thus far, briefly.

\section{A Food litigation in the United States}

In the United States there have been several attempts to litigate against the food industry. As with many obesity related issues, the analogy between the litigation against tobacco companies and food manufacturers, has been made. Tobacco litigation is often viewed as "pav[ing] the way for litigation to be used as a tool ${ }^{\prime 393}$ to control obesity. Notwithstanding the fact that food litigation has not been successful to date, such cases have served a role, both in making the food industry more accountable, and in promoting better health by making the public aware of the dangers of overconsumption of certain foods. ${ }^{394}$

\footnotetext{
${ }^{392}$ For a detailed discussion see for example John J Zefutie Jr "Comment: from Butts to Big Macs - can the Big Tobacco Litigation and nationwide settlements with States' Attorneys General serve as a model for Attacking the Fast Food Industry?" (2004) 34 Seton Hall L Rev 1383; Frazier, above n 76, 273; Mello, Rimm and Studdert, above n 42.

${ }^{393}$ Frazier, above n 76, 291.

${ }^{394}$ See Frazier, above n 76, 291, and Mello, Rim and Studdert, above n 42.
} 
The first example of such food litigation was a class action in 2002 brought because McDonald's advertised its fries as cooked 100 per cent in pure vegetable fat, but had not informed consumers that its fries were precooked in beef fat. The claim was ultimately settled with McDonald's paying over US\$10 million to various organisations, and issuing a formal apology. ${ }^{395}$

The first claim relating to the obesity of the plaintiff was brought by Caesar Barber, and was a class claim against McDonald's, Burger King, Wendy's and Kentucky Fried Chicken. It claimed, inter alia, that the defendant's products caused obesity; the defendants should have known that the consumption of its products would cause obesity; and that they should have warned consumers. The claim did not proceed to trial. ${ }^{396}$ Pelman, an action by two girls against McDonald's, followed. ${ }^{397}$ Pelman was not successful, but it gave an indication to possible future litigants of the pleading that might be necessary for a successful claim; the judge stating, inter alia, that "an amended complaint ... [might] establish that the dangers of McDonald's products were not commonly well known and thus that McDonald's had a duty to warn its customers." ${ }^{398}$

Despite fast food actions being unsuccessful there was sufficient concern to prompt the United States Congress to introduce the Personal Responsibility in Food Consumption Act 2003 (also known as the Cheeseburger Bill) to prevent further fast food lawsuits. The United States Senate also introduced the Commonsense Consumption Act 2003. Neither of these Acts has been enacted. ${ }^{399}$

\footnotetext{
${ }^{395}$ See good discussion of fast food litigation in Raymond Perry "Hold the Fries!" (2003) 153 NLJ 1858; and media coverage of fries litigation: "McDonald's Supersizes Hindu Endowment" Hinduism Today www.hinduismtoday.com (Accessed 18 November 2008); and "Fast Food nation: an Appetite for Litigation" (4 June 2002) Independent United Kingdom 4.

396 Barber v McDonald's Corporation, Burger King Corporation, KFC Corporation, E/BA Kentucky Fried Chicken, and Wendy's International, Inc No 23145/2002, (NY Sup Ct filed 23 July 2002).

${ }^{397}$ Pelman, above n 104.

398 Pelman, above n 104, 536 Sweet J; see commentary in: J Wald "McDonald's Obesity Suit Tossed" (2003) CNN Money.com www.cnnmoney.com (accessed 21 January 2009); Perry, above n 48; and Lianne S. Pinchuk "Are Fast Food Lawsuits Likely to Be the Next 'Big Tobacco" (28 February 2007) Law.com www.law.com (accessed 5 August 2008)

${ }^{399}$ See discussion in: Burnett, above n 84.
} 
These fast food actions were much criticised by the public, as were actions against tobacco companies, when they were first initiated. Ultimately tobacco litigation gained public support and this may also prove to be the case with obesity related food litigation. ${ }^{400}$ There has been no fast food litigation in New Zealand, but there has been litigation against tobacco companies. Therefore notwithstanding the fact that it did not succeed, it is worth examining the analogy between tobacco and food products further, in this context.

\section{B Does tobacco litigation provide a model for fast food litigation?}

Obesity related litigation against the food industry and litigation against tobacco companies are often compared, because both "target enormous industries for large-scale public health problems allegedly caused, at least in part, by the industries' tortious distribution of harmful products."401 As already discussed, the general analogy between tobacco and food in the context of obesity is an appropriate one to make. Nonetheless, the differences in the nature of tobacco and food products have more significance in the context of the requirements for a successful tortious claim.

\section{$1 \quad$ Food as an addictive product}

Tobacco was proved to contain an addictive substance; nicotine. This was a significant issue in the litigation against the tobacco companies because tobacco companies lied about the addictive properties of tobacco, failed to warn consumers, and altered levels of nicotine to promote addiction. Despite this, tobacco companies attempted to argue that the use of its products was a matter of personal responsibility. This argument was spurious because their products were addictive and the industry was aware of this. ${ }^{402}$

As already discussed, it is highly possible that conclusive proof that food products are addictive will be a reality in the future. The food industry continues to argue that the consumption of its products, leading to obesity, is also a matter

\footnotetext{
${ }^{400}$ See discussion in: Mello, Rimm, and Studdert, above n 42.

${ }^{401}$ Burnett, above n 84, 381.

${ }^{402}$ See discussion in Frazier, above $n 76$.
} 
of personal responsibility. This argument is clearly flawed if food products are addictive (which is known to be the case for those containing caffeine). The personal responsibility argument is further flawed due the effect of obesogenic influences on autonomy.

\section{Chain of causation}

There is a proven link between consumption of tobacco and the resulting detrimental health effects. Since obesity has a variety of causes it is extremely hard to prove that a particular food product, for example, a certain brand of fast food, was the cause of an individual's obesity. Additionally, food products "all foods have certain nutritional and caloric value necessary to sustain life unlike tobacco, which has no essential physiological value." ${ }^{, 403}$ Therefore, establishing a causal link between a particular food product and obesity would be extremely difficult. This was not the case with tobacco. ${ }^{404}$

\section{$3 \quad$ Range of food products, manufacturers and outlets}

Tobacco is a discrete product produced by an easily identifiable number of companies and therefore it was easy to identify the appropriate defendants in a legal action. This would not be so straight forward in the case of an obesity related food action. This is because there are many food products and manufacturers ranging from the large corporate to the corner dairy, the local cafe, and even a school canteen or charity sausage sizzle. The variety of manufacturers would make it extremely difficult to target a particular defendant or defendants for a legal action, given that a particular instance of obesity is likely to be due to a diet containing many different food products. ${ }^{405}$

In the context of the potential for litigation, the analogy between the consumption of tobacco and unhealthy foods is limited by the differences in the nature of the products. Litigation against the food industry therefore presents

\footnotetext{
${ }^{403}$ Burnett, above n 84, 381 .

${ }^{404}$ Discussed in Brownell and Warner, above n 61; and Burnett, above n 84.

${ }^{405}$ Ibid.
} 
quite different challenges. The possibility of such litigation in New Zealand will now be examined.

\section{Food litigation: a possibility in New Zealand?}

There is a possibility that litigation could also be used as a tool to change the eating environment in New Zealand. This is something that might be especially important should the appropriate regulatory structures not be implemented.

The idea of obesity related food litigation in New Zealand might be considered an outrageous prospect. As noted above, the public were initially similarly outraged by idea of suing the tobacco companies. There has to date, been no fast food litigation in New Zealand, but litigation has been initiated against tobacco companies; for example, Brandon Pou and Kasey Pou v British American Tobacco (New Zealand) Limited and WD \& H O Wills (New Zealand) Limited. ${ }^{406}$

This case was brought by a Mrs Pou who died at the age of 52 of lung cancer, having been a heavy smoker since the age of 17 . She had started smoking in 1968 prior to the date that the defendants starting displaying health warnings on cigarette packets (in 1974). She commenced proceedings against British American Tobacco (BAT) and Wills, alleging that these companies had breached duties of care in selling and distributing cigarettes. She claimed that these breaches made her start smoking, which ultimately caused her lung cancer. ${ }^{407}$ After Mrs Pou's death the claim was continued by her children as executors of her estate.

\footnotetext{
${ }^{406}$ Brandon Pou and Kasey Pou v British American Tobacco (New Zealand) Limited and W D \& H O Wills (New Zealand) Limited (3 May 2006) HC AK CIV2002-404-1729 Lang J.

${ }^{407}$ Ibid, para 3, Lang J.
} 
Mrs Pou claimed that the defendants breached duties of care "by failing to warn of the likely consequences of smoking cigarettes and by failing to stop manufacturing and distributing cigarettes"408 once they were aware of the dangers. She claimed that these breaches caused her to take up smoking and become addicted to cigarettes. As a result she could not stop smoking and contracted lung cancer "developed as a direct result of the fact that she smoked the defendants' cigarettes.",409

Thus it was necessary for her to establish that the defendants owed Mrs Pou a duty of care, namely: ${ }^{410}$

1. Did the defendants know, or ought they reasonably have known, that by 1968 smoking cigarettes:

a) was a major cause of lung cancer; and

b) could be addictive, or hard to give up.

2. If they did, was there any duty on them to cease producing cigarettes and to withdraw them from sale?

3. If there was not, was any duty to warn of those risks negated by the fact that:

a) the dangers of smoking cigarettes were obvious; or

b) the dangers of smoking cigarettes were common knowledge in 1968.

It was also necessary to establish causation and that, if the appropriate health warnings had been used in 1968, Mrs Pou would not have commenced smoking. Additionally, the Court had to decide whether her continued smoking, after warnings were placed on cigarette packets in 1974, constituted contributory negligence or constituted a waiver of her legal rights by voluntarily accepting the risks of smoking.

\footnotetext{
${ }^{408}$ Ibid, para 6(1) Lang J.

${ }^{409}$ Ibid, para 6(m) Lang J.

${ }^{410}$ Ibid, para 7 Lang J.
} 
The claim against Wills did not succeed as, on the balance of probabilities, causation could not be established. In relation to the duty of stop manufacturing and distributing cigarettes, the Court held that BAT (and Wills) had never had such a duty, ${ }^{411}$ and that to impose this duty would amount to "judicial prohibition of a product that, to this day, has always been sold legally.",412

In relation to the duty to warn, the Court held that the defendants were aware of the dangers of tobacco when Mrs Pou took up smoking in 1968, and that there was a prima facie duty to warn of these dangers. This did however, not at that time, include a duty to warn that cigarettes were addictive. ${ }^{413}$ Nonetheless, despite the Court's decision that a prima facie duty to warn existed, it held that the plaintiff's claim should fail because the dangers of smoking were common knowledge in 1968, and she would have been aware of them. Therefore because of this knowledge, the defendants could not be liable for a failure to warn. ${ }^{414}$

Notwithstanding that the defendants were not liable for a failure to warn, they were also not liable because the plaintiff did not establish causation. The Court held that any failure to warn on the defendants' part did not cause Mrs Pou's lung cancer because she could not establish that she would not have started smoking if she had been warned of the dangers when she commenced smoking in 1968. Furthermore, once she had been warned of the dangers (in 1974 when the health warnings were displayed on the cigarettes) she continued to smoke and this therefore broke the chain of causation. ${ }^{415}$

Thus, this claim against the tobacco companies did not succeed. Nonetheless a prima facie duty to warn was established (notwithstanding that the plaintiff's knowledge was in this case held to nullify the duty in this instance). Despite the failure of the tobacco claim in New Zealand in these particular

\footnotetext{
${ }^{411}$ Ibid, para 8(2) Lang J.

412 Ibid, para 22 Lang J.

${ }^{413}$ Ibid, paras 33-43 Lang J.

414 Ibid, paras 44-62 Lang J.

${ }^{415}$ Kate Tokeley "Case Note: Pou v British American Tobacco (NZ) Ltd - A Comprehensive Win for the New Zealand Tobacco Industry” (2006) 14 Waikato L Rev 136, 141.
} 
circumstances, it is worth examining whether a similar obesity related could be attempted in New Zealand and whether it might enjoy any success.

\section{$1 \quad$ A tortious claim and the Accident Compensation Act 2001}

New Zealand has a statutory bar on certain personal injury litigation under its accident compensation scheme provided for by the Accident Compensation Act (ACA). The majority of personal injury claims in New Zealand are statute barred, and in order to bring an obesity related food claim it must be one that falls outside the Act. ${ }^{416}$

Obesity is a condition that is caused gradually. The ACA provides that any personal injury caused by a "gradual process, disease, or infection" 417 is only covered if it falls within the possibilities listed in section 20 (2) (e)-(h) that is a: ${ }^{418}$

- personal injury caused by a work-related gradual process, disease, or infection suffered by the person: or

- $\quad$ personal injury caused by a gradual process, disease, or infection that is treatment injury suffered by the person or

- $\quad$ personal injury caused by a gradual process, disease, or infection consequential on personal injury suffered by the person for which the person has cover or

- $\quad$ personal injury caused by a gradual process, disease, or infection consequential on treatment given to the person for personal injury for which the person has cover.

Obesity that is caused, for example, by eating too much of a particular food type, does not fall within any of these categories and is not an injury covered by the ACA. Therefore, an obesity related action would not be statute barred. Having established that such an action would not be statute barred, various elements would have to be satisfied in order to make a successful claim. ${ }^{419}$

\footnotetext{
${ }^{416}$ Accident Compensation Act 2001, (formerly known as: Injury Prevention, Rehabilitation and Compensation Act 2001) s 317(1).

${ }^{417}$ Ibid, s 20(2)(e)-(h).

${ }^{418}$ Ibid, s 20(2)(e)-(h)

${ }^{419}$ See fuller discussion in: Kate Tokeley “Tobacco Litigation” (1997) October NZLJ 346, 347.
} 
To mount a successful negligence claim against a food manufacturer the plaintiff would also have to establish that:

- The food manufacturer owed the plaintiff a duty of care; and

- This duty of care had been breached; and

- The breach caused the personal injury.

(a) Do food manufacturers owe a duty of care?

A food manufacturer owes a duty to take reasonable care to those who purchase and consume its goods. ${ }^{420}$ The Court in Pou, held that this could include a prima facie duty to warn "consumers or users about the product's potentially harmful qualities or dangerous propensities." 421 This duty of care relates to dangers that would be reasonably foreseen when purchasing and consuming the particular product concerned. In Pelman, Judge Sweet noted that: ${ }^{422}$

\footnotetext{
Many products cannot possibly be made entirely safe for all consumption, and any food or drug necessarily involves some risk of harm, if only from over-consumption. ... The article sold must be dangerous to an extent beyond that which would be contemplated by the ordinary consumer who purchases it, with the ordinary knowledge common to the community as to its characteristics. Good whiskey is not unreasonably dangerous merely because it will make some people drunk, and is especially dangerous to alcoholics; but bad whiskey, containing a dangerous amount of fuel oil, is unreasonably dangerous.
}

Therefore, food manufacturers owe a duty of care to ensure that products are safe for consumption, but the duty only extends to dangers that would be reasonably contemplated when purchasing and consuming them.

\footnotetext{
${ }^{420}$ Donoghue v Stevenson [1932] AC 562 (HL).

${ }^{421}$ Brandon Pou and Kasey Pou v British American Tobacco (New Zealand) Limited and W D \& HO Wills (New Zealand) Limited, above n 402, para 33 Lang J

${ }^{422}$ Pelman, above n 104, 531 Sweet J.
} 
Therefore, in order to establish a breach of this duty, any claim would have to show that the particular food products involved were intrinsically dangerous. It might be argued that for some food products this is in fact the case due to the nature of the ingredients. For example, the ordinary consumer is likely to be unaware of the high levels of salt, fat, or sugar (and in some cases caffeine) in unhealthier food products. This is an argument that is unlikely to succeed unless a conclusive link is established between addiction and ingredients of this nature. If such a link was established it might be possible to argue successfully that such foods have been rendered intrinsically dangerous because of the high levels of such ingredients. Additionally, it could also be argued that many unhealthy foods have been so highly processed that they no longer resemble the product that the consumer expecting and that therefore, such foods have been rendered intrinsically dangerous.

(i) Are some food products more dangerous than consumers might reasonably expect?

It has been argued that some foods, for example, fast foods, are intrinsically "dangerous in a way other than that which [is] open and obvious to a reasonable consumer," ${ }^{423}$ due to the level of processing involved during manufacture. In such instances, it could be argued that such foods are intrinsically dangerous, and that "consumers are not actually getting what they think they are buying., ${ }^{424}$ If this is correct it could mean that some form of warning to the public is appropriate in order to fulfil the manufacturer's duty of care. This argument was one that found some favour in Pelman, in which the Judge indicated that the plaintiffs might demonstrate that a duty of care was owed if they could, "establish that the dangers of McDonalds' products were not commonly well known." ${ }^{, 425}$ As stated by District Judge Sweet the notion of free choice must be exactly that: ${ }^{426}$

\footnotetext{
423 Ibid.

${ }^{424}$ British Medical Association Board of Science, above n 100, 28.

${ }^{425}$ Pelman, above n 104, 536 Sweet J.

${ }^{426}$ Ibid, 533 Sweet J.
} 
As long as a consumer exercises free choice with appropriate knowledge, liability for negligence will not attach to a manufacturer. It is only when that free choice becomes but a chimera ... that manufacturers should be held accountable.

(b) Have manufacturers of foods believed to contribute to obesity breached the duty of care?

Unless a conclusive link between food products and addiction was established it would be extremely difficult to demonstrate that, merely because excessive quantities of a certain food product had been consumed leading to obesity, a duty of care had been breached. Many foods themselves are not dangerous per se as, when eaten in sensible quantities, they are not necessarily unhealthy or unsafe and will not cause obesity. This is not necessarily the case for food products containing caffeine (an additive that is both addictive and potentially harmful), or for other food products with certain ingredients, should a link between food and addiction be established. For such products it could be argued that, there had been a breach of a duty to warn. ${ }^{427}$

Therefore, it might be possible to establish that a duty to warn had been breached if it could be demonstrated that a manufacturer knew of the possibility of addiction to its products because of the nature and levels of certain ingredients, (and the inevitable over-consumption that this would lead to), and failed to warn the public. This argument would be particularly strong for caffeinated foods. ${ }^{428}$ Caffeine is also added to other foods and it is possible that "the degree to which industry intentionally manipulates caffeine to maximize consumption, especially by children, could emerge as an issue." ${ }^{29}$ This not only strengthens any analogy with tobacco, but also infers a degree of knowledge on the part of food manufacturers to the possibility of addiction to such products. The prospect that foods may be addictive could negate any defence based on the idea of personal responsibility, that is, that there had been contributory negligence on the part of

\footnotetext{
${ }^{427}$ Cantu, above n 136.

${ }^{428}$ See also the discussion in: Griffiths and Vernotica, above n 81; Frazier, above n 76; and Tokeley, above $\mathrm{n} 415$.

${ }^{429}$ Brownell, and Warner, above n 61, 281; see also the discussion in Center for Science in the Public Interest, above n 82 .
} 
the person who continued to consume the products. It is interesting to note however that the Court in Pou did not "take into account the possibility that Mrs Pou's addiction and failure to quite were, at least in part by the defendant's misconduct ... failing to warn about the dangers and likelihood of addiction."

Therefore, there is little chance of establishing a breach of a duty of care.

\section{(c) Food products and causation}

Since there are many factors that contribute to obesity it would be hard to establish that an individual's obesity was a result of consuming a particular manufacturer's product. Furthermore, it is unlikely that a person will consume one particular food item to the exclusion of all others. Therefore, demonstrating a causal link with a particular product would be extremely difficult, if not impossible. Furthermore given the decision in Pou that the continued smoking of Mrs Pou broke the chain of causation it might prove difficult to persuade the court otherwise by arguing that the products in question were addictive.

Given the potential difficulties in demonstrating causation, and a breach of the duty of care, the chances of a tortious food claim succeeding in New Zealand are slim.

A tortious claim does not represent the only means of initiating an action against the food industry, as there is scope for action when food products breach New Zealand consumer laws; for example, the Fair Trading Act.

${ }^{430}$ Tokely, above n 411, 141. 
The purpose of the Fair Trading Act is "to prohibit certain conduct and practices in trade, to provide for the disclosure of consumer information relating to the supply of goods and services and to promote product safety." ensures that measures are in place to prevent New Zealand consumers from being deceived by the sellers of goods and services.

The provisions of the Fair Trading Act make it a criminal offence to "engage in conduct that is misleading or deceptive or is likely to mislead or deceive."432 The Act's provisions are supported by criminal penalties that provide a strong incentive for companies not to engage in deceptive market practices. $^{433}$

Food related cases brought under the Fair Trade Act to date have not been due to obesity. Some of the issues litigated are however, relevant particularly when misrepresentations are made about the health merits of a product. For example, a misleading health claim such as the use of the words fat free made in Commerce Commission v Pacific Dunlop Holdings (NZ) Ltd ${ }^{434}$ when the Commerce Commission held, inter alia, that the words fat-free misled the consumer to believe that this was a product healthier than others, which was not the case. ${ }^{435}$ Another similar case Commerce Commission v Griffins Foods Ltd ${ }^{436}$ involved the use of the word "slims" on a product. In this case it was held however, that insufficient members of the general public would be misled by the use of the word. ${ }^{437}$

These cases and others like them illustrate the use of the Fair Trading Act as a tool to ensure that manufacturers and retailers do not make deceptive health

\footnotetext{
${ }^{431}$ Fair Trading Act 1986.

${ }^{432}$ Ibid, s 9

${ }^{433}$ Ibid s 40.

${ }^{434}$ Commerce Commission v Pacific Dunlop Holdings (NZ) Ltd (17 March1997) HC CHCH CRN6009009602-3 Abbot J.

${ }^{435}$ Brookers Online Library, Statutes Database, Fair Trading Act, s10, Commentary, Gault on Commercial Law, FT10.06 Liable to mislead; nature and characteristics (1)-(4), (2).

${ }^{436}$ Commerce Commission v Griffins Foods Ltd (5 September 1997) DC Ak CRN5009042565 Boshier J.

437 Brookers online Library, above $\mathrm{n}$ 431, Commentary, Liable to mislead; nature and characteristics (1)-(4), (3).
} 
claims about products. As the Fair Trading Act is a means of preventing misleading and deceptive conduct (for example, cases such as the first fast food action regarding the misrepresentation about the type of fat in which McDonald's cooked its fries), its use would be limited as a legal means of fighting obesity through litigation. Nonetheless, it might be possible to attempt a claim under the Fair Trading Act by attempting to demonstrate that a food manufacturer had, due to the processed nature of its products, engaged in misleading or deceptive conduct.

Nonetheless, despite the difficulties in establishing a successful claim against the food industry, the mere threat of action or an unsuccessful attempt at bringing a claim could, in itself, serve a purpose, by ensuring that manufacturers take steps to protect themselves from the possibility of any future claims. For example, by taking more care in the information provided about their products, giving warnings about overconsumption, altering marketing strategies and by altering certain ingredients to make products healthier. This type of industry response has already occurred overseas (for example, the action taken by Kraft Foods following the initiation of litigation due to "failure to list the trans fat content of its Oreo biscuits"438). An obesity related food claim in New Zealand, represents an expensive option for the individual consumer who would be ill advised to instigate an action with so little prospect of success. Therefore its role in improving/changing the obesogenic environment in New Zealand is limited. It is unlikely that fast food litigation has any future in New Zealand, even as the legal solution of last resort in an insufficiently regulated food environment. ${ }^{439}$

\footnotetext{
${ }^{438}$ Reynolds, above n 7, 165.

${ }^{439}$ Useful discussion of the role of litigation in the absence of regulation in ibid.
} 


\section{CONCLUSION}

The world is in the midst of an obesity epidemic, with New Zealand already in the unenviable position of being a world leader in obesity rates. Particularly alarming is the rate of obesity amongst children. High levels of obesity are due to a lifestyle of eating the wrong foods in excess and insufficient exercise. This has resulted from the evolution of the eating environment, due a variety of obesogenic influences, into one in which it is easier to lead an unhealthy lifestyle. These influences include aggressive marketing of certain food products, lack of appropriate, standardized and user friendly nutritional information on labels, cheaper and more accessible junk foods, and the very real possibility that some foods are addictive. The health, economic, and social ramifications of obesity for New Zealand are extremely serious, and will ultimately affect the entire population. An analogy has frequently been made between the consumption of tobacco and the consumption of certain food products leading to obesity. This analogy is a valid one to make, although it does have some limitations given the difference in the nature of the products themselves. The analogy is an extremely useful one, and approaches to obesity control can draw on the experiences with tobacco products.

It is therefore essential that measures are taken immediately to control obesity in New Zealand. The law has an essential part to play in this by providing the appropriate structures to regulate the food industry, and for the implementation of a fat-tax regime.

Legal measures for obesity control are frequently (and successfully) opposed on paternalistic grounds. Such opposition is raised in the face of measures that employ both a hard and soft paternalistic approach. It is therefore essential to be able to justify a level of paternalism for the sake of obesity control, even if the proposed measures are not overly paternalistic in nature, in order to deal with such opposition.

Due to the threat that obesity poses to both individual and community health and public resources, coupled with a lack of autonomy in the current eating 
environment, a paternalistic approach to obesity control is justified. This is particularly so when implementing obesity control measures aimed at children, who are a particularly vulnerable group, and therefore deserving of a higher level of protection. Paternalistic measures to protect this significant portion of the population are therefore fully justified even in situations where such measures would be considered draconian from an adult perspective.

Notwithstanding such justifications for the use of paternalism, it is currently not necessary to adopt a hard paternalistic approach to obesity control in New Zealand. By using the law to improve the regulation of the food industry, rather than its use to force individual eating choices, a healthier environment can be created. The regulation of the food industry requires immediate change to mandate for more relevant and accurate information to be disseminated about food products.

Current labelling of food products in New Zealand is predicated on the prevention of misrepresentation and fraud, and is of very little use to the average consumer in making decisions based on health. This requires change by amending the labelling requirements to mandate for more nutritionally relevant information that can be understood at a glance by consumers. This should include the mandatory display of a nutrient profile on the front-of-pack for certain food products. The labelling requirements should be mandatory for pre-packaged food products, and restaurant/fast food chains that exceed a specified turnover only. This will avoid imposing compliance costs on smaller businesses. For many of products that such a regime would include, the nutritional information is already be available, and would merely require reformulating.

Additionally, for some products (caffeinated sweetened soft drinks being a strong candidate), the use of a health warning pointing out the risks (and when appropriate the risk of addiction) of overconsumption is appropriate. A universal health warning on unhealthy food products is however, not necessary at this time. This must however, be kept under review, particularly as studies linking food products and addiction continue to emerge. Whether or not food is addictive 
could prove to be crucial element in persuading the public and government to implement regulatory measures. This is because attitudes to the obesity epidemic are likely to change a great deal if a link between certain food products and addiction is conclusively established.

The food industry spends significant sums of money on marketing with the intention of increasing consumption. Studies show that this is a significant influence in the current eating environment, encouraging consumption of foods that are unhealthy. This influence is particularly significant for children who are too young to understand marketing's influences and manipulative potential. Legal regulation of food marketing to children is therefore an urgent priority. New Zealand's reliance on self-regulation is no longer appropriate, not least due to the obvious conflict of interest in an industry setting and adjudicating its own standards.

Such regulatory restrictions must be mandated by statute and administered by an independent body. Regulation must ensure that there are strict controls on marketing of unhealthy food products to children that extend beyond television coverage and include other marketing techniques (such as the internet, sports sponsorship and school based programmes). Rules should take a realistic approach to marketing campaigns that are not strictly intended for a young audience, to ensure that marketers do not seek to avoid rules by claiming that their campaigns are intended for adults. Given overseas experiences and industry reaction to proposed measures in the Public Health Bill, this will not necessarily prove a popular policy, but given the threat to children posed by the obesity epidemic, it is an essential one. Although a legal restriction on advertising is a limitation of freedom of expression provided for in the New Zealand Bill of Rights Act, this restriction is justified because it can be "reasonably and demonstrably justified in a free and democratic society," ${ }^{, 40}$ and restricting advertising in this way is a proportional response in the context of the potential harm that such advertising poses to children. ${ }^{441}$

\footnotetext{
${ }^{440} R v$ Oakes, above n 304.

${ }^{441}$ Ibid.
} 
An essential preliminary step in improving food product information is the development of a universal nutrient profiling system for New Zealand. All obesity control measures require a method of food classification to determine whether or not a particular product should subject to the requirements of increased regulation. Such a system would therefore allow certain food products to be consistently and reliably categorised. To ensure that such a system is universal, it would be necessary to legislate for it to mandate profiling for pre-packaged foods and food products sold by fast-food restaurants exceeding a certain turnover.

Improved labelling, marketing regulation and a nutrient profiling system could all be achieved via new legislation, existing food legislation, or via inclusion in public health legislation. The Public Health Bill 2007, ${ }^{42}$ if enacted, would provide a mechanism for the implementation of such legislation.

The implementation of a fat-tax would also target one of the environmental influences causing obesity; namely price disparity between unhealthy and healthy foods (the former often being cheaper). Revenue could be used to help offset the costs of other obesity control measures or to subsidise healthier options. It is often thought to be too paternalistic a way of controlling obesity, but this is not the case given the lack of autonomy in the current eating environment, and the fact that consumers would still be free to choose unhealthy food products notwithstanding the fact that they would be more expensive, once a fat-tax is levied. The use of a fat-tax can also be viewed as a way to counteract the various environmental influences, and a way to pass some of the obesity related costs on to those who consume unhealthy food products in excess.

A realistic option for a fat-tax in New Zealand would be the use of the current GST regime, by taxing a specific type of food product (being those more notoriously associated with obesity, for example, soft drinks or particular brands of fast food), or by levying a fat-tax on those products with an unhealthy nutrient profile. A fat-tax would inevitably penalise some individuals who do not eat an excess of unhealthy foods, however not imposing such a tax would result in reduced access to public services in the future and therefore this is a trade-off that

${ }^{442}$ Public Health Bill, above n 372. 
public should be persuaded to make. Furthermore, this effect would be ameliorated by using the revenue to subsidise healthy food products

Food litigation, by the obese against food companies, has become a reality in other jurisdictions. Nevertheless, a tortious action of this nature in New Zealand faces little prospect of success. Therefore, the use of litigation to force change in the current environment in the absence of the appropriate regulatory measures, is not a realistic prospect.

New Zealand as a world leader in obesity levels is already a frightening reality and there is an urgent need for steps to control it. New Zealand law can provide the appropriate regulatory regimes to change the current environment and in doing so help control obesity. There is no reason why, with the use of such measures, New Zealand cannot become a world leader in measures to control obesity rather than a leader in obesity rates. 
XI BIBLIOGRAPHY

I PRIMARY SOURCES

A Legislation

$1 \quad$ New Zealand

(i) Statutes

Accident Compensation Act 2001.

Consumer Guarantees Act 1993.

Defamation Act 1992.

Education Act 1989.

Fair Trading Act 1986.

Food Act 1981.

Goods and Services Tax Act 1985.

Health Act 1956.

Human Rights Act 1993.

Immigration Act 1987.

Misuse of Drugs Act 1975.

New Zealand Bill of Rights 1990.

New Zealand Health and Disability Act 2000.

Sale of Liquor Act 1989.

Securities Act 1978.

Sentencing Act 2002.

Smoke Free Environments Act 1990. 
(ii) Regulations

Land Transport (Road User) Rule 2004 (SR 2004/417).

(iii) Bills

Food Bill 2010, no 160-2.

Goods and Services Tax (Exemption of Healthy Food) Amendment Bill 2010, no 140-1.

Public Health Bill 2007, no 77-2.

2 Canada

(i) Statutes

Consumer Protection Act RS Q c P-40.1.

Food and Drugs Act RS C 1985 c F-27

Canadian Charter of Rights and Freedoms (Part 1 of Constitution Act RS C c-11 1982).

Quebec Charter of Human Rights and Freedoms RS Q c-12.

(ii) Regulations

Food and Drug Regulations (CR C, c. 870).

$3 \quad$ United Kingdom

(i) Statutes

Communications Act 2003. 
Food Safety Act 1990.

(ii) Regulations

Food Labelling Regulations 1996 (SI No 1499).

$4 \quad$ United States

(i) Acts

Federal Food Drug and Cosmetic Act 21 USC 301.

(ii) Bills

Common Sense Consumption Act 2003.

Personal Responsibility in Food Consumption Act 2003.

Bill to amend the Federal Food, Drug, and Cosmetic Act to prescribe nutrition labeling of foods and other purposes (introduced 1989).

(iii) Regulations

United States Code of Federal Regulations Title 21 Food Labeling parts 100 to 169 and parts 170 t 199.

\section{B Cases}

$1 \quad$ New Zealand

Brandon Pou and Kasey Pou v British American Tobacco (New Zealand) Limited and WD \& H O Wills (New Zealand) Limited (3 May 2006) HC AK CIV2002404-1729 Lang J. 
Commerce Commission v Pacific Dunlop Holdings (NZ) Ltd (17 March1997) HC CHCH CRN6009009602-3 Abbot J.

Commerce Commission v Griffins Foods Ltd (5 September1997) DC Ak CRN5009042565 Boshier J.

Hansen $v R$ [2007] 3 NZLR 1 (SCNZ).

$2 \quad$ Canada

$R v$ Chaulk [1992] 3 SCR 1303.

Irwin Toy Ltd v Quebec (Attorney General) [1989] SCR 927 para 17.

$R v$ Oakes [1986] SCR 103 para 14.

$3 \quad$ United Kingdom

Donoghue v Stevenson [1932] AC 562 (HL).

$4 \quad$ United States of America

Barber v McDonald's Corporation, Burger King Corporation, Kentucky Fried Chicken, and Wendy's International, Inc No 23145/2002, (NY Sup Ct filed July 23 2002).

Pelman v McDonald's Corp. (2003) 237 F.Supp.2d, 512 (SDNY).

\section{Standards}

Food (Imported Milk and Milk Products) Standard 2009.

Food (Prescribed Foods) Standard 2007.

Food (Tutin in Honey) Imported Food Standard 2008.

Food (Tutin in Honey) Standard 2008.

Food (Uncooked Comminuted Fermented Meat) Standard 2008. 
New Zealand (Australia New Zealand Food Standards Code) Food Standards 2002.

New Zealand (Bee Product Warning Statements - Dietary Supplements) Food Standards 2002.

New Zealand Food (Supplemented Food) Standard 2010.

New Zealand Food (Supplemented Food) Standard 2010.

New Zealand (Mandatory Fortification of Bread with Folic Acid) Food Standard 2007.

New Zealand (Maximum Residue Limits of Agricultural Compounds) Food Standards 2010.

\section{Conventions}

United Nations Convention on the rights of the child UNGA Doc A/RES/44/25 (12 December 1989).

\section{E Codes}

Advertising Standards Authority (ASA) Children's Code for Advertising Food (ASA, Wellington, 2010).

ASA Code for Advertising to Children (ASA, Wellington, 2010).

ASA Code for Advertising of Food (ASA, Wellington, 2010).

\section{F Rulings}

ASA Complaint number 08/100 (26 February 2008); Complainant: D Murtagh; advertisement: McDonald's Family Restaurants.

ASA Complaint number 08/241 (10 June 2008); Complainant: M Apa; advertisement: Bluebird Chippies "Rugby Superstars" Promotion. 


\section{G Guidelines}

New Zealand Broadcasters Council Advertising on Television: Getting it right for Children (New Zealand Broadcasters Council, Auckland, 2008) (available at www.nztbc.co.nz (accessed 5 June 2010)).

\section{SECONDARY SOURCES}

A Texts

Alcohol Advisory Council of New Zealand Alcohol.org.nz: The newsletter of the Alcohol Advisory Council of New Zealand Volume 1 (Alcohol Advisory Council of New Zealand, Wellington, 2000).

Alcohol Healthwatch Alcohol Health and Safety Advisory Statements (Warning Labels) in New Zealand: Briefing Paper 2003 (Alcohol Health Watch, Wellington, 2003).

ASA Bugger, it's okay - the case for Self-Regulation (ASA,Wellington) (available at www.ASA.co.nz (accessed 6 July 2010)).

ASA Final report on the Review of the Code for Advertising to Children and the Code for Advertising of Food (ASA, Wellington, 2010).

British Medical Association Board of Science Preventing Childhood Obesity (British Medical Association, England, 2005).

The Broadcast Committee of Advertising Practice Television Advertising Standards Code (The Broadcast Committee of Advertising Practice, England, 2002).

Centre for Science in the Public Interest (CSPI) Caffeine Content of Food and Drugs (CSPI, United States, 2007).

CSPI Taxing Sugared Beverages would help trim State Budget Deficits, Consumers' Bulging Waistlines, and Health Care Costs (CSPI, United States, 2009).

Centre for Social Marketing, University of Strathclyde (CSM), Review of Research on the Effects of Food Promotion to Children, Final Report (CSM, Scotland, 2003)

Collins, David and Helen Lapsley The Economics of Tobacco Policy (David Collins and Helen Lapsley, Australia, 2002). 
Consumer NZ, Consumer Report 'Food Labelling' (Consumer NZ, 2006, Wellington) (highlights at www.consumer.org.nz (accessed 27 October 2009)).

Currie, Janet, Stefano DellaVigna, Enrico, Moretti and Vikram Pathania The Effect of Fast Food Restaurants on Obesity and Weight Gain (National Bureau of Economic Research, United States, 2009).

Diabetes New Zealand and Fight the Obesity Epidemic, Inc. Cutting the Fat: How a Fat Tax can Help Fight Obesity (Diabetes New Zealand and Fight the Obesity Epidemic Inc, Nelson, 2004).

United Kingdom Department of Trade and Industry (DTI) Extending Competitive Markets: Empowered Consumers, Successful Business (DTI, United Kingdom, 2004).

European Food Safety Authority [EFSA] The Setting of Nutrient Profiles for Foods Bearing Nutrition and Health Claims Pursuant to Article 4 of the Regulation (EC) No 1924/2006: The EFSA Journal (2008) 644, 1-44 Scientific Opinion of the Panel on Dietetic Products, Nutrition and Allergies (EFSA, Parma, 2008).

Food Label Review Issues Consultation Paper: Food Labelling Law and Policy Review (Food Label Review, Australia, 2010).

Fight the Obesity Epidemic (FOE) Information Sheet: The Public Health Bill: Why Submissions are Very Important (FOE, New Zealand, 2008).

FOE Responses of New Zealand Political Parties to Questions about Obesity Prevention (FOE, Wellington, 2008).

Goldman, Dana, Darius Lakdawalla and Yuhui Zheng Food Prices and the Dynamics of Body Weight (National Bureau of Economic Research, Massachusetts, United States, 2009).

Harker, Debra and Michael Harker Review of Advertising's Role in Diet and Exercise in New Zealand and Australia: Developing a Research Agenda (FOE, Wellington, 2007).

Hastings, Stead, McDermott, Forsyth, MacIntosh, Raynor, Godfrey, Caracher and Angus Review of Research on the Effects of Food Promotion to Children (Food Standards Agency, United Kingdom, 2003).

Health Select Committee Inquiry into Obesity and Type 2 Diabetes in New Zealand (Parliament, Wellington, 2007).

Jacobson, Michael F Liquid Candy: How Soft Drinks Are Harming Americans' Health (CSPI, Washington DC, 2005). 
Leatherhead Food International Evaluating the Impact on Business of Changes to Nutrition Labelling Requirements in the UK (Leatherhead Food International, United Kingdom, 2003).

Livingstone, Sonia A Commentary on the Research Evidence Regarding the Effects of Food Promotion on Children (United Kingdom Department of Media and Communications, London, 2004).

Lu, Yang and Dana Goldman The Effects of Relative Food Prices on Obesity Evidence from China 1991-2006 (National Bureau of Economic Research, Massachusetts, United States, 2010).

John Stuart Mill On Liberty (Longman, Roberts \& Green, New York, 1869).

Ministry of Health (MOH) A Portrait of Health: Key results of the 2002/03 New Zealand Health Survey (MOH, Wellington, 2004).

MOH A Portrait of Health: Key results of the 2006/07 New Zealand Health Survey (MOH, Wellington, 2008).

MOH Food and Nutrition Guidelines for Healthy Adults: A Background Paper (MOH, Wellington, 2003).

MOH Looking Upstream: Causes of Death Cross-classified by Risk and Condition (MOH, Wellington, 1997).

MOH Food and Nutrition Guidelines for Healthy Children Aged 2-12 Years (MOH, Wellington 1997).

MOH The Food and Beverage Classification System Nutrient Framework for Schools (MOH, Wellington, 2008).

MOH Tobacco Tax -The New Zealand Experience (MOH, Wellington, 2000).

Ministry of Youth Development Third and Fourth Periodic Report for the United Nations Committee on the Rights of the Child (Ministry of Youth, Wellington, 2008).

National Health Committee Public Health Advisory Committee Advice on Obesity Inquiry (National Health Committee, Wellington, 2006).

New Zealand Food Safety Authority (NZFSA) Caffeine Intake and Effects Studied (NZFSA, Wellington, 2010).

NZFSA Health, Nutrition and Related Claims: Enabling Provisions in New Zealand Law: NZFSA Public Discussion Document No 04/07 (NZFSA, Wellington, 2007). 
New Zealand Government New Zealand Submission on Food Labelling and Policy Review (New Zealand Government, Wellington, 2010).

New Zealand House of Representatives Inquiry into Obesity and Type 2 Diabetes in New Zealand Report of the Health Committee (New Zealand House of Representatives, Wellington, 2007).

New Zealand House of Representatives Order No 130 (provisional) for Tuesday 3 August 2010 (New Zealand House of Representatives, Wellington, 2010).

New Zealand House of Representatives Order Paper No 166 for Wednesday 15 December 2010 (New Zealand House of Representatives, Wellington, 2010).

New Zealand Parliament Hansards (debates) Goods and Services Tax (Exemption of Healthy Food) Amendment Bill - First Reading (New Zealand Parliament, Wellington, 2010) Volume 666, page 13803.

New Zealand Television Broadcasting Council Advertising on Television: Getting it Right for Children (New Zealand Television Broadcasting Council, New Zealand, 2008).

Obesity Action Coalition (OAC) Would you Like Lies with that? Food, Kids and $T V$ advertising (OAC, Wellington, 2007).

OAC Effects of Advertising Restriction in other Jurisdictions (Diabetes Australia, Deakin University and the Cancer Council Victoria, Victoria, 2007).

Organisation for Economic Cooperation and Development (OECD) OECD Health Data 2010 - How does New Zealand Compare (OECD, Paris, 2010).

Rayner, Mike, Peter Scarborough and Lynn Stockley British Heart Foundation Health Promotion Research Group Nutrient Profiles: Options for Definitions for Use in Relation to Food Promotion and Children's Diets Final report (Department of Public Health, Oxford, 2004).

Review of Food Labelling Law and Policy A Summary of the Submissions to the Initial Public Consultation (Review of Food Labelling Law and Policy, Australia, 2010).

Rudd Center for Food Policy \& Obesity Soft Drink Taxes Opportunity for Public Policy (Rudd Center for Food Policy \& Obesity, Yale University, United States, 2009).

Schardt, David Nutrition Action Health Letter: Caffeine, the Good, the Bad, and the Maybe (CSPI, United States, 2008).

Schwartz, Marlene B, The Role of the Food Industry in Childhood Obesity (Rudd Center for Food Policy and Obesity Yale University International Society of Behavioural Nutrition and Physical Activity, Boston, 2006). 
Scientific Committee of the Agencies for Nutrition Action Does Watching TV Contribute to Increased Body Weight and Obesity in Children? (Scientific Committee of the Agencies for Nutrition Action, Wellington, 2006).

Scragg, Robert Review of Harker, Debra, and Michael Harker Advertising's Role in Diet and Exercise in New Zealand and Australia (School of Population Health, University of Auckland, Auckland, 2007).

Skegg, P D G, Ron Patterson (eds), Joann Manning, John Dawson, Nicola Peart and Warren Brookbanks Medical Law in New Zealand (Thomson Brookers, Wellington. 2006).

Thomson, Dr Barbara, and Sonja Schiess Risk Profile: Caffeine in Energy Drinks and Energy Shots (NZFSA, Christchurch, 2010).

Todd, Stephen (ed), John Hughs, John Burrows, John Smillie, Cynthia Hawes The Law of Torts in New Zealand (Brookers, Wellington, 2009).

United Kingdom Office of Communications Television Advertising of Food and Drink Products to Children: Statement and further Consultation (United Kingdom Office of Communications, London, 2006).

United States Department of Health and Human Services Preventing Tobacco use among Young People: A report of the Surgeon General (United States Department of Health and Human Services, Washington, United States, 1994).

Well-Connected ADAM Inc Exercise (Well-Connected ADAM Inc, Atlanta, 2009).

White, John Freedom of Choice and the Public Health Bill (John White, Wellington, 2008).

Willemsen, Marc C, and Boudewijn de Biij Tobacco Advertising (Doctors and Tobacco, Tobacco Control Resource Centre, The Hague, Netherlands).

World Cancer Research Fund (WCRF), and American Institute for Cancer Research (AICR) Policy and Action for Cancer Prevention Food, Nutrition, and Physical Activity: a Global Perspective (WCRF and AICR, Washington DC, 2009).

World Health Organisation (WHO) Diet, Nutrition and the Prevention of Chronic Diseases: WHO Technical Report Series 916 (WHO, Geneva, 2003).

WHO Global Strategy on Diet, Physical Activity and Health (WHO, Geneva, 2002).

WHO Marketing Food to Children: the Global Regulatory Environment (WHO, Geneva, 2004). 
WHO Forum and Technical Meeting United Marketing of Food and NonAlcoholic Beverages to Children report of a WHO forum and Technical Meeting (WHO Forum and Technical Meeting, Geneva, 2006).

\section{B Articles}

Alderman, Jess, Jason A Smith, Ellen J Fried and Richard A Daynard "Application of the Law to the Childhood Obesity Epidemic" (2007) 35.1 Journal of Law Medicine \& Ethics 90.

Arani, Shireen "State Intervention in Cases of Obesity-related Medical Neglect" (2002) 82 B U L Rev 875.

Ashe, Maurice, Lisa M Feldstein, Samantha Graff, Randolph Kline, Debora Pinkas and Leslie Zellers "Local Venues for Change: Legal Strategies for Healthy Environments" (2007) 35.1 Journal of Law Medicine \& Ethics 138.

Ashley, B "The Role of Litigation in Combating Obesity Among Poor Urban Minority Youth: A Critical Analysis of Pelman v McDonald's Corp" (2009) 15 Cardozo Journal of Law \& Gender 275.

Austin, Regina "Super Size Me and the Conundrum of Race/Ethnicity, Gender, and Class for the Contemporary Law Genre Documentary Film Maker" (20062007) 40 Loyola of Los Angeles Law Review 687.

Baker, Cynthia A "Bottom Lines and Waist lines: State Governments Weigh in on Wellness" (2008) 5 Ind Health L Rev 185.

Banham, Kelly “Is the Law a Fat Ass?” (2007) 157.1761 NLJ 269.

Bassett , M T, T Dumanovsky, C Huang, L D Silver, C Young, C Nonas, T D Matte, S Chideya and T R Frieden "Purchasing Behaviour and Calorie Information at Fast Food Chains in New York City" (2007) 98.8 Am J Public Health 1457.

Bassett, Mary T and Sarah Perl "Obesity: The Public Health Challenge of Our Time" (2004) 94.9 Am J Public Health 1477.

Beaglehole, Robert "Science, Advocacy and Health Policy: Lessons from the New Zealand Tobacco Wars” (1991) 12.2 Journal of Public Health Policy 175.

Benkin, Donald E, Meredith S A Reynolds and Alicia S Hunter "National Summit on Legal Preparedness for Obesity Preventions and Control" (2009) Summer Journal of Law Medicine \& Ethics 5.

Borgmeier, Ingrid, J and Joachim Westenhoefer "Impact of Different Food Label Formats on Healthiness Evaluation and Food Choice of Consumers: a Randomised-controlled Study" (2009) 9 BMC Public Health 184. 
Borzekowski, Dina L G and Thomas N Robinson "The 30-Second Effect: An Experiment Revealing the Impact of Television Commercials on Food Preferences of Preschoolers" (2001) 101.1 Journal of the American Dietetic Association 42.

Bloche, Gregg M "Exchange: Obesity Policy Choices: Obesity and the Struggle within Ourselves" (2004-05) 93 Geo L J 1334.

Breslow, Lester "Public Health Aspects of Weight Control" (2006) 35 International Journal of Epidemiology 10.

Browne, Neil M, Lauren Frances Biksacky and Alex Frondorf "Advertising to Children and the Commercial Speech Doctrine: Political and Constitutional Limitations" (2009) 58 Drake L Rev 67.

Brownell, Kelly D and Thomas R Frieden "Ounces of Prevention - The Public Policy Case for Taxes on Sugared Beverages" (2009) 18 New England Journal of Medicine 1805.

Brownell K D and K E Warner "The Perils of Ignoring History: Big Tobacco Played Dirty and Millions Died. How similar is Big Food?" (2009) 87.1 Milbank Quarterly 259.

Burnett, David "Fast Food Lawsuits and the Cheeseburger Bill: Critiquing Congress's Response to the Obesity Epidemic" (2006) 14.3 Va J Soc Pol'y \& L 357.

Burton, Scot, Elizabeth Cryer, Jeremy Kees and Kyle Huggins "Attacking the Obesity Epidemic: The Potential Benefits of Providing Nutrition Information in Restaurants" (2006) 96.9 Am J Public Health 1669.

Byrd, Sayward "Civil Rights and the Twinkie" Tax: The 900-Pound Gorilla in the War on Obesity” (2004) 65 La L Rev 303.

Cantu, Charles E "Fattening Food: Should Purveyors of Fast Food be Required to Warn? A Call for a New Tort” (2006) 2 J Food L \& Pol'y 39.

Caraher, Martin, and Gill Cowburn "Taxing Food: Implications for Public Health Nutrition" (2005) 8.8 Public Health Nutrition 1242.

Caraher, Martin, Jane Landon and Kath Dalmeny "Television Advertising and Children: Lessons from Policy Development" (2005) Public Health Nutrition 9(5) 596.

Cardin, Michael, Thomas A. Farley, Amanda Purcell, and Janet Collins "Preventing Obesity and Chronic Disease: Education vs. Regulation vs. Litigation" (2007) 35.4 Journal of Law Medicine \& Ethics 120. 
Catlin, Graham M "A More Palatable solution? Comparing the Viability of Smart Growth Statutes to other Legislative Methods of Controlling the Obesity Epidemic" (2007) 5 Wis L Rev 1091.

Chacko, Emme, Ingrid McDuff and Rod Jackson "Replacing Sugar-based Soft Drinks with Sugar-free Alternatives could Slow the Progress of the Obesity Epidemic: have your Coke and Drink it too" (2003) 116.1184 NZMJ.

Choi, Esther "Trans Fat Regulation: A Legislative Remedy for America's Heartache" (2008) 17 S Cal Interdisc L J 507.

Collins Perdue, Wendy, Alice Ammerman and Sheila Fleischhacker "Assessing Competencies for Obesity Prevention and Control" (2009) Summer Journal of Law Medicine \& Ethics 37.

Creighton, Robert "Cheeseburgers, Race, and Paternalism" (2009) 30.2 Journal of Legal Medicine 249.

Darwin, David "Advertising Obesity: Can the US follow the Lead of the UK in Television Marketing of Unhealthy Foods to Children" (2009) 42 Van J Transnat'l L 317.

David, Ludwig S, Karen E Peterson and Steven L Gortmaker "Relation between Consumption of Sugar Sweetened Drinks and Childhood Obesity: A Prospective, Observational Analysis" (2001) 357.9255 Lancet 505.

Davis, Jackson S "Fast Food, Zoning, and the Dormant Commerce Clause: was it Something I Ate?” (2008) 35 B C Envtl Aff L Rev 259.

Davis, Wendy N "Biting back at Obesity: the Big Apple's Calorie-counting Law is Staying on the Menu" (2009) 95.8 ABA J 17.

Daynard, Richard A "Lessons from Tobacco Control for the Obesity Control Movement" 24 Journal of Public Health Policy 291.

Dentzer, Susan "Global Health: Good Ideas Without Borders" (2008) Health Affairs.

Dentzer, Susan "The Child Abuse we Inflict through Child Obesity" (2010) 29.3 Health Affairs 342.

Denzer, Christian, Eva Reithofer, Martin Wabitsch and Kurt Wildhalm "The Outcome of Childhood Obesity Management depends highly upon Patient Compliance" (2004) 163 European Journal of Paediatrics 99.

Dietz, William H and Alicia S Hunter "Legal Preparedness for Obesity Prevention and Control: The Public Health Framework for Action" (2009) Summer Journal of Law Medicine \& Ethics 9. 
Dietz, William H, Mary Groves Bland, Steven L Gortmaker, Meg Molloy and Thomas L Schmid "Policy Tools for the Childhood Obesity Epidemic" 30.3 Journal of Law Medicine \& Ethics 83.

Drewnowski, Adam, Dean D Kruhm, Mark A Demitrack, Karen Nairn and Blake A Gosnell "Naxolone, an Opiate Blocker, Reduces the Consumption of Sweet High-fat Foods in Obese and Lean Female Binge Eaters" (1995) 61 Am J Clin Nutr 1206.

Drewnowski, Adam and S E Spector "Poverty and Obesity: the Role of Energy Density and Energy Costs" (2004) 79 Am J Clin Nutr 6.

Dworkin, Gerald “Moral Paternalism” (2004) 24 Law and Philosophy 305.

Edwards, Phil, and Ian Roberts "Transport Policy is Food Policy" 371.9625 Lancet 1661.

Elliott, Tracy "No need for the Fat Police" (2007) 157 NLJ 427.

Epstein, Richard A "In Defence of the 'Old' Public Health: The Legal Framework for the Regulation of Public Health" (2004) 69 Brook L Rev 1421.

Frazier, Dustin A "The Link between Fast Food and the Obesity Epidemic" (2007) 17.2 Health Matrix 273.

Freeman, Andrea "Fast Food: Oppression through Poor Nutrition" (2007) 95 Cal L Rev 2221.

Fried, Ellen and Michelle Simon "Thirty-seventh Annual Administrative Law Issue: Essay: The Competitive Food Conundrum: can Government Regulation Improve School Food" (2007) 56 Duke L J 1491.

Frieden, Thomas R, William Dietz and Janet Collins "Reducing Childhood Obesity through Policy Change: Acting now to Prevent Obesity" (2010) 29.3 Health Affairs 357.

Gitzi, Lauren F "State Menu-labeling Legislation: A Dormant Giant waiting to be Awoken by Commerce Clause Challenges" (2008-2009) 58 Cath U L Rev 501.

Gladding, Patrick and Jocelyne R Benatar "Trans Fats in New Zealand: Time for Labelling Regulations?” (9 November 2007) 120.1265 NZMJ.

Gostin, Lawrence O and M Gregg Bloche "The Politics of Public Health: a response to Epstein" (2003) 46.3 Perspectives in Biology and Medicine S160.

Gostin, Lawrence, Jennifer L Pomeranz, Peter D Jacobson and Richard N Gotfried "Assessing Laws and Legal Authorities for Obesity Prevention and Control" (2009) 37 Journal of Law and Medicine \& Ethics 28. 
Griffiths, Roland R and Ellen M Vernotica "Is Caffeine a Flavouring Agent in Cola Soft Drinks" (2000) 9 Arch Fam Med 727.

Hardy, Louise, Timothy A Dobbins, Elizabeth A Denney-Wilson, Anthony D Okely and Michael L Booth "Sedentariness, Small-screen Recreation, and Fitness in Youth" (2009) 36.2 American Journal of Preventative Medicine 120.

Heshka, S and D B Allison "Is Obesity a Disease?" (2001) 25 International Journal of Obesity 1401.

Hoek J and Maubach N "Self-regulation, Marketing Communications and Childhood Obesity: a Critical Review from New Zealand" (2006) 39.138 Loyola of Los Angeles Law Review 140.

Howells, Geraint "The Potential Limits of Consumer Empowerment by Information" (2005) 32.3 Journal of Law and Society 349.

Hunter, Nicole E "Revisiting the Regulation Debate: The Effect of Food Marketing on Childhood Obesity" (2009) 7 Pierce L Rev 205.

Huscroft, Grant "Reconciling Duty and Discretion: The Attorney General in the Charter Era" (2009) 34 Queens L J 773.

Ingleby, Richard, Lauren Prosser and Elizabeth Waters "Fast Food Restaurants and Obesity: How about Planners making a Difference through Zoning Legislation?" (2007) 44.2 Australian Planner 12.

Ip, John "What a Difference a Bill of Rights Makes? The Case of the Right to Protest in New Zealand" (2010) 24.2 NZULR 239.

Jain, Anjali "Temptations in cyberspace: New Battlefields in Childhood Obesity" (2010) 29.3 Health Affairs 425.

Jain, Anjali "Treating Obesity in Individuals and Populations" (2005) 331 BMJ 1387.

Jacobson, Michael F and Kelly D Brownell "Small Taxes on Soft Drinks and Snack Foods to Promote Health" (2000) 90.6 Am J Public Health 854.

James, Jennifer "The Obesity Time Bomb: Jennifer James gets to grips with the Weight of the Nation" (2008) 7305 NLJ.

Karpyn, Allison, Miriam Manon, Sarah Treuhaft, Tracey Giang and others "Policy Solutions to the 'Grocery Gap' (2010) 29.3 Health Affairs 473.

Keane, Steve "Can a Consumer's Right to Know survive the WTO?: The Case of Food" (2006) 16 Transnational Law and Contemporary Problems, University of Iowa 291. 
Kelly B, L King, A Bauman, B J Smith and V Flood "The Effects of Different Regulation Systems on Television Food Advertising to Children" (2007) 31.4 Australian and New Zealand Journal of Public Health 340.

Kelly, Laura A "What should be the Standards for Intervening between Parent and Child? The Parental Prosecution for a Young Boy's Obesity" (2000-2001) IX Buffalo Women's Law Journal 7.

Kennedy, Nicki "Comment: Stop in the Name of Public Policy: Limiting 'Junk Food' Advertisements During Children's Programming” (2008) 16 CommLaw Conspectus 503.

Kouzoukas, Demetrios L "Legal Preparedness for Obesity Prevention and Control: The Structural Framework and the Role of Government" (2009) Summer Journal of Law Medicine \& Ethics 24.

Levmore, Saul "Taxing Obesity - or Perhaps the Opposite" (2005-2006) 53 Cleve St L Rev 575.

Linn, Susan and Josh Golin "Beyond Commercials: How Food Marketers Target Children" (2006) 39 Loyola of Los Angeles Law Review 13.

Lockett, Cordelia "Carry that Weight” (2003) 191.3316 NZ Listener.

Ludwig, David S and Marion Nestle "Can the Food Industry Play a Constructive Role in the Obesity Epidemic?” (2008) 300.15 JAMA 1808.

Maher, Anthony, Nick Wilson and Louise Signal "Advertising and Availability of 'Obesogenic' Foods around Schools: a Pilot Study” (2005) 118.1218 NZMJ.

Maher, Anthony, Nick Wilson, Louise Signal and George Thomson "Patterns of Sports Sponsorship by Gambling, Alcohol and Food Companies: an Internet Survey" (2006) 6 BMC Public Health 95.

McColl Smith, Alexander "Beyond Autonomy" (1997-98) 14 Health Law \& Policy 23.

Meier, Benjamin Mason "Advancing Health Rights in a Globalized World: Responding to Globalization through a collective human right to public health" (2007) 35 Journal of Law Medicine \& Ethics 545.

Mello, Michelle M, Eric B Rimm and David M Studdert "The McLawsuit: The Fast Food Industry and Legal Accountability for Obesity" (2003) 22.6 Health Affairs 207.

Mello, Michelle M, David M. Studdert and Troyen A. Brennan "Obesity the New Frontier of Public Health Law: Health Policy Report" (2006) 354.24 New England Journal of Medicine 2601. 
Mhurchu, Cliona Ni and Siddharth Ogra "the Price of Healthy Eating: Cost and Nutrient Value of Selected Regular and Healthier Supermarket Foods in New Zealand" (2007) 120.1248 NZMJ.

McColl, Karen "Fat Taxes and the Financial Crisis" (2009) 373 Lancet 797.

Mhurchu, Cliona Ni, Tony Blakely, Yannan Jiang, Helen C Eyles and Anthony Rogers "Effects of Price Discounts and Tailored Nutrition Education on Supermarket Purchases: a Random Trial (2010) 91 Am J Clin Nutr 736.

Michels, Karen "A Maternalistic Approach to Prevention”, (2005) 34.1 International Journal of Epidemiology 3.

Millstone, Erik and Tim Lang "Risking Regulatory Capture at the UK's Food Standards Agency" (2008) 372 Lancet 94.

Morse, Rachel E "Note: Resisting the Path of Least Resistance: Why the Texas "Pole Tax" and the New Class of Modern Sin Taxes are Bad Policy" (2009) 29 Boston College Third World Law Journal 189.

Mytton, Oliver, Alastair Gray, Mike Rayner and Harry Rutter "Could Targeted Food Taxes Improve Health?" (2007) 61 Journal of Epidemiology and Community Health 689.

Mytton, Oliver, Alastair Gray, Mike Rayner and Harry Rutter "Evidence Based Public Health Policy and Practice" (2007) 61 Journal of Epidemiology \& Community Health 689.

Neuhouser, Marian I, Kristal, Alan , and Ruth E Patterson "Use of food Labels is associated with Lower Fat Intake" (1999) 99.1 Journal of the American Dietetic Association 45.

O’Rourke, Raymond "Legislators Target our Trolleys" (2006) 59 European Lawyer 44.

Patel, Deena "Super-sized kids: Using the Law to Combat Morbid Obesity in Children" (2005) 43.1 Family Court Review 164.

Perry, Raymond "Hold the Fries" (2003) 153.7108 NLJ 1858.

Peterson, Karen E and Mary Kay Fox "Addressing the Epidemic of Childhood Obesity through School Based Interventions: What has been Done and Where do we go From Here?” 2007) 35.1 Journal of Law Medicine \& Ethics 113.

Pomeranz, Jennifer L "Television Food Marketing to Children Revisited: the Federal Trade Commission has the Constitutional and Statutory Authority to Regulate" (2010) Spring Journal of Law Medicine \& Ethics 98. 
Pomeranz, L Jennifer and Lawrence O Gostin "Improving Laws and Legal Authorities for Obesity Prevention and Control" (2009) Summer Journal of Law Medicine \& Ethics 61.

Pope, Thaddeus Mason "Counting the Dragon's Teeth and Claws: the definition of Hard Paternalism" (2004) 20.3 G St U L Rev 659.

Pope, Thaddeus Mason "Is Public Health Paternalism really never Justified? A response to Feinberg (2005) 30 City University Law Rev 121.

Posner, Eric A “Tobacco Regulation or Litigation?” (2003) 70.3 University of Chicago Law Review 1141.

Pulver, Adam R “An Imperfect Fit: Obesity, Public Health, and Disability Antidiscrimination Law” (2008) 41 Colum J L \& Soc Probs 365.

Quigley, Robert and Carolyn Watts "Challenging Beliefs about the Marketing of Food" (2005) 118.1218 NZMJ.

Reid, Caroline "Freedom of Expression, Commercial Expression and Tobacco in Canada" (2008) September VUWL 343.

Reynolds, Christopher "Law and Public Health: Addressing Obesity" (2004) 29.4 ALJ 162.

Richards, Edward P, Maile S L Shimbukuro, Susan Combs and Marshall W Kreuter "Applying Law to Front-burner Issues: Innovative Legal Tools to Prevent Obesity" (2004) 32 Journal of Law Medicine and Ethics 59.

Rizzo, Mario and Douglas Glen Whitman "Perspectives on the New Regulatory Era: Little Brother is Watching you New Paternalism on the Slippery Slopes" (2009) 51 Ariz L Rev 685.

Roberts, Ian "Corporate Capture and Coca-Cola" (2008) 372.9654 Lancet 1934.

Robinson, Thomas N, Dina L G Borzekowski, Donna M Matheson and Helena C Kraemer "Effects of Fast Food Branding on Young Children's Taste Preferences" (2007) 161 Archives of Pediatric Medicine 792.

Rothenberg, Joan R "In Search of the Silver Bullet: Regulatory Models to Address Childhood Obesity” 65 Food \& Drug L J (2010) 185.

Rutkow, Lainie, Jon S Vernick, James G Hodge Jr and Stephen P Terret "Preemption and the Obesity Epidemic: State and Local Menu Labelling Laws and the Nutrition Labeling and Education Act" (2008) Winter Journal of Law, Medicine \& Ethics 772 .

Sauder, JoAnne "Using Food and Beverage Price Interventions to Address Obesity" 18.1 Health Law Review 21. 
Savage, Jennifer S, Jennifer Orlet Fisher and Leann L Birch "Parental Influence on Eating Behaviour: Conception to Adolescence" (2007) Spring Journal of Law, Medicine \& Ethics 22.

Schauer, Frederick "On the Relation between Chapters One and Two of John Stuart Mill's On Liberty” (2011) 39 CAPULR 571.

Schulman, Tamara "Menu Labelling: Knowledge for a Healthier America" (2010) 47 Harv J on Legis 587.

Schwartz, Marlene B and Kelly D Brownell "Actions Necessary to Prevent Obesity: Creating the Climate for Change" (2007) 35 Journal of Law Medicine and Ethics 78.

Scoccia, Danny “In Defence of Hard Paternalism” (2008) 27 Law and Philosophy 351.

Sellers, MNS “An Introduction to the Value of Autonomy in Law" (2007) 1 IUSGEN 1.

Shaw, Caroline "(Non) Regulation of Marketing of Unhealthy Food to Children in New Zealand (2009) 122 NZMJ 76.

Signal, Louise, Tolotea Lanumata, Jo-An Robinson, Alitasi Tavila, Jenny Wilton and Cliona Ni Mhurchu "Perceptions of New Zealand Nutrition labels by Mãori, Pacific and Low-income Shoppers" (2007) 11.7 Public Health Nutrition 706.

Simon, Michele "Can Food Companies be Trusted to Self-regulate? An Analysis of Corporate Lobbying and Deception to Undermine Children's Health" (2006) 39 Loyola of Los Angeles Law Review 173.

Small, Dana M, Robert J Zatorre, Alain Dagher, Alan C Evans and Marilyn Jones-Gotman "Changes in Brain Activity Related to Eating Chocolate: from Pleasure to Aversion" (2001) 124.9 Brain 1720.

Smith, Jason A "Setting the Stage for Public Health: the Role of Litigation in Controlling Obesity" (2006) 28 University of Arkansas Little Rock Review 443.

Stender, S, J Dyerberg and A Astrup "Fast Food: Unfriendly and Unhealthy" (2007) 31 International Journal of Obesity 867.

Stice, Eric, Sonja Yokum, Kenneth Blum and Cara Bohon "Weight Gain is Associated with Reduced Striatal Response to Palatable Food” (2010) 30.39 Journal of Neuroscience 13105.

Sturm, R and A Datar "Body Mass Index in Elementary School Children, Metropolitan Area Food Prices and Food Outlet Density" (2005) 119 Public Health 1059. 
Sturm, R and A Datar "Food Prices and Weight Gain during Elementary School: 5-year update" (2008) 122 Public Health 1140.

Sugarman, Stephen D and Nirit Sandman "Using Performance-based Regulation to Reduce Childhood Obesity" (2008) 5.26 Australia and New Zealand Health Policy 26.

Thaler, Sunstein, "Libertarian Paternalism is not an Oxymoron" (2003) $70.4 \mathrm{U}$ Chi L Rev 1159.

Thomson, George, and Nick Wilson "One Year of Smoke Free Bars and Restaurants in New Zealand: Impacts and Responses" (2006) 6 BMC Public Health 64.

Thornley, Simon, Hayden McRobbie, Helen Eyles, Natalie Walker and Greg Simmons "The Obesity Epidemic: Is Glycemic Index the Key to Unlocking a Hidden Addiction?" 71.5 (2008) Medical Hypotheses 709.

Thorpe, Kenneth E, Curtis S Florence, David H Howard and Peter Joski "The Impact of Obesity on Rising Medical Spending" (2004) October Health Affairs 480 .

Tokeley, Kate "Pou v British American Tobacco (NZ) Ltd - A Comprehensive Win for the New Zealand Tobacco Industry” (2006) 14 Waikato L Rev 136.

Tokeley, Kate “Tobacco Litigation” (1997) October NZLJ 346.

Verhagen, Hans and Henk van den Berg "A Simple Visual Model to Compare Existing Nutrient Profiling Schemes" (2008) 52 Food \& Nutrition Research.

Wang, Lucy "Weight Discrimination: One size fits all Remedy" (2008) 117.8 Yale L J 117.

Ward, Laura E "Review of Selected 2007 California Legislation: Education: Chapter 235: Strict Nutrition Standards in California Public Schools" (2007) 38 McGeorge L Rev 85.

Wildhalm, K and D Fussenegger "Actions and Programs of European Countries to Combat Obesity in Children and Adolescents: a Survey" (2005) 29 International Journal of Obesity 130.

Wilson, Nicholas, Robert Quigley and Osman Mansoor "Food Ads on TV: A Health Hazard for Children?" (1999) 23 Australian and New Zealand Journal of Public Health 647.

Winterfeld, Amy "PE Makes a Comeback" (2007) 33.10 State Legislatures 36.

Yosifon, G David "Legal Theoretical Inadequacy and Obesity Epidemic Analysis" (2008) 15 Geo Mason L Rev 681. 
Zefutie, John J Jr "Comment: from Butts to Big Macs - can the Big Tobacco Litigation and Nationwide Settlements with States' Attorneys General Serve as a Model for Attacking the Fast Food Industry?” (2004) 34 Seton Hall L Rev 1383.

“Obesity and TV viewing: News Briefs" (July 1985) 32.1 American Family Physician 220.

"Review of Selected California Legislation: Education Chapter 235: Strict Nutrition Standards in California" (2007) 38 McGeorge L R 85.

"Speakable and Unspeakable Facts about BMI and Mortality: Comment" (28 March 2009) 373 Lancet 1055.

\section{Letters to the editor}

Booth M L "Behavioural Food Labelling" (2006) 30 International Journal of Obesity 1800 .

\section{ELECTRONIC}

\section{A Websites}

Advertising Standards Authority www.asa.co.nz (accessed 16 January 2006).

American Beverage Association www.ameribev.org (accessed 4 November 2009).

Amnesty International www.amnesty.org.nz (accessed 16 November 2008).

BAN TRANS FATS www.bantransfats.com (accessed 6 May 2009).

BBC News www.bbc.co.uk (accessed 27 April 2009).

BUPA www.hcd2.bupa.co.uk (accessed 14 November 2010).

California Centre for Public Health Advocacy www.publichealthadvocacy.org (accessed 1 March 2010).

California Project Lean www.californiaprojectlean.org (accessed 25 November 2009).

Canadian Food Inspection Agency www.inspection.gc.ca (accessed 12 November 2009). 
Center for Consumer Freedom www.consumerfreedom.com (accessed 5 May 2009).

Center for Science in the Public Interest www.cspinet.org (accessed 31 March 2010).

Coalition for Responsible Nutrition information www.nationalnutritionstandards.com (accessed 4 December 2009).

Coca Cola Amatil NZ www.coke.co.nz (accessed 12 may 2009).

Diabetes New Zealand www.diabetes.org.nz (accessed 10 March 2010).

Eatwell UK www.eatwell.gov.uk/foodlabels/trafficlights (accessed 18 November 2010).

EurActiv www.euractiv.com (accessed 2 March 2010).

The 2007 Florida Statutes www.leg.state.fl.us (Accessed 19 May 2009).

Food and Nutrition Guidelines www.moh.govt.nz/foodandnutrition (accessed 13 July 2010).

Food Legal www.foodlegal.com.au (accessed 18 August 2009).

Food Standards Australia New Zealand www.foodstandards.govt.nz (accessed 12 November).

Fruit in Schools www.moh.govt.nz/fruitinschools (Accessed 27 April 2009).

Green Party www.greens.org.nz (accessed 6 May 2009).

GovTrac US www.govtrack.us/congress (accessed 9 July 2010).

Tom Harkin www.harkin.senate.gov (accessed 11 May 2009).

Health Canada www.hc-sc.ca (accessed 28 October 2009).

International Association for the study of obesity www.iotf.org (accessed 4 June 2011).

Kraftfoods.com www.kraftfoods.com (accessed 13 April 2009).

Local Government Association www.lga.gov.uk (accessed 12 January 2009).

Ministry of Health www.moh.govt.nz (accessed 12 August 2008).

Ministry of Youth Development www.myd.govt.nz (accessed 18 November 2009). 
National Association of Fat Acceptance www.naafa.org (accessed $10^{\text {th }}$ November 2008).

New York State www.state.ny.us (accessed 7 July 2010).

New Zealand Broadcasters Council www.nzbtc.co.nz (accessed 16 January 2009).

New Zealand Food Safety Authority NZFSA www.nzfsa.co.nz (accessed 16 January 2009).

New Zealand Drug Foundation www.nzdf.org.nz (accessed 29 October 2009).

NZherald.co.nz www.nzherald.co.nz (accessed 28 February 2009).

Obesity Action Coalition www.obesityaction.org.nz (accessed 22 January 2009).

Obesity Focused www.obesityfocused.com (accessed 10 May 2009).

Offcom website www.ofcom.org.uk (accessed 5 November 2009).

Ontario e-laws www.e-laws.gov.on.ca (accessed 19 May 2009)

Reuters www.reuters.com (accessed 6 May 2009).

Scoop www.scoop.co.nz (accessed 17 December 2008).

Scottish government www.scotland.gov.uk (accessed 27 April 2009).

Slate.com www.slate.com (accessed 28 February 2009).

Smart Choices Program www.smartchoicesprogram.com (accessed 28 October 2009).

Tobacco Control Resource Centre www.tobacco-control.org (accessed 21 August 2009).

TVNZ www.tvnz.co.nz (accessed 17 December 2008).

UNICEF www.unicef.org (accessed 18 November 2009).

United Kingdom Advertising Standards Authority www.asa.org.uk (accessed 17 November 2009).

United Kingdom Department of Health www.dh.gov.uk (accessed August 2008).

United Kingdom Food Standards Agency www.food.gov.uk (accessed 11 June 2010).

United Kingdom legislation www.opsi.gov.uk (accessed 12 November 2009). 
United States Department of Health and Human Services www.cdc.gov (accessed 12 January 2009, 7 June 2010).

United States Department of Health and Human Services www.hhs.gov (accessed 7 June 2010).

United States National Cancer Institute www.cancer.gov (accessed 27 May 2010).

United States Food and Drug Administration www.fda.gov (accessed 13 April 2009).

WashingtonWatch.com www.washingtonwatch.com/bills/show (accessed 1 July 2010).

World Cancer Research Fund www.wcrf.org (accessed 3 June 2010).

World Health Organisation www.who.int (accessed 12 August 2008).

Yale University Rudd Centre for Food Policy and Obesity www.yaleruddcenter.org (accessed 5 May 2009).

\section{B Online data-bases}

Brookers online Library, Statute Database.

Brookers online Library, Statute Database, Gault on Commercial Law.

Brookers online Library, Regulations of New Zealand.

Brookers online Library Personal Injury in New Zealand.

\section{News Articles}

Bellaart, Darrell "Trans-fat Ban on the Way: BC will Regulate Food Additives across the Province" (1 October 2009) Canada.com www.canada.com.components (accessed 14 April 2009).

Chapman, James "Obesity Poses as Big a Threat to Our Nation as Terrorism, Government adviser warns" (15 August 2008) MailOnLine www.dailymail.co.uk/news/article (accessed 19 August 2008).

Coca Cola Amatil (NZ) Limited and Frucor Beverages Group Limited "Companies Remove Full Sugar Drinks from Schools" (10 December 2009) Infonews.co.nz www.infonews.co.nz/news (accessed 9 July 2010). 
Doering, Christopher "Senators want to Expel Junk food from U.S. Schools" (30 April 2009) Reuters www.reuters.com/article (accessed 6 May 2009).

English, Simon "McDonald's has a Case to Answer" (15 June 2003) Telegraph.co.uk www.telegraph.co.uk/finance (accessed 28 April 2009).

Fletcher, Anthony "UK Industry Slams Food Ad Restrictions" (23 February 2007) Foodnavigator.com www.foodnavigator.com (accessed 1 April 2009).

Frumkin, Paul "Breaking News Congress to reconsider LEAN Act" (11 March 2009) Restaurant News www.nrm.com (accessed 4 December 2009).

Hall, Louise "Revealed: Why some Foods are Addictive" (13 January 2009) Sydney Morning Herald www.smh.com.au (accessed 16 January 2009).

Heller, Lorraine "UK Solution to Junk Food Ads more Effective says Lobby Group" (24 November 2006) Foodnavigator-USA.com www.foodnavigatorusa.com (accessed 1 April 2009).

Hoag, Christina "LA Blocks New Fast Food Outlets from Poor Areas" (30 July 2008) nzherald.co.nz www.nzherald.co.nz/obesity/news (accessed 14 March 2009).

Houlahan, Mike "Pineapple Lump Ban Next - business weighs into food debate" (24 April 2008) NZherald.co.nz www.nzherald.co.nz (accessed 12 June 2008).

Geiger, Kim, and Tom Hamburger "Soft Drink Tax Battle Shifts to States" (21 February 2010) Los Angeles Times online (Los Angeles Times Article Collections) www.articles.latimes.com (accessed 14 June 2010).

Jeffreys, Branwen "Child Obesity 'Form of Neglect"” (14 June 2007) BBCNews www.bbc.co.uk (accessed 2 August 2008).

Johnston, Martin "Govt Cuts off Cash to Obesity Coalition" (26 May 2009) nzherald.co.nz www.nzherald.co.nz/nz/newsprint (accessed 26 May 2009).

Johnston, Martin "NZers Gaining in the Weight War" (4 June 2008) nzherald.co.nz www.nzherald.co.nz/section/1/story (7 August 2008).

Johnston, Martin "Sausage Sizzles, Pies and Chocolate back at School" (6 February 2009) nzherald.co.nz www.nzherald.co.nz/health/news (accessed 14 March 2009).

Kahn, Michael "Obesity Contributes to Global Warming: Study" (15 May 2008) Reuters www.reuters.com/article (accessed 19 August 2008).

Lueck, Thomas J "Big Brother in the Kitchen? New Yorkers Balk" (28 September 2006) The New York Times.Com www.nytimes.com (accessed 6 May 2009). 
Lyall, Sarah "Glorious Food? English School Children Think Not" (18 October 2006) nytimes.com www.nytimes.com/2006/10/18 (accessed 2 September 2009).

Macey, Richard "Fat, Sugar 'Addiction' Linked to Obesity" (31 January 2003) theage.com.au www.theage.com.au.articles/2003/01/30 (accessed 7 September 2008).

Martin, Daniel "Pay the Obese to Take a Walk: Now the Nanny State Offers Rewards just for Losing Weight in £30m Health Drive" (11 November 2008) Mail Online www.dailymail.co.uk/news (accessed 11 November 2008).

Martin, Daniel "Treat Child Obesity as Neglect, say Doctors" (15 June 2007) Mail Online www.dailymail.co.uk/news (accessed 2 August 2008).

Martin, Daniel "5,000 need Hospital Treatment every Year because they are Obese" (26 February 2009) MailOnline www.dailymail.co.uk/health/article (accessed 27 February 2009).

Martin, Yvonne "Who Shoulders the Blame for Obesity?" (3 March 2007) The Press Stuff www.stuff.co.nz (accessed 14 August 2008).

Masters, Catherine "Keep Smokers and Obese People Out - Doctors" (30 June 2007) New Zealand Herald online www.nzherald.co.nz/health/news (accessed 13 November 2008).

McLean, Tamara "Gastric Banding Helps Big Women have Babies" (13 November 2008) Stuff.co.nz www.stuff.co.nz/print (accessed 13 November 2008).

Miles, Alice "The Chance of Cutting Obesity? A Big Fat Zero" (17 January 2009) Timesonline www.timesonline.co.uk (accessed 25 January 2009).

Newcombe, Rachael "Is Junk Food Addictive" (19 July 2003) BUPA Investigative News www.bupa.co.uk (accessed 16 January 2009).

Obesity Focused "Obesity and Fast Food: The McDonald's Lawsuit" www.obesityfocused.com (accessed 10 May 2009).

Odato, James O "New Taxes, Cuts in Budget Plan" timesunion.com www.timesunion.com/ASPStories (accessed 17 December 2008).

Oliver, Paula "Tough Food Controls in Anti-obesity Bill” (13 March 2008) New Zealand Herald Auckland www.nzherald.co.nz (accessed 7 august 2008).

Pinchuk, Lianne S "Are Fast Food Lawsuits Likely to Be the Next 'Big Tobacco" (28 February 2007) Law.com www.law.com (Accessed 5 August 2008).

Poulter, Sean "Europe Bows to Food Firms' Pressure to Kill off 'Traffic Light' Labelling that would Identify Unhealthy Products" (16 June 2010) MailOnline www.dailymail.co.uk/newsarticle (accessed 17 June 2010). 
Ramesh, Randeep "Food Standards Agency to be Abolished by Health Secretary: Victory for Food Manufacturers as Health Groups Accuse Andrew Lansley of Caving in to Big Business" (12 July 2010) Gardian.co.uk www.gardian.co.uk (accessed 18 November 2010).

Rose, David "Change4Life Shock Adverts to Reduce Child Obesity" (12 December 2008) Timesonline www.timesonline.co.uk (accessed 9 April 2009).

Saletan, William "Food Apartheid: Banning Fast Food in Poor Neighbourhoods" (31 July 2008) Slate.com www.slate.com (accessed 28 February 2009).

Szep, Jason "Massachusetts sets Tough Fast Food Rules" (13 May 2009) Reuters United Kingdom www.uk.reuters.com (accessed 4 December 2009).

Templeton, Sarah-Kate "Fat Boy may be put in Care" (25 February 2007) TimesOnLine www.timesonline.co.uk/tol/news/uk/health/article (accessed 22 August 2008).

Templeton, Sarah-Kate "Focus: The Thin Line between Poor Diet and Child Abuse" TimesOnLine www.timesonline.co.uk/tol/news/uk/health (accessed 2 August 2008).

Todd, Rebecca "Govt Criticised for Lack of Action on Obesity" (12 July 2010) stuff.co.nz Www.stuff.co.nz/national/health (accessed 12 July 2010).

Toor, Mark "Sales Tax on Soft Drinks Not too Popular: New York Governor Revives Tax Plan, Opposition Piles On" (14 February 2010) Suite101 www.suite101.com (accessed 23 February 2010).

Voiland, Adam “10 Things the Food Industry Doesn't Want You to Know" (17 October 2008) USNews.co www.health.usnews.com/health-news/articles (accessed 4 February 2009).

Wald, Donald "McDonald's Obesity Suit Tossed" (17 February 2002) CNNMoney.com www.CNNMoney.com? (accessed 21 January 2009).

Watkins, Tracy "Tobacco Price Increase Prompts Helpline Spike" (14 July 2010) Stuff New Zealand www.stuff.co.nz (accessed 13 November 2010).

Weaver, Matthew "Treat Childhood Obesity as Act of Neglect, say Doctors" (14 June 2007) guardian.co.uk www.guardian.co.uk/society/2007 (accessed 30 October 2008).

“ASA dismisses Change4Life Ad Complaints" (March 2009) GamesIndustry.biz www.gamesindustry.biz/articles (accessed 9 April 2009).

"Call to List Fat Content of Food" (28 July 2006) Guardian.co.uk www.guardian.co.uk/society/2006/jul/28/health (accessed 6 May 2009). 
"Crushed Flier Wins Obesity Payout" (21 October 2002) BBC News www.bbc.co.nz (accessed 12 November 2010).

"Fat Tax Roundup" (1 July 2003) Consumerfreedom.com www.consumerfreedom.com/news (accessed 5 May 2009).

"Food Industry are Misleading Children and Advertising in the Classroom" (5 January 2009) Sustainweb www.sustainweb.org/news (accessed 22 July 2010).

"Food Labelling Campaign Launched" (1 April 2007) BBCNews www.newsvote.bbc.co.uk (accessed 14 April 2009).

"Government Considers Fat Tax" (25 June 2003) TVNZ www.tvnz.co.nz/view/pages (accessed 17 December 2008).

"Govt Cuts off Cash to Obesity Coalition" (26 May 2009) nherald.co.nz www.nzherald.co.nz/news (accessed 26 November 2009).

"Government must Ban Fast Food Advertising to Kids" (5 July 2006) Scoop Independent News www.scoop.co.nz (accessed 17 Dec 2008).

"GPs Vote against "Chocolate Tax"” (12 March 2009) BBCNews www.news.bbc.co.uk (accessed 27 April 2009).

"Health Academic Supports Regulation of Food Ads" (1 May 2008) Stuff.co.nz www.stuff.co.nz (accessed 12 June 2008).

"Junk Food Ads - Fewer on TV but more in Print Media" (14 October 2008) Medical News Today www.medicalnewstoday.com/articles (accessed 12 July 2010).

"McDonald's Supersizes Hindu Endowment" Hinduism Today www.hinduismtoday.com (Accessed 18 November 2008).

"New York City Passes Trans Fat Ban: Restaurants must Eliminate ArteryClogging Ingredient by July 2008" (5 December 2006) MSNBC.com www.msnbc.msn.com (accessed 14 April 2009).

"Police Search for 252kg Boy" (22 May 2009) Stuff NZ www.stuff.co.nz (accessed 22 May 2009).

"Romania becomes First Country to Introduce Junk-food Tax" (7 January 2010) EurActiv www.euractiv.com/en/health/romania-country-introduce-junk-food-tax (accessed 2 March 2010).

"Sony considering Legal Action over Change4life ad" (9 March 2009) The.games business.inprint.online www.mcvuk.com/news/33477/Sony-considering-legalaction-over-Change4Life-ad (accessed 9 April 2009). 
"Taking GST off Fresh Fruit and Vegetables a Step in the Right Direction" (27 September 2010) University of Otago News www.otago.ac.nz/news (accessed 2 November 2010).

"275-Pound Woman says Hospital told her to use Zoo MRI" (13 January 2009) FoxNews.Com www.foxnews.com (accessed 15 January 2009).

\section{Texts}

Advertising Standards Authority Bugger, it's okay - the Case for Self-regulation (ASA, Wellington) available at www.ASA.co.nz (accessed 6 July 2010).

Advertising Standards Authority Code of Advertising Practice www.cap.org.uk (accessed 11 November 2010).

BUPA Physical Activity www.hcd2.bupa.co.uk (accessed 14 November 2010).

Human Genome Research Project Choosing Genes for Future Children: Regulating Preimplantation Genetic Diagnosis (Human Genome Research Project, Dunedin, 2006) (main findings www.otago.ac.nz/genome/resources/index (accessed 12 May 2008)).

Internet Encyclopaedia of Philosophy www.iep.utm.edu/milljs (accessed 11 January 2011).

Review of Food Labelling Law and Policy www.foodlabelling.gov.au (accessed 22 November 2010).

Stanford Encyclopaedia of Philosophy www.plato.stanford.edu (accessed 2 April 2010).

Understanding Labelling Rules at United Kingdom Food Standards Agency www.food.gov.uk (accessed 11 June 2010).

United States Food and Drug Administration, Food Labelling and Nutrition www.foodsafety/label.com (accessed 25 January 2009).

White, David Take Two Servings of Paternalism (21 December 2006) The American (the Journal of the American Enterprise Institute www.american.com (accessed 24 May 2011).

WHO Fact Sheet number 311 Obesity and Overweight www.who.int/mediacentre/factsheets (accessed 11 January 2011). 


\section{OTHER SOURCES}

\section{A Research Papers}

Tait Emma "Medical Care of Young Children in New Zealand: Should Parents or the State have the Final say?" LLB (Hons) Seminar Paper Victoria University of Wellington Law Faculty 2008.

Gillbanks, T “The Obesity Epidemic: what should the Government do?" LLB (Hons) Research Paper, Victoria University of Wellington, 2004).

\section{B News Articles}

Abbot, Tony (10 May 2006) "A Plan to Win the Battle of the Bulge” The Sydney Morning Herald Sydney.

Abdollah, Tami "A Strict Order for Fast Food" (10 September 2007) The Los Angeles Times, Los Angeles United States, A1.

Adler, Jerry, Karen Springen and Joan Raymond "True or False: The Obese should have to Pay More for Airline Tickets" (14 July 2008) Newsweek United States.

Arlidge, John "McDonald's says get some Exercise, Fatso" (17 April 2005) Sunday Times London 11.

Blythman, Joanna "A Fat lot of Good: Until the Government has the Guts to take on the Supermarkets, its latest Measures to Tackle Obesity are Doomed to Failure, warns Britain's Leading Food Campaigner" (12 October 2006) Daily Mail London 15.

Bevins, Anthony "Food Lobby Jeopardises Drive for Healthy Eating" (24 November 1997) The Independent London.

Branswell, Brenda "Learning about Healthy Eating: LESS FAT is featured in School Cafeterias this year as Dieticians work to meet new Quebec Guidelines" (28 August 2008) The Gazette Montreal A8.

Brindley, Madeleine "Demand for Rethink on Planning law for Fast Food Restaurants" (27 December 2007) Western Mail, Wales.

Britton, Broun "Hospitals Struggle to Cope with Obese Kiwis" (15 February 2008) The Dominion Post Wellington. 
Cameron, Michael "Taken from Parents for being Obese at Three" (30 August 2000) The Daily Telegraph Australia 41.

Chan, Bernard "Food Labelling Boils down to Public Health" (9 May 2008) South China Morning Post China 12.

Charder, David "Fast Food Tax to tip Scales in War on Obesity - and Slim down huge Deficit; Romania" (16 January 2010) The Times London 5.

Clifford, Stephanie "Tug of War in Food Marketing to Children" (30 July 2008) The New York Times United States.

Cloud, John "Why Exercise won't make you Thin" (9 August 2009) Time United States.

Colavecchio van Sickler Shannon "Go to Gym Class; it's the Law" (4 May 2007) St Petersburg Times Florida, United States, 1B.

Connor, Steve "Junk Food could be Addictive 'like Heroin'; Rats become 'Hooked' on Sausage and Cheesecake in the same way as Drug Abusers" (29 March 2010) The Independent United Kingdom.

Cordova, Elizabeth Butler "Health Department issues Mass Citations to Food Chains; McDonald's and Dunkin' amass most Calorie Violations" (20 October 2008) Crain's New York Business New York 4.

Critser, Greg "Why France has an Edge in the Battle of the Bulge" (22 May 2003) International Herald Tribune New York 7.

Davies, Hannah "Fat Tax Imposed on Obese" (2 March 2008) The Sunday Telegraph, Australia 19.

Davies, Hannah "Obese Face Hefty Insurance - Premiums get as Big as Waistlines" (2 March 2008) Sunday Mail Australia 11.

Edwards, Adam "Jump at Change to bring back PT Classes" (30 July 2008) The Express, United Kingdom 16.

Feuer, Alan "Judge says no to Rule on Calories" (12 September 2007) New York The Times United States 1.

Fox, Maggie "Tax Junk Food, Drinks to Fight Child Obesity" (1 September 2009) Reuters Washington.

Fynes-Clinton, Jane “An Alcoholic Stupor” (11 February 2010) Courier Mail Australia.

Gaines, Sarah "Child obesity: Council to Ban Takeaways near Schools" (21 October 2008) The Guardian United Kingdom. 
Giles, Darrell "Tearful Mum Pleads for return of 54kg Toddler" (26 October 2000)The Advertiser Los Angeles.

Goldreich, Samuel "Consumer Group gets Edgy about Caffeine Information" (1 August 1997) The Washington Times United States B7.

Grice, Andrew "Obese may be Denied Priority NHS Care; Patients with 'Self Inflicted' Illnesses Face Discrimination" (26 December 2006) The Independent London, 56.

Gumbel, Andrew "Fast Food Nation: An Appetite for Litigation. US Lawyer John Banzhaf was the First to Sue the Tobacco Companies in the Mid-sixties. Now he wants to Prosecute the Junk-food Industry for making Americans Obese" (4 June 2002) The Independent London.

Hailstone, Barry "Krystal is only 3 and she Weighs $37 \mathrm{~kg}$. Her Sister is 5 and Weighs 17.5kg" (22 September 2000) Advertiser Los Angeles.

Hamilton, Graeme "The Junk Food Wars: Quebec Scores Sweet Victory in Battle against Childhood Obesity" (27 January 2009) National Post Canada.

Hale, Beth, and Sophie Borland "Overweight Youngsters will be Taken into Care” (16 August 2008) The Daily Mail London 7.

Hartevelt, John “Who's Overweight? Who can Tell? (5 February 2009) The Press Christchurch.

Henderson, Mark "Welcome to the Town that will Make you Lose Weight" (18 February 2008) The Times (London) 3.

Hinde, Suellen "Call to Restrict Fast Food in 'Burbs"” (20 April 2008) The Sunday Territorian, Australia, 8.

Johnson, Alan "Let's Make a Change ..... for Life; Health Minister Writes for the Sun” (3 January 2009) The Sun United Kingdom 8.

Johnston, Matt "Health Problems for Roly-poly Trainer Nightmare on Fat Street" (8 April 2009) Herald Sun, Australia, 13.

Johnston, Martin "The Price of Free Choice" (25 July 2009) The New Zealand Herald Auckland.

Jones, Hannah “I Wouldn't want People to Eat Here Every Day: Admits Big Mac Chief on McJob Mission” (21 July 2007) The Western Mail Wales 15.

Kalinowski, Tess "Compulsory Workout for Student Body" (5 September 2006) The Toronto Star, Canada A04. 
Kelleher, Jennifer Sinco "Fitness Policies out of Shape; Studies say Students are not Getting enough Physical Exercise Education; Educators cite Academic Demands and Lack of Space, Time and Teachers" (25 January 2009) Newsday, New York A14.

Kelleher, Jennifer Sinco "Profiting from Vending" (27 October 2008) Newsday New York A15.

Kiong, Errol "Lessons Learned from Healthier School Setting" (10 March 2007) The New Zealand Herald Auckland.

Lague, Marissa "Insurance to Rely on BMI for Risk Analysis" (16 August 2004) The West Australian Perth 36.

Lam, Miawling "Fat Chance of Getting a Job - Survey shows Employers won't Hire Obese Workers" (18 November 2007) The Sunday Telegraph Australia, 19.

Larkin, Mike "Crane Gang Called in to Help Bury Bulky Scots; Undertakers Feeling the Strain of Scotland's Obesity Crisis" (22 October 2007) The Express Scotland.

Larkin, Mike "Obese Scots Coffins Crisis" (22October 2007) The Daily Record Scotland 22.

Levine, Susan, Lori Aratani "Sweet Surrender; Under Siege, Companies Begin Replacing Familiar Junk-Food Pitches and Products" (22 May 2008) The Washington Post United States, D01.

Luscombe, Richard "Florida Fights Childhood Obesity with New Gym Rule" (17 November 2008) Christian Science Monitor, United States 1.

Martin, Arthur "Obese could be Denied Priority NHS Care" (26 December 2006) The Daily Mail London, 8.

McDonald, Barry, and James Watt "Experts in Bid to Boost Health but do you Buy the Idea of a Fat Charge? 'Fat tax' on cakes could save 3000 lives a year" (13 July 2007) Evening Times, Glasgow 12.

McGarry, Andrew "Polies Gutless on Obesity: Health Guru" (6 November 2007) The Australian Australia 9.

McNally, Shelagh "What your Food is Trying to Tell You; Nutrition Labels" (23 September 2008) National Post Canada AL4.

Mick, Hayley "Gym Class no Solution for Obesity: Study” (31 March 2009) The Globe and Mail, Canada, L1.

Newton, Katherine "Schools' Healthy Food Rule Scrapped" (6 February 2009) The Dominion Wellington. 
Oliver, Paula "Tough Food Controls in Anti-obesity Bill" (13 March 2008) The New Zealand Herald Auckland 1.

Owens, Anne Marie “Obesity New Factor in Grading Parents; Children's Diets Key Issue in Custody Case" (3 March 2008) National Post Canada A1.

Pallot, Peter "Good Free Care? Fat Chance As the NHS begins to Discriminate against the Overweight and Smokers, People in those Categories are turning to Budget Health Insurance Schemes" (30 March 2008) The Sunday Telegraph London, 15.

Prince, Rosa "Anti-obesity Drive could Ban Fast Food near Schools" (21 November 2008) The Daily Telegraph London 12.

Proietto, Joseph "Surgery will do more than Education to Fix the Obesity Epidemic" (19 February 2008) The Age Melbourne 11.

Riches, Chris "Anger at Crematorium 'Fat Tax' on Overweight" (27 January 2010) The Express United Kingdom 32.

Rittenhous, Amanda "Trans Fat Expelled" (8 February 2007) The Philadelphia Inquirer, Philadelphia, United States, B01.

Rivera, Ray "Fight to Put Calories on Menus may Widen" (13 September 2007) The New York Times United States 3.

Robertson, Tasha "Overweight Girl Sparks Custody Fight" (7 September 2000) The Boston Globe United States.

Rogers, Lois "Junk Food as Addictive as Cocaine" (5 September 2010) The Sunday Times London, 9.

Sharples, Sarah "Law should Help Trim the Fat" (30 January 2009) Lawyers Weekly Australia 1.

Shepherd, Tony "Focus on Children's Health can be Damaging" (17 January 2009) The Advertiser Australia 13.

Sherman, Jill "Fat Children should be taken into Care" (16 August 2008) The Times London 3.

Smith, Rebecca "Don't Kill Children with Kindness, Parents told" (29 December 2008) The Daily Telegraph London 11.

Smyth, Jamie "EU to make Food Firms use Labels showing Nutritional Information" (31 January 2008) The Irish Times Ireland 7.

Sparks, Ian "French 'Fat Tax' on Pizzas, Crisps and Hamburgers" (6 August 2008) The Evening Standard, London 27. 
Tanner, Lindsey “Americans' Obesity adds to Gasoline Consumption, Study says” (October 2006) USA Today United States.

Thompson Elizabeth "That which we Sell as a Jelly Bean by the Same Label would Taste as sweet" (22 August 2007) The Gazette Montreal A12.

Thompson, Tanya "Nanny State Ban on Full-fat Milk for all Scots pupils" (26 March 2009) The Scotsman, Scotland 7.

Vierra, Paul "Canada Kicks off Fight over Meat Labelling; US law” (2009) National Post's Financial Post \& FP Investing Canada FP4.

Vine, Sarah "A Tax on Chocolate? Utterly Idiotic ... but a Surcharge on Sugar would Taste Sweet" (13 March 2009) The Times London 10.

Washington, Jerome Bernard "US Health Plan says Obesity is a Disease" (2004) Sun Herald Sydney 20.

Warner, Melanie "McDonald's bets on Healthier Food" (22 February 2005) The International Herald Tribune United States 16.

Watson, Lois “Weigh up what you're Eating” (12 April 2009) The Sunday Star Times Auckland A7.

Weaver, Claire "Call for Airlines to Levy a "Fat Tax" (11 November 2007) The Sunday Telegraph (Regional Queensland Edition), Australia 9.

Weaver Clair "McFatty Meal - Doctors Urge Consumers not to Trust the Heart Foundation's Tick of Approval" (11 February 2007) The Sunday Telegraph Australia 79.

Weeks, Carly "BC Trans-fats Ban will Cost Restaurant Owners" (10 March 2009) The Globe and Mail, Canada, L1.

Yeoman, Fran, Rosemary Bennett "Anti-obesity Message is 'Driving Girls to Anorexia"' (3 February 2007) The Times London 9.

Zajac, Andrew "FDA Clamps down on Food Labelling" (21 October 2009) The Los Angeles Times United States B2.

“AMA’s Plans to Combat Obesity” (5 May 2008) Hobart Mercury, Australia 7.

"Battling against Big Food" (21 December 2002) The Economist United Kingdom 116.

“Can a Fat Tax Work as Intended?" (28 December 2009) The Straits Times Singapore. 
"Employers are Turning to Lawyers for Guidance on Obesity" (30 January 2007) Personnel Today United Kingdom.

“Fat Taxes could Save 3,000” (12 July 2007) The Daily Mail London 29.

"Familiar Junk-Food Pitches and Products" (22 May 2008) The Washington Post US D01.

"Fast Food Nation: an Appetite for Litigation" (4 June 2002) The Independent England.

"Five ways to Fight Obesity Epidemic; Health: Parents are urged to Act to Combat problem of Overweight Children Change 4 Life" (27 March 2009) Birmingham Evening Mail United Kingdom 63.

"Food Sector Braces for Battle" (10 January 2008) The New Zealand Herald Auckland.

"France set for Tax on Junk Food" (7 August 2008) The Daily Record Scotland 30 .

"How to Improve our Health" (20 March 2009) The Courier Australia 48.

"It's the Packaging that Counts" (31 July 2007) The Irish Times Ireland 5.

“Le Mac Warning” (1 November 2002) Herald Sun Melbourne 11.

"Lessons Learned from Healthier School Setting" (10 March 2007) The New Zealand Herald, Auckland.

“Obesity Prevention" (11 January 2008) Drug Week United States of America 1058.

"Obesity; Research from University of Strasbourg Reveals New Findings on Obesity" (1 December 2008) Biotech Business Week, United States 238.

"Parents and Schools must Fight Fat" (24 October 2007) The Gazette Montreal.

"Small Changes can make a Big Difference" (10 March 2009) Birmingham Evening Mail United Kingdom 30.

"Tax on Sugary Drinks could put Fizz into Anti-obesity Fight" (9 April 2008) The Dominion Post, Wellington 9.

"Tuckshop Free-for all Invites Obesity, say Greens" (7 February 2009) The New Zealand Herald Auckland. 
"University of Minnesota, US; Researchers from University of Minnesota, US, Publish New Findings" (10 September 2007) Biotech Business Week, United States. 1747.

\section{Conference Papers}

Bailey, Doug "Regulation and the Threat to Self-determination" (Food and Beverage Law Conference 2008, New Zealand, 13 November 2008).

Bismark, Dr Marie "Public Health Bill" (Medical Law Conference, Wellington, April 2008).

Brance, Dr Francesco "10 things you Need to Know about Obesity" in (WHO, 10 things you need to know about obesity, European Ministerial Conference on Counteracting Obesity, 2006).

Friesen, Rick “Obesity: Regulation versus Responsibility: Panel Discussion: Food Advertising and the Media" (Food and Beverage Law Conference 2008, New Zealand, 13 November 2008).

Hamilton, Vicki "Obesity: Regulation versus Responsibility: What really is Driving what we Eat and is there too much Interference?" (Food and Beverage Law Conference 2008, New Zealand, 13 November 2008).

Pollard, Sue "Front of Pack labelling" (Food and Beverage Law Conference 2008, New Zealand, 13 November 2008).

Souter, Hilary "Regulation versus Responsibility: Advertising, Promotions and Competitions" (Food and Beverage Law Conference 2008, New Zealand, 13 November 2008).

\section{Press Releases}

Agencies for Nutrition Action "Link between Advertising and Children's Food Choices Strong, say Report Authors" (6 July 2006) Press Release

Australian Broadcasting Corporation "Blewett to Chair Food Label Review" (26 October 2009) Press Release.

Australia and New Zealand Food Regulation Ministerial Council "Food Ministers announce Dr Neal Blewett to Chair the Food Labelling Review" (23 October 2009) Press Release (at Food Standards Australia New Zealand www.foodstandards.gov.au (accessed 28 October 2009)). 
Australia and New Zealand Food Regulation Ministerial Council "Review of Food Labelling Law and Policy" (28 October 2009) Press Release (at Food Standards Australia New Zealand www.foodstandards.gov.au (accessed 28 October 2009)).

British Broadcasting Association "Obesity a Factor in at Least 20 Child Protection Cases in the Last Year" (14 June 2007) Press Release.

Campaign for a Commercial-free Childhood (CCFC) "Statement of CCFT's Susan Linn on the FTC Report: Marketing Food to Children and Adolescents: A Review of Industry Expenditure, Activities, and Self-regulation" (29 July 2008) News Release.

Centre for Consumer Freedom "Study on Menu Labelling Effectiveness NYC's Battle of the Bulge Falls Flat (8 October 2009) Press Release.

Centre for Science in the Public Interest "Label Caffeine Content of Foods, Scientists tell FDA. Health Activists Say Caffeine Causes More than a 'Buzz': Miscarriages, Withdrawal Symptoms, Poor Nutrition” (31 July 1997) Press Release.

Coca Cola Amatil "World First Agreement on Soft Drinks in Schools" (11 December 2006) Press Release.

Council of Australian Governments "Release of Issues Consultation Paper on Review of Food Labelling" (5 March 2010) Press Release.

Diabetes New Zealand "Cutting the Fat: How a Fat Tax can help Fight Obesity" (24 August 2004) Press Release.

FOE "Food Industry Tactics on Public Health Bill Questioned" (21 July 2008) Press Release.

FOE "NZ: National Reversal on Healthy Food in Schools "Incredible" (5 February 2009) Media Release.

Hodgson, Pete "Full Sugar Fizzy Drinks out of Schools by 2009" (11 December 2006) Press Release.

Kloeppel, James E, University of Illinois "Weight Gain of U.S. Drivers has Increased Nation's Fuel Consumption” (24 November 2006) News Release.

Local Government Association (UK) "Overhaul of Food and Alcohol Labelling needed to Tackle Obesity” (27 May 2008) Press Release.

Local Government Association (UK) " $£ 6.3$ Billion Bill by 2015 shows Britain is fast becoming the 'Obesity Capital of the World' (7 October 2008) Press Release. 
Maclay, Kathleen, "Linking Fast Food Proximity to Obesity" (4 March 2009) News Release.

Mãori Party "Goods and Services Tax (Exemption of Healthy Food): First Reading, Wednesday $8^{\text {th }}$ September 2010; 8.00pm” (9 September 2010) News Release.

National Restaurant Association "National Restaurant Association Applauds LEAN Act Introduction in US House and Senate" (11 March 2009) News Release.

Newman, Dr Muriel, New Zealand Associate Health Spokesman "Banning Fast Food Advertising is Preposterous" (3 December 2002) Press Release.

New Zealand Drug Foundation "Parliament and Alcohol does not Mix" (12 October 2000) Press Release.

New Zealand Food Safety Authority "Caffeine Intake and Effects Studied" (2 June 2010) Press Release.

New Zealand Food Safety Authority "Food Review has Green Light" (8 October 2009) Press Release.

Obesity Action Group "Obesity Action Group Backs Call to Reinstate Healthy School Guidelines" (15 September 2009) Press Release.

Public Health Association of New Zealand "Call for Ban on Fast Food Advertising" (6 July 2006) Press Release.

Public Health Association "Government must Ban Fast Food Advertising to Children says PHA" (5 July 2006) Press Release.

Ryall, Tony "Fruit in Schools Future Confirmed" (29 October 2009) Press Release.

Social Issues Research Centre, Oxford "The Side Effects of Health Warnings: Shock-tactics in Health-promotion Campaigns have Backfired: New Analysis from the Social Issues Research Centre in Oxford indicates that Health Warnings may have Hidden Psychological Side Effects" (12 May 1999) Press Release.

Stewart, Barbara, New Zealand First "Fat Tax Today - Fat Police Tomorrow" (24 August 2004) Press Release.

University of Otago "Many Cancers could be Prevented across the Globe: Landmark Report" (27 February 2009) Press Release.

University of Otago "NZ Lags in Marketing Unhealthy Food to Children" (24 February 2009) Press Release. 
Virginia Commonwealth University "Weight gain of US Drivers has increased Nation's Fuel Consumption" (24 October 2006) Press release.

Wilkinson, Kate, Minister of Food Safety "New Food Bill introduced to Parliament” (26 May 2010) Press Release.

\section{Testimony}

Surgeon General Richard H Carmona "Testimony before the Subcommittee on Education Reform and Committee on Education and the Workforce, United States House of Representatives" (The Obesity Crisis in America, Washington, 16 July 2003). 